University of Louisville

ThinkIR: The University of Louisville's Institutional Repository

Electronic Theses and Dissertations

$8-2020$

\title{
Nonlinear control and observation of full-variable speed wind turbine systems.
}

Nicholas Hawkins

University of Louisville

Follow this and additional works at: https://ir.library.louisville.edu/etd

Part of the Controls and Control Theory Commons

\section{Recommended Citation}

Hawkins, Nicholas, "Nonlinear control and observation of full-variable speed wind turbine systems." (2020). Electronic Theses and Dissertations. Paper 3484.

https://doi.org/10.18297/etd/3484

This Doctoral Dissertation is brought to you for free and open access by ThinkIR: The University of Louisville's Institutional Repository. It has been accepted for inclusion in Electronic Theses and Dissertations by an authorized administrator of ThinkIR: The University of Louisville's Institutional Repository. This title appears here courtesy of the author, who has retained all other copyrights. For more information, please contact thinkir@louisville.edu. 
NONLINEAR CONTROL AND OBSERVATION OF FULL-VARIABLE SPEED WIND TURBINE SYSTEMS

\author{
By \\ Nicholas Hawkins \\ B.S., University of Louisville, 2016 \\ M.Eng., University of Louisville, 2017 \\ A Dissertation \\ Submitted to the Faculty of the \\ J.B. Speed School of Engineering of the University of Louisville \\ in Partial Fulfillment of the Requirements \\ for the Degree of \\ Doctor of Philosophy \\ in Electrical Engineering \\ Department of Electrical and Computer Engineering \\ University of Louisville \\ Louisville, Kentucky
}

August 2020 

NONLINEAR CONTROL AND OBSERVATION OF FULL-VARIABLE SPEED WIND TURBINE SYSTEMS

\author{
By \\ Nicholas Hawkins \\ B.S., University of Louisville, 2016 \\ M.Eng., University of Louisville, 2017
}

A Dissertation Approved on

June 16, 2020

by the following Dissertation Committee:

$\overline{\text { Michael McIntyre, Dissertation Director }}$

Brian Robinson

Tamer Inanc

Nicholas Jewell 


\section{ABSTRACT \\ NONLINEAR CONTROL AND OBSERVATION OF FULL-VARIABLE SPEED WIND TURBINE SYSTEMS \\ Nicholas Hawkins}

June 16, 2020

With increasing concern for the environmental effects of power generation from fossil fuels, wind energy is a competitive source for electrical power with higher efficiency than other clean sources. However, the nature of this power source makes controlling wind turbines difficult. The variability of wind as a source either requires highly accurate measurement equipment or sophisticated mathematical alternatives. In addition to the unknown quantities of the weather itself, the efficiency of power capture at the turbine blades is highly nonlinear in nature and difficult to ascertain. The ability of either determine these troublesome quantities, or control the system despite ignorance of them, greatly increases the overall efficiency of power capture. To this end, a series of nonlinear controllers and observers have been developed for wind turbine systems. 
TABLE OF CONTENTS

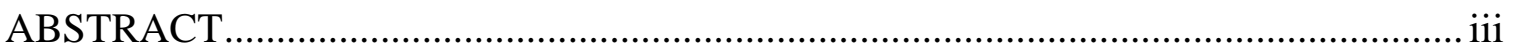

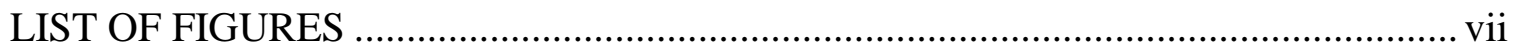

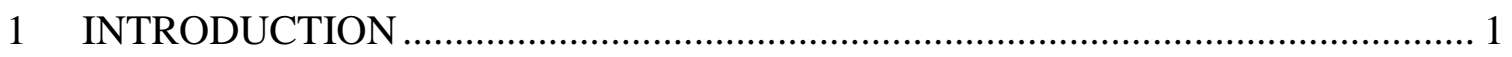

1.1 WIND TURBINE CONFIGURATION TYPES .......................................... 2

1.2 PMSG CONTROL BACKGROUND ................................................... 6

1.3 SCIG CONTROL BACKGROUND.................................................. 9

1.4 MOTIVATION FOR WIND TURBINE CONTROLS ................................ 14

1.5 OBJECTIVES .................................................................................... 15

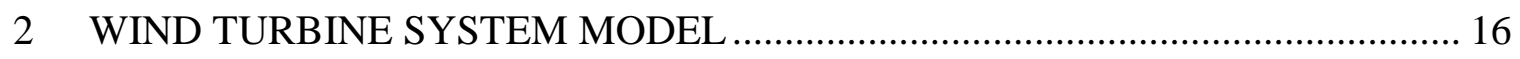

2.1 WIND TURBINE MECHANICAL MODEL ............................................ 16

2.2 PMSG ELECTRICAL MODEL ............................................................ 18

2.3 SCIG ELECTRICAL MODEL ........................................................... 21

2.4 MODEL UNCERTAINTIES ................................................................ 23

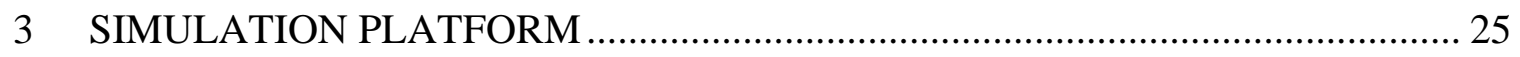

3.1 PMSG SIMULATION PARAMETERS .................................................. 26

3.2 SCIG SIMULATION PARAMETERS ................................................. 27 


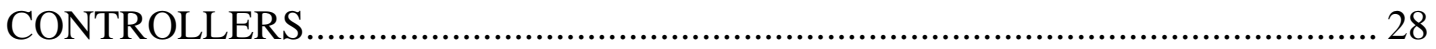

4.1 PMSG SPEED TRACKING CONTROL .................................................... 28

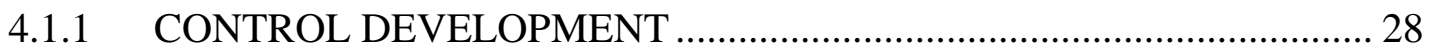

4.1.2 STABILITY ANALYSIS .............................................................. 32

4.1.3 SIMULATION RESULTS ........................................................... 35

4.1.4 LINEAR CONTROLLER STEUP ................................................... 39

4.1.5 COMPARATIVE SIMULATION RESULTS ....................................... 40

4.2 SCIG SPEED TRACKING CONTROL ...................................................... 44

4.2.1 CONTROL DEVELOPMENT …....................................................... 44

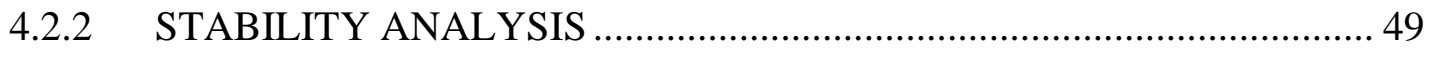

4.2.3 LINEAR CONTROLLER SETUP .................................................... 52

4.2.4 COMPARATIVE SIMULATION RESULTS ...................................... 53

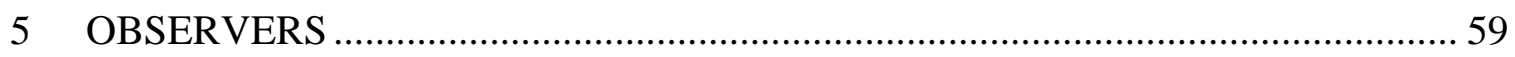

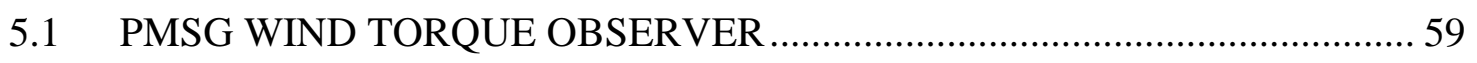

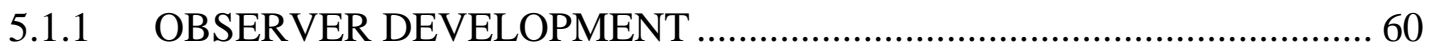

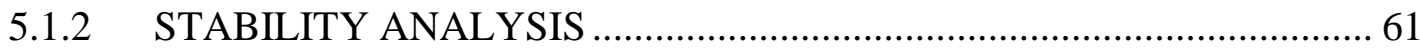

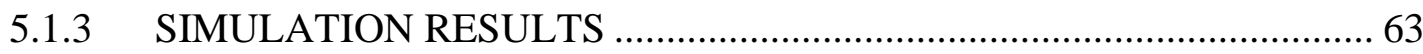

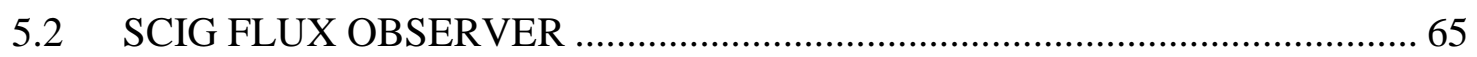

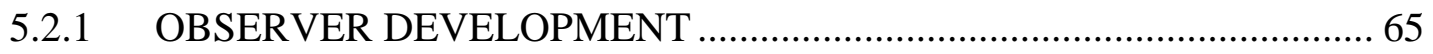

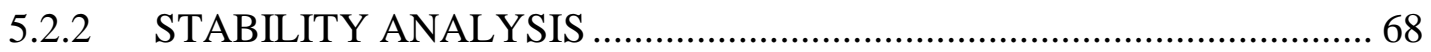




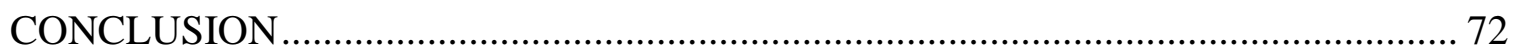

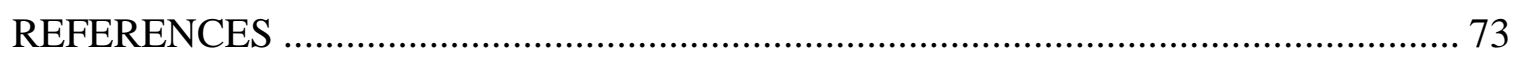

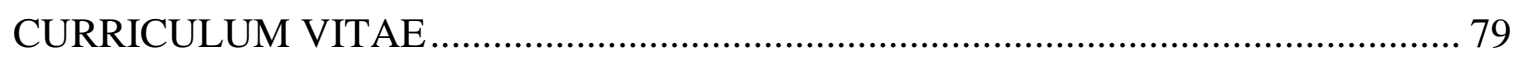




\section{LIST OF FIGURES}

Figure 1. Installed Wind Turbine Capacity Worldwide (from IRENA) ......................... 1

Figure 2. US Renewable Energy Consumption by Source (from Table 10.1 of EIA) ....... 2

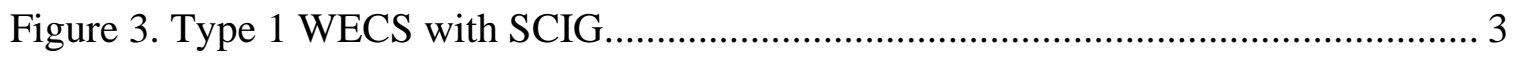

Figure 4. Type 2 WECS with WRIG .................................................................. 3

Figure 5. Type 3 WECS with DFIG .................................................................. 4

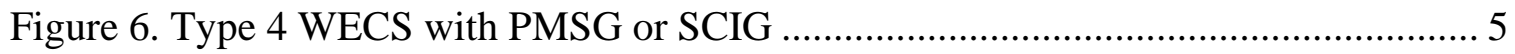

Figure 7. Typical Cascaded PI Controller for PMSG WECS ....................................... 7

Figure 8. Architecture for induction machine vector control. ................................... 11

Figure 9. Typical configuration of a full-variable WECS ......................................... 16

Figure 10. The per-phase equivalent circuit of a PMSG. ........................................ 18

Figure 11. Initialization of the rotor magnet angle as compared to the $\mathrm{ABC}$ frame........ 19

Figure 12. Power coefficient used for simulated WECS for speed controller................. 36

Figure 13. Varied wind speed profile used as input to turbine system in speed controller.

Figure 14. a) rotational speed of PMSG (top), b) TSR of PMSG (bottom).................... 38

Figure 15. PMSG DQ currents versus their reference values................................... 38

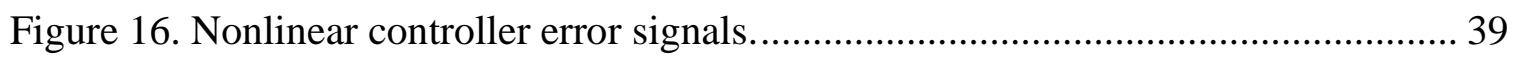

Figure 17. Step response of PMSG linear controller (top) and nonlinear controller (bottom)

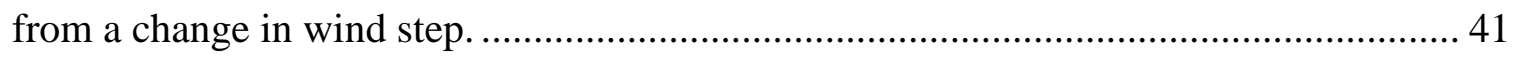

Figure 18. Turbulent wind speed for PMSG controller comparison. .............................. 42 
Figure 19. Desired speed trajectory for PMSG controller comparison.

Figure 20. Speed tracking error of PMSG linear controller (top) and nonlinear controller (bottom)

Figure 21. Response of SCIG vector controller (top) and nonlinear controller (bottom) to a step in wind speed. 55

Figure 22. Nonlinear SCIG controller speed error during wind step........................... 56

Figure 23. Nonlinear SCIG controller filtered speed error during wind step................. 56

Figure 24. Nonlinear SCIG controller flux error during wind step. ........................... 56

Figure 25. Nonlinear SCIG controller adaptive inertia observer during wind step......... 57

Figure 26. Turbulent wind speed profile used for SCIG controller comparison. ............. 57

Figure 27. Desired speed trajectory used for SCIG controller comparison..................... 58

Figure 28. SCIG speed controller errors for a vector controller (top) and nonlinear controller (bottom) in response to wind turbulence............................................... 58

Figure 29. Observed versus actual rotational speed of PMSG. ................................... 64

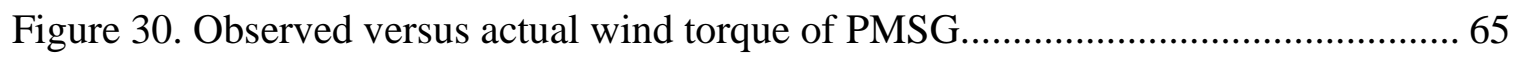

Figure 31. Scalar control architecture for SCIG. ................................................ 70

Figure 32. SCIG current versus observed values.............................................. 71

Figure 33. SCIG rotor flux magnitude versus observed value..................................... 71

Figure 34. SCIG synchronous speed versus observed value. ................................... 71 


\section{INTRODUCTION}

The use of wind energy for electricity production has been increasing rapidly over the last few decades. Worldwide, installed wind energy conversion systems (WECS) have been responsible for $282.6 \mathrm{GW}$ of power in 2012, compared to 74,223 $\mathrm{MW}$ in 2006 or 6,100 MW in 1996 [1] [2]. This growth within the last decade has continued at an increasing rate, as seen in Figure 1 [3].

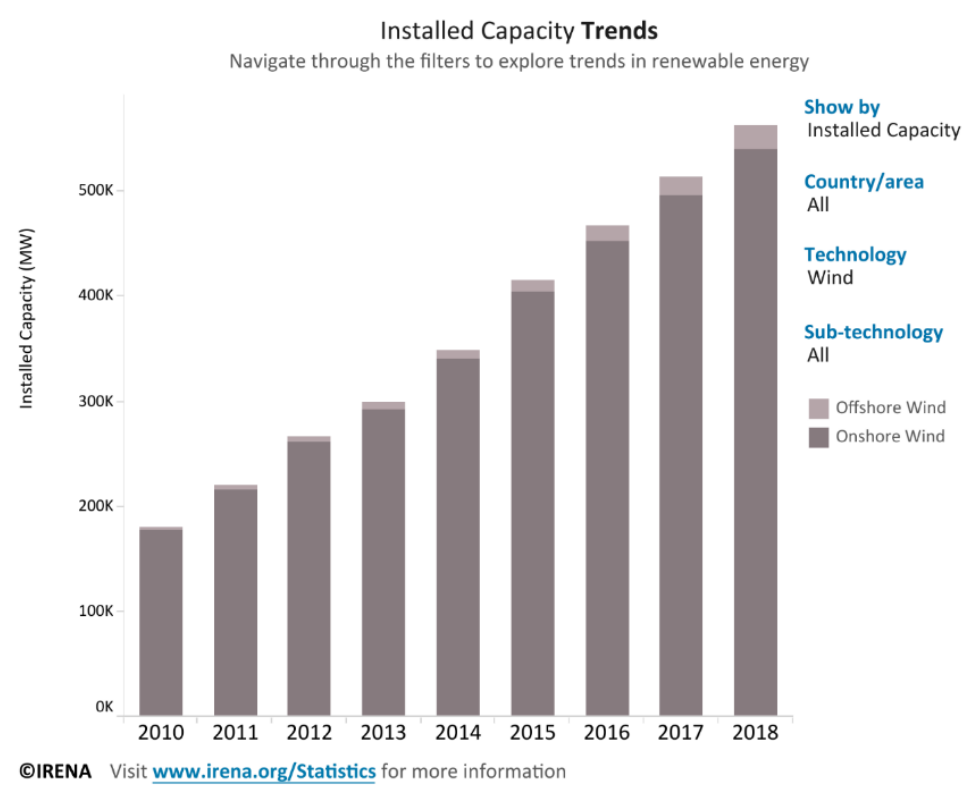

Figure 1. Installed Wind Turbine Capacity Worldwide (from IRENA)

In the United States alone, wind energy is increasingly consumed compared to solar and geothermal sources, and is nearly as widely used as hydroelectric, as seen in Figure 2 [4]. Wind turbines are also economically attractive, potentially creating over 600,000 jobs and saving the US utility consumer $\$ 280$ billion by 2050 [5]. 


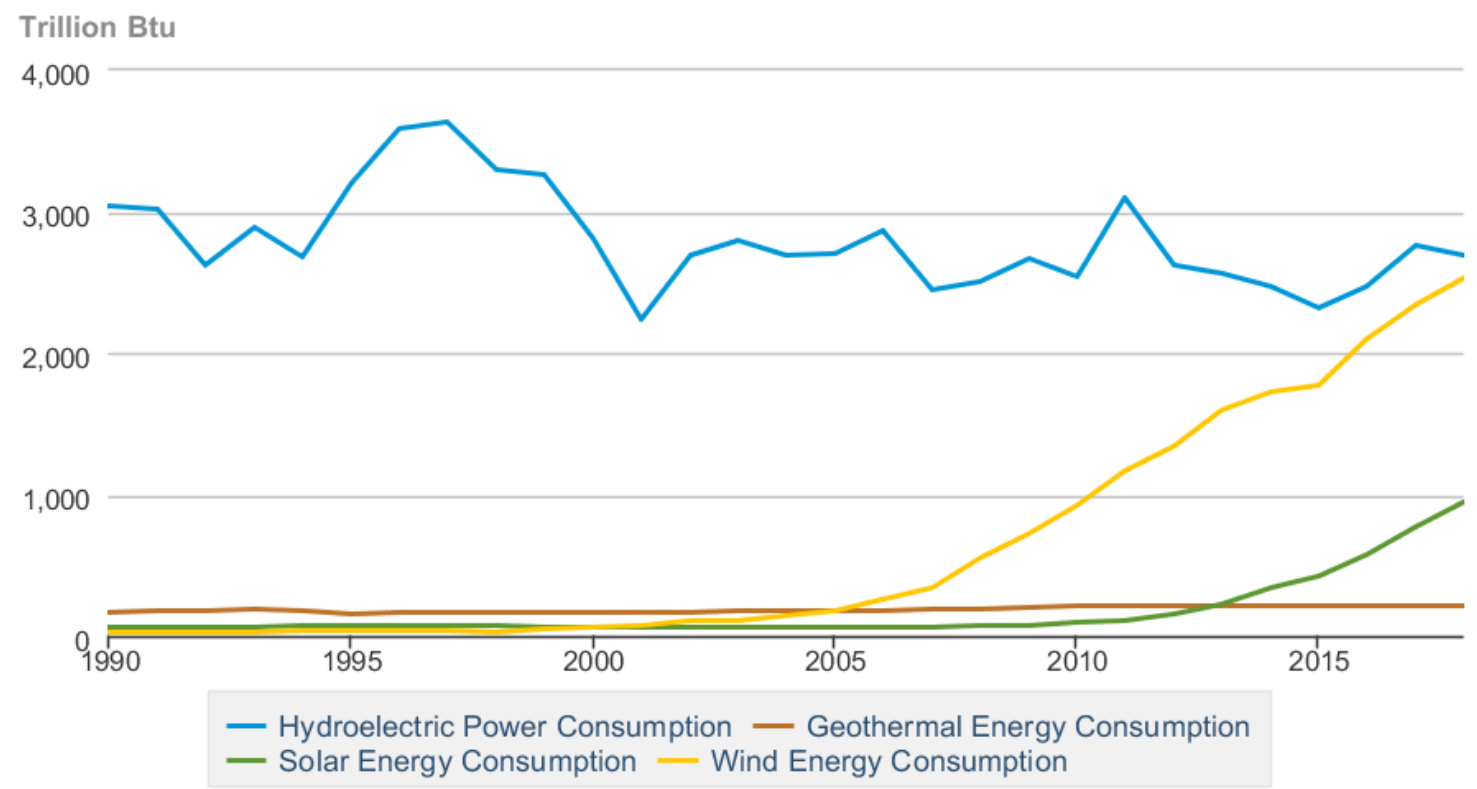

Data source: U.S. Energy Information Administration

Figure 2. US Renewable Energy Consumption by Source (from Table 10.1 of EIA)

\subsection{WIND TURBINE CONFIGURATION TYPES}

There are a variety of WECS topologies that have been employed since large-scale use of wind turbines began, which have now been designated by "types" [2]. The Type 1 turbine (see Figure 3) utilizes a squirrel-cage induction generator (SCIG) that is connected to the grid via a step-up transformer. Due to the direct electrical connection to the grid (i.e. lack of power converter stage), this is classified as a fixed-speed WECS, and typically require a gearbox to manage the conversion of turbine and generator speeds in addition to a soft starter between the SCIG and the grid. Also, capacitor banks are required to manage the power factor at the grid side. Operating at a fixed speed comes with several drawbacks. The inability to search for optimal speeds leads to lower efficiency [6], and changes in wind speed are reflected in the grid and stress physical components [7]. 


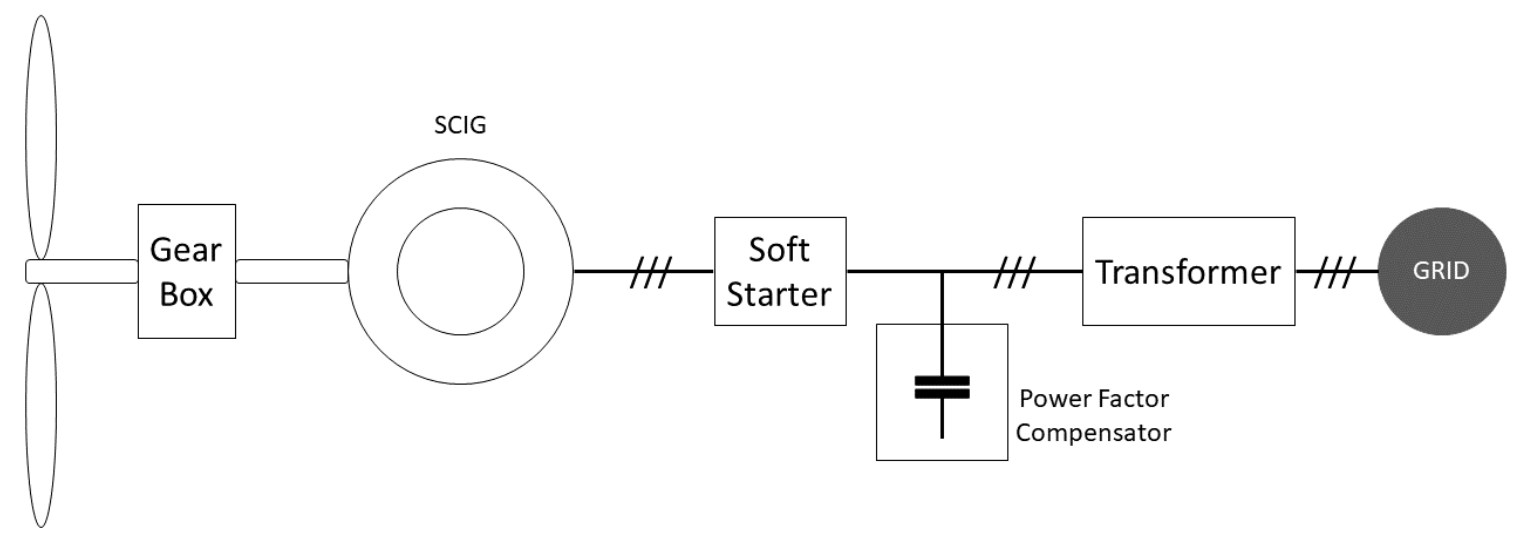

Figure 3. Type 1 WECS with SCIG

This led to the evolution of Type 2 configurations (see Figure 4), which utilize woundrotor induction generators (WRIG) with a variable rotor resistance. This variable resistance allows this configuration to change generator speeds up to $\pm 10 \%$ of its rated speed, hence the designation of this type as semi-variable speed. This reduces the mechanical stress due to changes in wind speed and allows for small speed-based control of the generator [2]. However, as the speed variation is not very large, a soft starter is still required for this configuration. Since there is still no power converter stage in this type, the capacitor banks needed for Type 1 converters are still needed here as well.

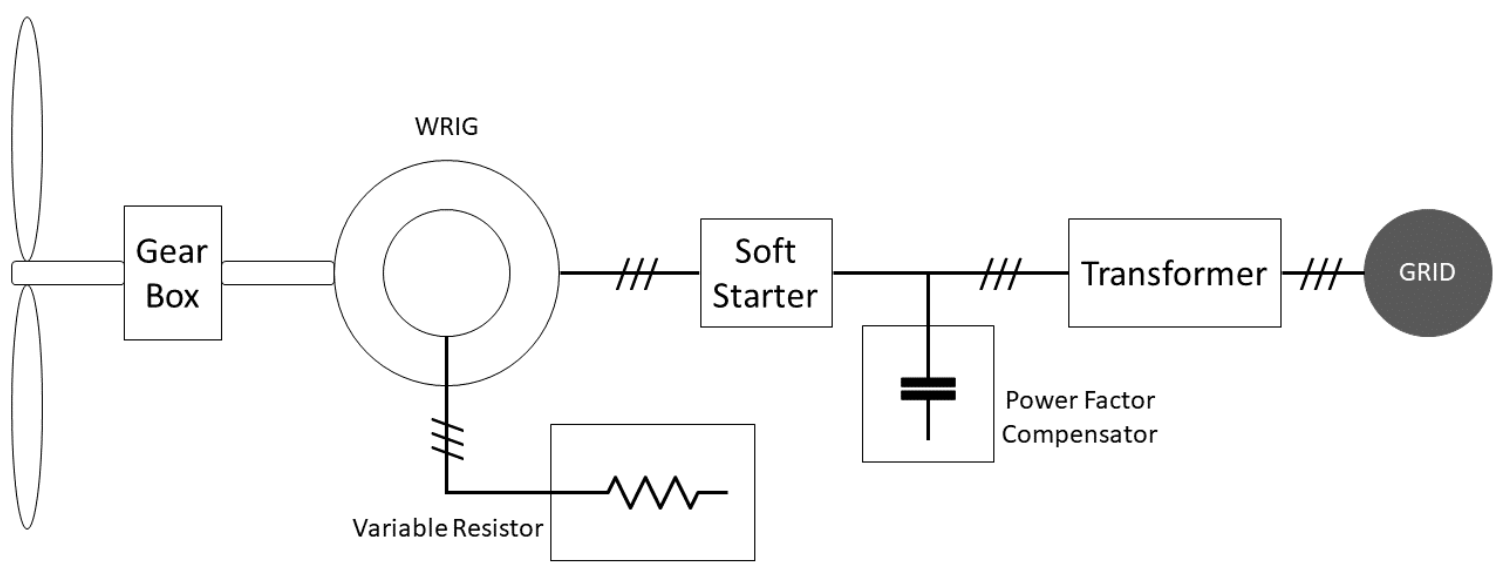

Figure 4. Type 2 WECS with WRIG 
Further development of semi-variable WECS is found through Type 3 configurations (see Figure 5), which forgo a WRIG for a doubly fed induction generator (DFIG). In this topology, power is fed to the grid through the rotor and stator separately [8], where the stator is connected similarly to a Type 1 converter, and the rotor is sent through an active rectifier and inverter (AC-AC converter) before connecting to the grid. While still only semi-variable, the use of a power converter allows for greater speed variations, up to $\pm 30 \%$ of its rated speed. This allows for the use of maximum power point tracking (MPPT) methods, which increase the overall system efficiency beyond that of Type 1 or 2 configurations [2].

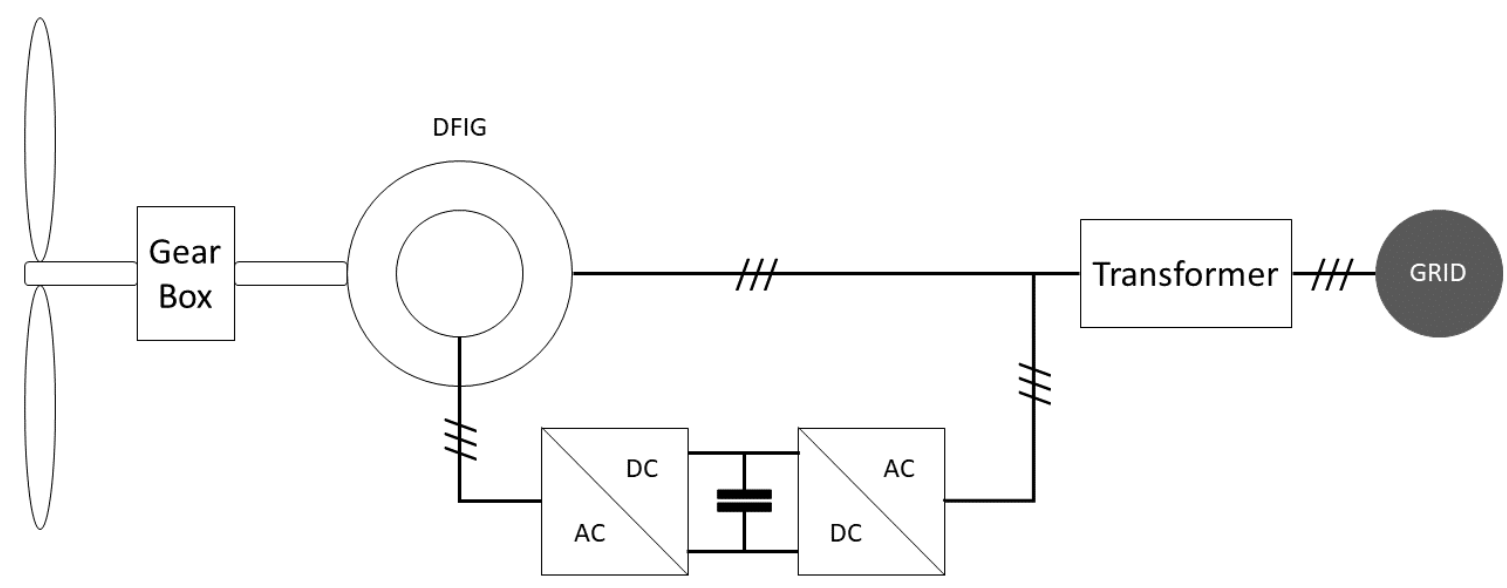

Figure 5. Type 3 WECS with DFIG

In the efforts of attaining a full-variable speed WECS, the Type 4 configuration (see Figure 6) was developed. This topology typically utilizes either a permanent magnet synchronous generator (PMSG) or a squirrel cage induction generator (SCIG) followed by a series of power converters - a rectifier followed by an inverter - that connects to the grid. This means that unlike a Type 3 WECS, $100 \%$ of the power generated in this system is run 
through the power converters. Type 4 systems have only recently gained popularity due to increased switching component performance.

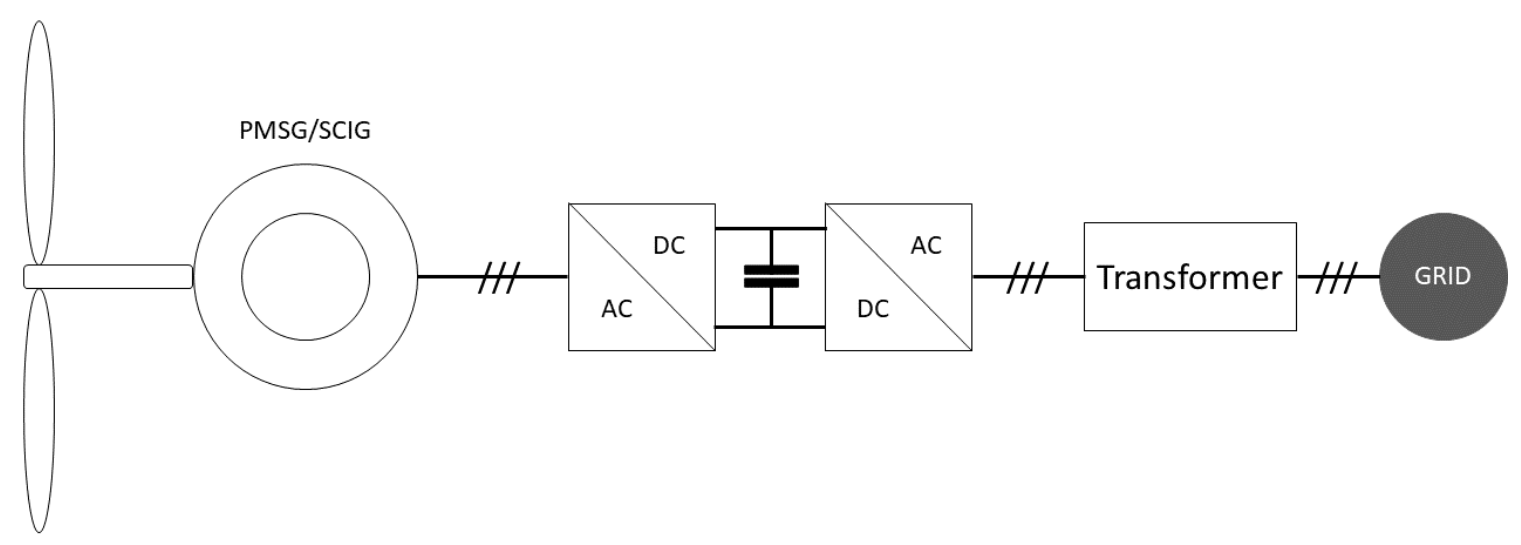

Figure 6. Type 4 WECS with PMSG or SCIG

This full decoupling from the grid includes several advantages. It allows for full speed variation without a gearbox, reducing faults [9], and grid-smoothing controls [2], as well as higher fidelity control of both active and reactive power generation [1]. It has also been determined that Type 4 configurations have been increasing in market share recently due to the need for larger capacity systems [10]. A series of studies have developed comparisons between the different generator types used for Type 4 configurations [2] [10] [11], which has been summarized in Table 1.

Among these reasons, the primary motivation for utilizing Type 4 topologies in this work is the ability to fully control the movement of power in the system. As the purpose of this work is to improve the performance of WECS technology through intelligent control systems, this system configuration allows for controls to have the highest potential impact. 


\section{Table 1}

Summary of Type 4 Machine Qualities

\begin{tabular}{|c|c|c|}
\hline Metric & PMSG & SCIG \\
\hline Literature Published & Numerous & Little \\
\hline Cost to Manufacture & High & Low \\
\hline Gearbox Requirement & No & Usually \\
\hline Power Range & Fair & Few \\
\hline Installation Amount & Many & \\
\hline
\end{tabular}

\subsection{PMSG CONTROL BACKGROUND}

The control of PMSG has been studied widely for WECS applications, though the roots of these control schemes take place before Type 4 configurations. Traditionally, PMSG have been controlled using a linear control method called vector control. Early iterations of this scheme put all of the burden of control on the grid-connected inverter [12] as opposed to utilizing an active rectifier to connect the PMSG to a DC bus. This particular system also generates reference values using a look-up table, which requires trusting the configuration to behave with identical repeatability.

Today, this scheme utilizes a cascaded architecture of proportional-integrator (PI) controllers to manage the speed of the machine (see Figure 7). Typically, this is done through the dq reference frame, and the speed control is the outer control loop that provides a reference for the inner q-axis current control loop [13] [14] [15] [16]. In these schemes, the d-axis current is controlled separately. 


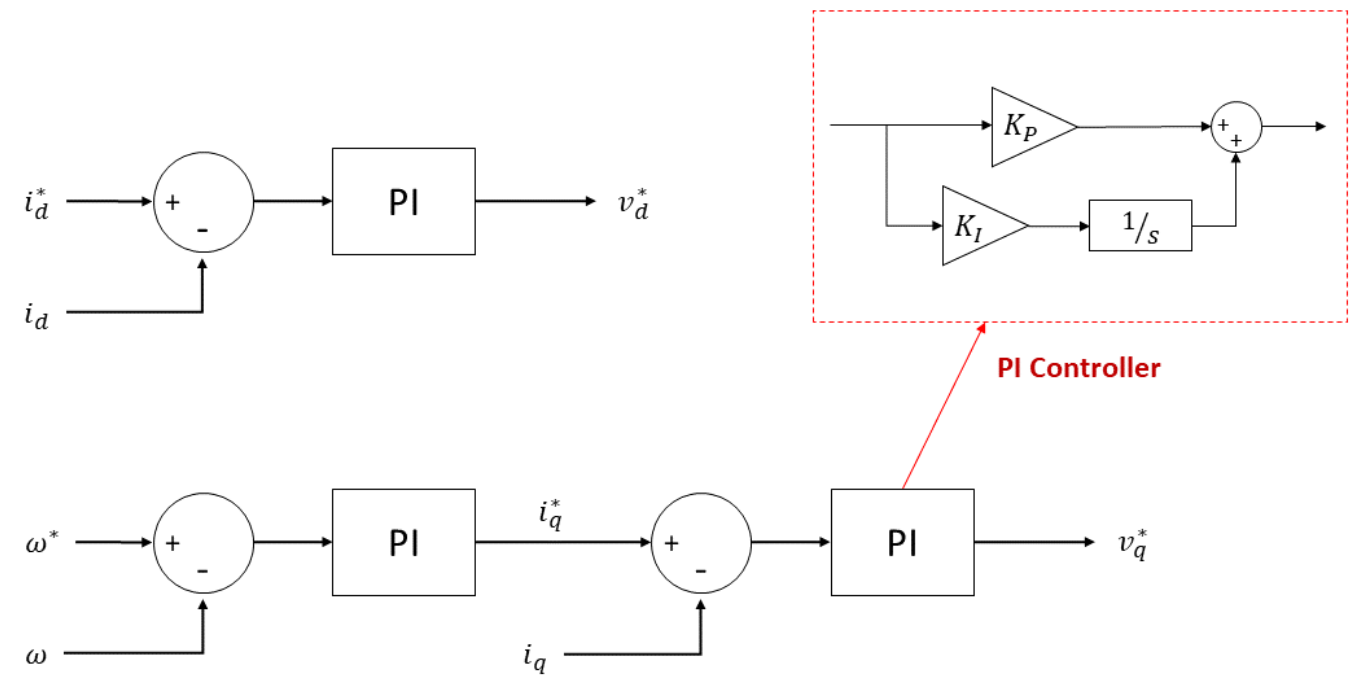

Figure 7. Typical Cascaded PI Controller for PMSG WECS

While vector control is well known and widely used, it is not the most efficient way to control PMSG systems. Due to the use of PI controllers, vector control is particularly weak to system nonlinearities and rapidly changing dynamics, such as large wind gusts, which require much faster response from controllers.

Attempts have been made to improve the performance of vector controllers with augmented linear schemes. Among these are controllers utilizing feedforward techniques to reduce the computational load on the integrators of the PI controllers [17]. Other linear controllers attempt to simplify the control architecture through elimination of the outer speed loop [18]. In this scheme, the q-axis current reference is directly calculated, which attempts to reduce response time.

Additionally, there are controllers that employ the use of proportional-resonant (PR) controllers, which behave similarly to PI controllers. The primary advantage to using a PR controller is that they more easily obtain zero steady-state error for tracking sinusoidal-like 
trajectories [19]. As wind speeds often oscillate when turbulent, the conjecture that a speed trajectory for a PMSG WECS is logical.

Another method used to augment vector control strategies is the utilization of fuzzy logic alongside the PI controllers. The purpose of the fuzzy logic controllers is to provide more effective reference values to the front-end of the PI controllers, which improves response time by easing the work being performed by the integrators [20] [21].

The primary shortcoming of these controllers is the inability to manage system nonlinearities and structural uncertainties. Permanent magnet generators are inherently highly nonlinear in nature and attempting to linearize them about certain operating points often yields poor results when the system operation shifts even slightly [22].

One approach being used to minimize the negative effects of system uncertainties is the use of optimal singular adaptive observers to determine unknown system parameters [23]. This observer is used to feed state information to a vector controller. Additionally, this approach is able to observe the initial state vector of the system should measurements be withheld.

Some efforts have been made to control these systems with nonlinear methods, most commonly using sliding-mode control [24] [25], which attempts to manage parameter uncertainties. Sliding mode controllers manage uncertainties through variable structure control and use a model-based approach to improve dynamic response times. Comparison to vector control shows that sliding mode controllers reduce overshoot and response time when there is a shift in operation point [26] [27].

Another method of nonlinear control seeks to use linearization techniques alongside robust control methods to minimize the issues caused by system nonlinearities [28] [29] 
[30]. These controllers utilize a known equilibrium point to significantly reduce the complexity of model equations, assuming the system always operates near that known point. This method then creates a transfer function from the reduced nonlinear model.

The problem with these systems is the need for accurate understanding of the mechanical subsystem. These model-based approaches attempt to estimate the mechanical efficiency of the WECS but doing so is very specific to individual turbines and would take large amounts of mechanical testing to find. In addition, it is difficult to ascertain the accuracy of these mathematical representations, which is evident from the many variations of the equation [31].

Model predictive control is a method that has come about more recently to mitigate the issues with typical nonlinear controllers. Model predictive control shifts the unknown model until the controller functions as intended [32] [33]. This means that as a system point of operation shifts (in this context, due to changing wind speeds), this control scheme changes its reference model to account for such changes.

\subsection{SCIG CONTROL BACKGROUND}

While Type 4 configurations utilizing SCIG are relatively new, the control of induction machines (IM) for motoring applications has been widely studied. Particularly, it is well known that two dynamics must be managed while controlling the speed of these machines: current and flux.

Early methods of speed management in IM, called scalar or volts-hertz control, involve providing three-phase voltages of a certain magnitude and frequency to the IM. The IM 
then rotates near the frequency of the voltages, and the magnitude manages the rotor flux [34] [35].

As with most uncontrolled systems, open-loop scalar control suffers from large inaccuracies. From this, linear methods have been used to manage the synchronous speed provided to IM. Typically called slip control, these methods provide increased accuracy using proportional-integral (PI) control schemes [36]. In IM applications, the slip refers to the difference between the rotor and synchronous speeds, and by managing the slip, the synchronous speed is managed. These types of controllers can also be referred to as direct torque control (DTC), as controlling the slip ultimately serves to manage the electromagnetic torque of the IM.

However, even these slip control methods struggle due to their reliance on a single integrator to manage the speed. Hence, the electrical dynamics of IM influences a form of control known as vector control, in which a pair of cascaded PI controllers are used to manage the speed and flux separately. Vector control is performed in the rotating (dq) reference frame, so that the flux objective is met through the d-axis current and voltage and the speed objective is met through the q-axis current and voltage [37], as seen in Figure 8.

Notably, the ability to manage the flux in vector control is not trivial, as it is impractical to measure rotor flux in an IM in real time. Therefore, vector control heavily relies on the need for an accurate flux observer to maintain performance. Typically, these observers also provide a synchronous speed observation, which is needed to transform the dq voltages to the standard three-phase frame. 


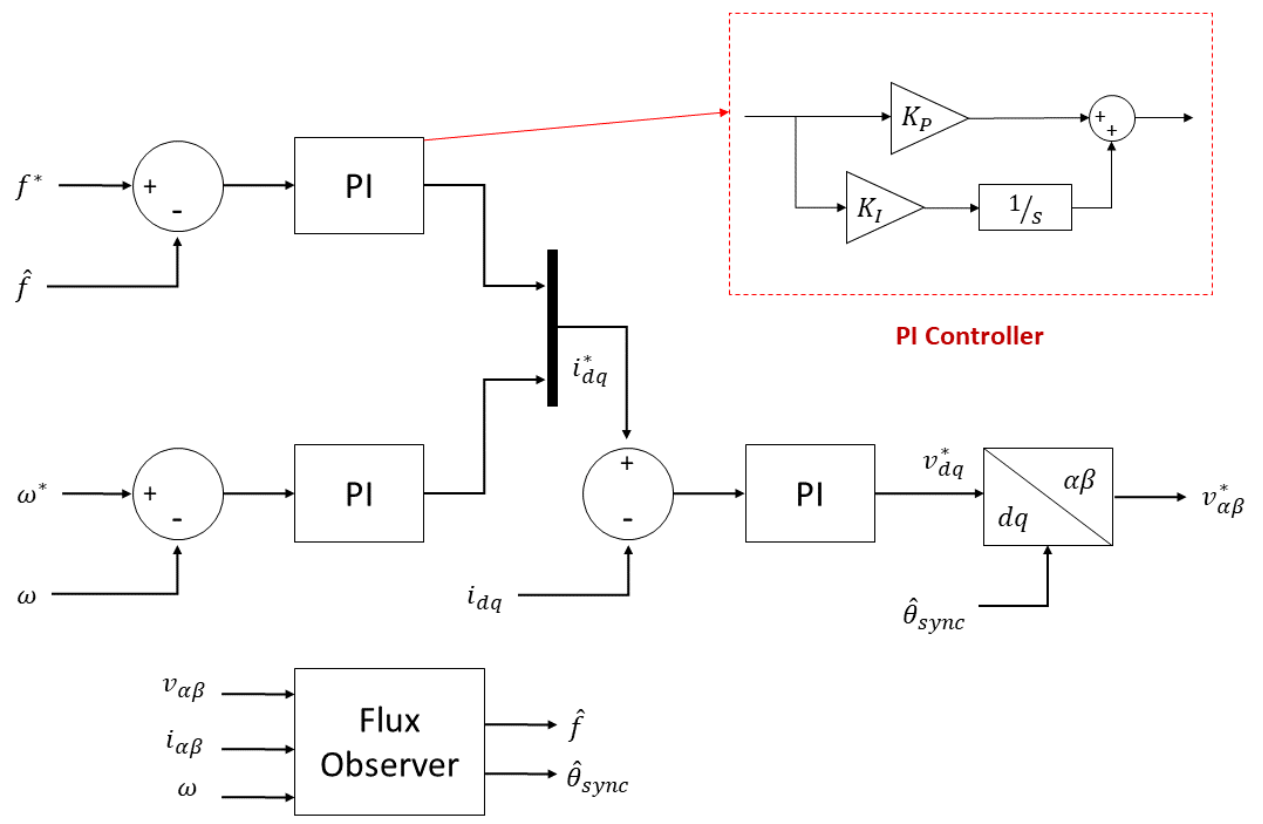

Figure 8. Architecture for induction machine vector control.

While vector control is popular even today, there are still issues with the linear control scheme it employs. While the cascading nature of vector control spreads the mathematical load across multiple controllers, PI-based control typically suffers from slow response times and difficulty with managing system nonlinearities.

To improve upon the aforementioned difficulties with both scalar and vector control, various improvements have been developed. A common improvement employs the use of fuzzy logic to better handle nonlinearities during operation. Fuzzy logic treats analog signals as continuously digital in nature, and categorically determines control inputs based on these "fuzzified" measurements. This strategy has been employed as a front-end scheme that determines the objectives for either scalar [38] [39] or vector [40] [41] PI controllers.

Another method used to improve vector control employs feedback linearization techniques. These schemes look to linearize nonlinear systems about a known operating 
point and control within that space [42]. While this greatly simplifies the mathematical model for control, it also makes the control less effective in any other operating point.

Another strategy for improving upon linear methods is the use of neural network control. This form of control attempts to estimate nonlinear functions that are unknown through repetitive learning algorithms [43].

Additionally, model-based methods have become more commonly used to manage parameter uncertainties and system nonlinearities. One nonlinear method that has been used is adaptive controls, which use model dynamics and measurable system states to estimate parameter uncertainties. Adaptive methods have been utilized for the purposes of both speed control [44] [45] [46] and flux observation [47] [48].

Another nonlinear method that has been utilized for IM applications is sliding mode control (SMC). In SMC, the system is forced to slide along a cross-section of the system's normal behavior using a model-based approach. These control schemes have been used similarly to both slip [49] and vector [50] [51] objectives. While these controllers are typically good at managing parameter uncertainty, they also suffer from high computation time to function.

Yet another method for managing IM systems is model predictive control, in which parts of the mathematical model utilized or SMC or adaptive schemes is treated as unknown. These schemes predict changes in systems states based on measurable changes, which can compensate for system uncertainties [52] [53].

As aforementioned, Type 4 SCIG wind turbines have been studied little in comparison to other wind turbine systems. Some studies employ scalar control [54] or open-loop performance validation [55] [56]. These studies ignored the control aspects of the system 
and instead focused on hardware validation. While these systems are not necessarily efficient, they successfully prove that SCIG are valid options for WECS.

A more recent application of SCIG as a wind turbine employs DTC and is validated using hardware in loop (HIL), which can accurately simulate real-time machinery [57]. This method tests the control scheme for various types of wind inputs, such as wind steps and turbulent wind profiles.

Most WECS systems thus far have employed some form of vector control to manage the rotational speed, as is typical in motoring applications. Due to the nature of wind speeds creating varying load torques, the selection of desired speeds and fluxes can be critical to operation. For this reason, some of these experiments utilize strategies that determine optimal desired flux values to minimize motor losses [58] [59]. However, other experiments have shown that operation is possible without such an addition [60] [61].

To improve upon the performance of traditional vector controllers, recent studies have used fuzzy logic to determine more optimal speed and flux trajectories [62] [63] [64]. These control schemes tend to focus on maximizing electrical power output rather than internal motor efficiency, which can potentially account for model or parameter inaccuracies.

Some more recent designs have used SMC to further improve the fidelity of the system control [65] [66]. Wind turbines in particular present difficulty in ascertaining mechanical parameters, such as inertia and friction, due to the size and complexity of the mechanical subsystem. SMC is well-known for its ability to manage parameter uncertainty to improve performance. 


\subsection{MOTIVATION FOR WIND TURBINE CONTROLS}

Various reports from the US Department of Energy (DoE) and its National Renewable Energy Laboratory (NREL) within the past few years [5] [67] have highlighted the areas of Wind Energy that require development to best advance the power source for wide consumption. In these reports, the DoE/NREL have identified a series of technologies that would benefit the field as it grows into a major source for power in the US.

A few of these technologies pertain to greater understanding of the turbine system for the purposes of reliability. This involves advanced monitoring of the power supplied by the wind as well as the loading of this power on the turbine itself. Additionally, advancements are needed in estimation of energy production that can incorporate uncertainties in the system alongside necessary measurements.

Another category of improvements these reports discuss are the management of the turbines themselves. One of the more well-known considerations is controlling the generator to extract maximum power from the wind for a single turbine. However, there is also a necessity to control a series of turbines in a wind plant (or wind farm) to manage overall maximum performance, which includes management of the energy transfer between turbines to reduce structural loading. Essentially, these technologies serve to both

improve performance regarding power capture in addition to increasing the lifespan of turbine components. 


\subsection{OBJECTIVES}

Based on the aforementioned reviews of contemporary control systems available to wind turbine systems, as well as desired future improvements as indicated by the US DoE, the following objectives have been determined to improve the performance of Type 4 wind turbine systems through the use of nonlinear control theory:

1. Improve the system efficiency of Type 4 wind turbines.

2. Effectively operate Type 4 wind turbines through turbulent wind conditions.

3. Prevent system failures in Type 4 wind turbines.

The use of nonlinear control principles can be used to accomplish these objectives. The first and second objectives can be met through the use of intelligent control systems that increase the system efficiency through rotational speed control of the generator, which should be accomplished while managing the nonlinearities associated with turbulent wind characteristics. The final objective can be met through the use of accurate observation systems, which determine time-varying system states that are otherwise unobtainable through measurement. Knowledge of key states that influence the health and performance of wind turbine systems can assist system engineers with the prevention of scenarios that would cause system downtime. Details of the specific objectives for these controllers and observers, as well as the mathematical development for these systems, will be provided in subsequent sections. 


\section{WIND TURBINE SYSTEM MODEL}

A visual representation of a Type 4 system model is shown in Figure 9. As shown, there are multiple stages to the energy conversion present in a WECS. The kinetic energy present in wind is converted to rotational energy through turbine blades, which then spin a rotor. This rotor is connected to the mechanical input of the generator itself, which in turn provides electrical power out in the form of three-phase voltages and currents.

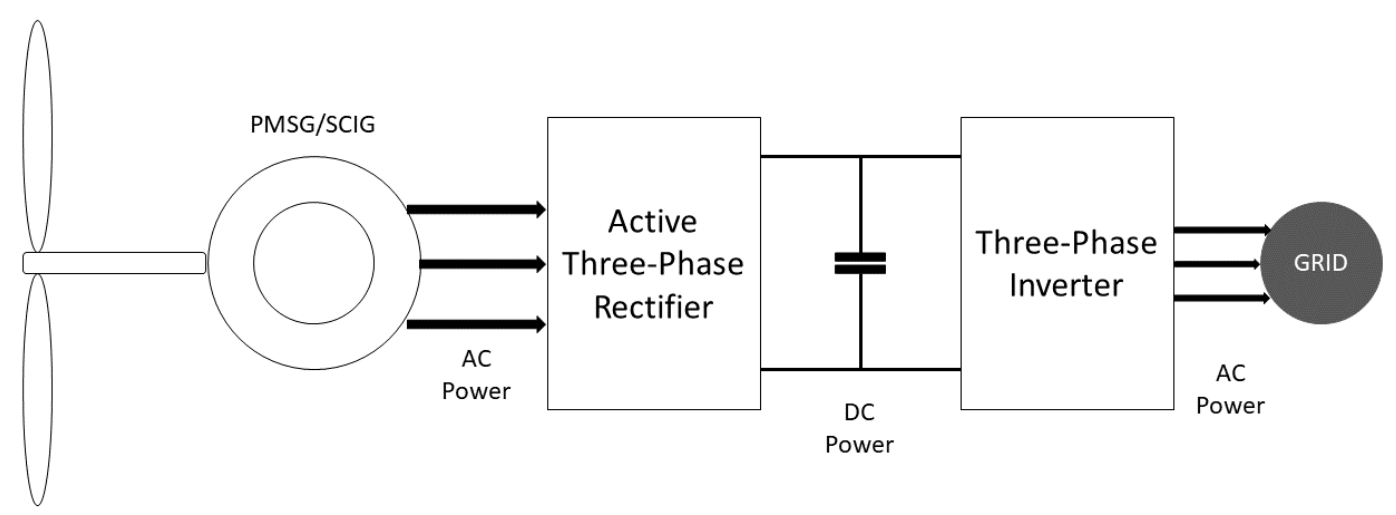

Figure 9. Typical configuration of a full-variable WECS

\subsection{WIND TURBINE MECHANICAL MODEL}

The power provided by wind energy in the context of a wind turbine is modelled as

$$
P_{\text {wind }} \triangleq \frac{1}{2} \rho A v^{3}
$$

where $\rho$ is the density of the air, $A$ is the swept area of the wind turbine blades, and $v$ is the velocity of the wind. However, this describes the power of the wind as it approaches a wind turbine, and it is not possible for this quantity to be entirely captured by turbine 
blades. For wind to generate power, some kinetic energy must be present downstream of the turbine (i.e. the wind must flow through the turbine, not stop at it), otherwise the turbine would never turn in the first place. This relationship was discovered and quantified by German physicist Albert Betz, who determined that the maximum power capture efficiency of a wind turbine is $16 / 27$, or $59.3 \%$ [68]. Therefore, the aerodynamic power captured by the turbine blades is

$$
P_{\text {aero }} \triangleq \frac{1}{2} \rho A v^{3} C_{p}
$$

where $C_{p} \in\left[0, \frac{16}{27}\right]$ is the power coefficient that effectively describes the efficiency of power capture at the blades.

Upon examining the forces present at the junction of the wind turbine blades and rotor, a mathematical representation for the mechanical model can be expressed as

$$
J \dot{\omega}+B \omega+T_{L}=T_{E}
$$

where $\omega$ is the rotational velocity (in rad/s) of the wind turbine shaft, $J$ is the total turbine inertia, $B$ is the damping coefficient, $T_{L}$ is the mechanical load torque, and $T_{E}$ is the electrical generator torque. Using the mechanical power of a rotating body, the load torque can be described as

$$
T_{L}=-\frac{P_{\text {aero }}}{\omega}=-\frac{\rho A v^{3} C_{p}}{2 \omega} .
$$

The electrical torque is a result of the generator dynamics and will be discussed alongside the subsequent electrical modeling. 


\subsection{PMSG ELECTRICAL MODEL}

The per-phase equivalent circuit for a PMSG can be modeled as shown in Figure 10 [69].

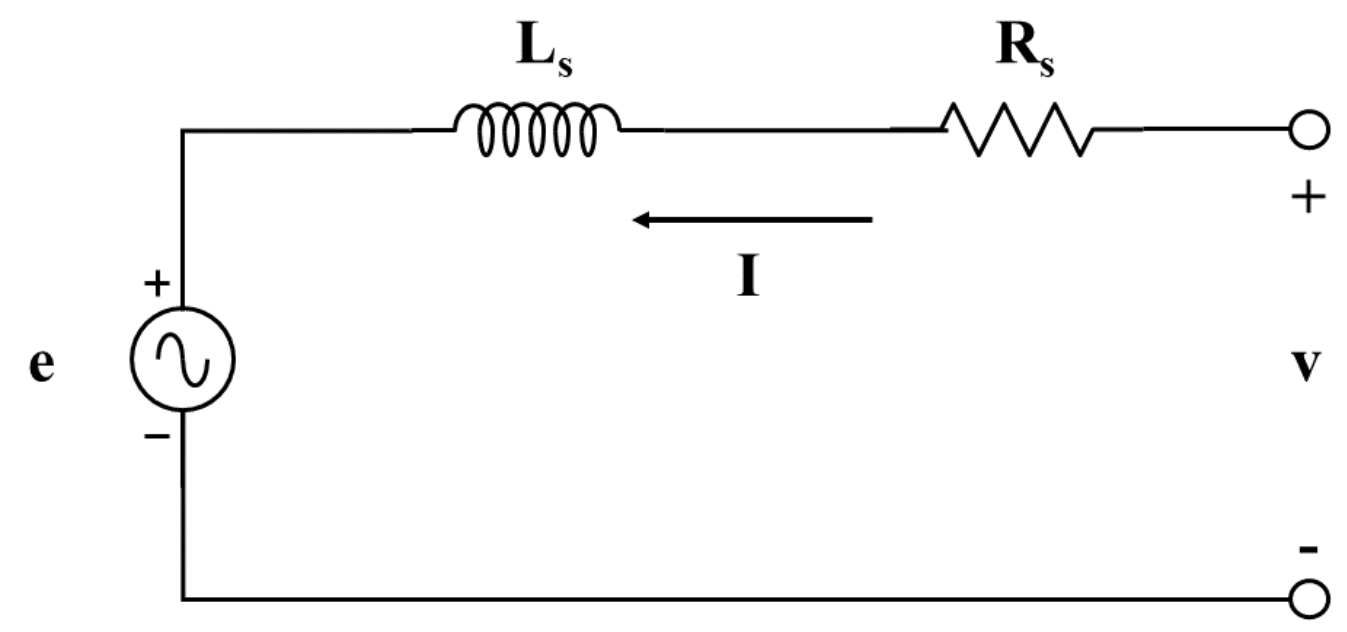

Figure 10. The per-phase equivalent circuit of a PMSG.

By taking into consideration all three phases of a PMSG and analyzing the voltage loop present in the circuit, the electrical model in the abc frame can be described as

$$
\left[\begin{array}{l}
v_{a} \\
v_{b} \\
v_{c}
\end{array}\right]=R_{s}\left[\begin{array}{l}
I_{a} \\
I_{b} \\
I_{c}
\end{array}\right]+L_{s}\left[\begin{array}{l}
\dot{I}_{a} \\
\dot{I}_{b} \\
\dot{I}_{c}
\end{array}\right]+\left[\begin{array}{c}
e_{a} \\
e_{b} \\
e_{c}
\end{array}\right]
$$

where $v_{a}, v_{b}, v_{c}$ are the phase-neutral voltages, $R_{s}$ is the stator resistance, $I_{a}, I_{b}, I_{c}$ are the phase currents, $L_{s}$ is the stator inductance, and $e_{a}, e_{b}, e_{c}$ are the phase back EMFs defined as

$$
\left[\begin{array}{l}
e_{a} \\
e_{b} \\
e_{c}
\end{array}\right] \triangleq \lambda_{m} \omega_{r}\left[\begin{array}{l}
f_{a} \\
f_{b} \\
f_{c}
\end{array}\right]
$$


where $\omega_{r}$ is the rotational velocity of the rotor magnet and $f_{a}, f_{b}, f_{c}$ are the per-phase winding distributions of the stator, which are a function of the rotor magnet angle $\theta_{r}$. The electromagnetic torque for a PMSG can be defined as

$$
T_{E} \triangleq \frac{P}{2} \lambda_{m}\left[\begin{array}{l}
f_{a} \\
f_{b} \\
f_{c}
\end{array}\right]^{T}\left[\begin{array}{l}
I_{a} \\
I_{b} \\
I_{c}
\end{array}\right]
$$

where $P$ is the number of magnetic poles in the generator.

Remark 2.1: The difference in the rotor angle $\theta_{r}$ and the turbine angle $\theta_{m}$ is dependent on the number of magnetic poles. This expression can be written as $\theta_{r}=\frac{P}{2} \theta_{m}$.

While the rotor angle $\theta_{r}$ can be referenced arbitrarily (i.e. the motor location where $\theta_{r}=0$ ), it will influence the subsequent Clarke and Park transformations. Hence, for the purposes of this work, the rotor angle is initialized $90^{\circ}$ clockwise (in the negative direction) from the a-axis, as shown in Figure 11.

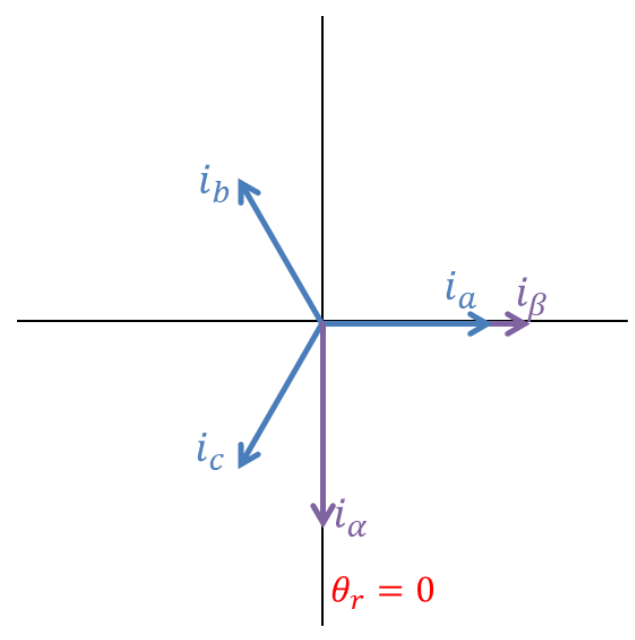

Figure 11. Initialization of the rotor magnet angle as compared to the $\mathrm{ABC}$ frame.

Mathematically, this orientation of the winding distributions is written as 


$$
\left[\begin{array}{l}
f_{a} \\
f_{b} \\
f_{c}
\end{array}\right]=\left[\begin{array}{c}
\cos \left(\theta_{r}\right) \\
\cos \left(\theta_{r}-\frac{2 \pi}{3}\right) \\
\cos \left(\theta_{r}+\frac{2 \pi}{3}\right)
\end{array}\right]
$$

Substituting (8) into (6) and that into (5) yields

$$
\left[\begin{array}{c}
v_{a} \\
v_{b} \\
v_{c}
\end{array}\right]=R_{s}\left[\begin{array}{c}
I_{a} \\
I_{b} \\
I_{c}
\end{array}\right]+L_{s}\left[\begin{array}{c}
\dot{I}_{a} \\
\dot{I}_{b} \\
\dot{I}_{c}
\end{array}\right]+\lambda_{m} \omega_{r}\left[\begin{array}{c}
\cos \left(\theta_{r}\right) \\
\cos \left(\theta_{r}-\frac{2 \pi}{3}\right) \\
\cos \left(\theta_{r}+\frac{2 \pi}{3}\right)
\end{array}\right]
$$

and substituting (8) into (7) yields

$$
T_{E}=\left(\frac{P}{2}\right) \lambda_{m}\left[\begin{array}{c}
\cos \left(\theta_{r}\right) \\
\cos \left(\theta_{r}-\frac{2 \pi}{3}\right) \\
\cos \left(\theta_{r}+\frac{2 \pi}{3}\right)
\end{array}\right]^{T}\left[\begin{array}{c}
I_{a} \\
I_{b} \\
I_{c}
\end{array}\right]
$$

Utilizing the Clarke Transformation, (9) and (10) can be rewritten in the $\alpha \beta$ frame as

$$
\begin{gathered}
{\left[\begin{array}{c}
v_{\alpha} \\
v_{\beta}
\end{array}\right]=R_{s}\left[\begin{array}{c}
I_{\alpha} \\
I_{\beta}
\end{array}\right]+L_{s}\left[\begin{array}{c}
\dot{I}_{\alpha} \\
\dot{I}_{\beta}
\end{array}\right]+\lambda_{m} \omega_{r}\left[\begin{array}{c}
-\sin \left(\theta_{r}\right) \\
\cos \left(\theta_{r}\right)
\end{array}\right]} \\
T_{E}=\left(\frac{3}{2}\right)\left(\frac{P}{2}\right) \lambda_{m}\left[-\sin \left(\theta_{r}\right) \quad \cos \left(\theta_{r}\right)\right]\left[\begin{array}{c}
I_{\alpha} \\
I_{\beta}
\end{array}\right] .
\end{gathered}
$$

From here, while taking Remark 2.1 into account, the Park Transformation can be used to rewrite (11) and (12) in the $d q$ frame as

$$
\begin{gathered}
{\left[\begin{array}{l}
v_{d} \\
v_{q}
\end{array}\right]=\left[\begin{array}{cc}
R_{s} & -\frac{P}{2} \omega L_{s} \\
\frac{P}{2} \omega L_{s} & R_{s}
\end{array}\right]\left[\begin{array}{l}
I_{d} \\
I_{q}
\end{array}\right]+L_{s}\left[\begin{array}{c}
\dot{I}_{d} \\
\dot{I}_{q}
\end{array}\right]+\lambda_{m} \frac{P}{2} \omega\left[\begin{array}{l}
0 \\
1
\end{array}\right]} \\
T_{e m}=\left(\frac{3}{2}\right)\left(\frac{P}{2}\right) \lambda_{m} I_{q} .
\end{gathered}
$$

Note that the existence of an electrical current in the torque equation above illustrates that this is a coupled dynamic system; i.e. the mechanical subsystem affects the 
electrical subsystem and vice versa. This is why the linear controllers in Section 1 required cascaded controls that manage states in both the mechanical and electrical dynamics.

\subsection{SCIG ELECTRICAL MODEL}

Taking into account all three phases of the machine, the electrical model for a SCIG can be written in the abc frame as

$$
\left[\begin{array}{l}
v_{a_{s}} \\
v_{b_{s}} \\
v_{c_{s}}
\end{array}\right]=R_{s}\left[\begin{array}{l}
I_{a_{s}} \\
I_{b_{s}} \\
I_{c_{s}}
\end{array}\right]+\left[\begin{array}{l}
\dot{\psi}_{a_{s}} \\
\dot{\psi}_{b_{s}} \\
\dot{\psi}_{c_{s}}
\end{array}\right]
$$

where $v_{a_{s}}, v_{b_{s}}, v_{c_{s}}$ are the phase-neutral voltages, $R_{s}$ is the stator resistance, and $\psi_{a_{s}}, \psi_{b_{s}}, \psi_{c_{s}}$ are the phase stator flux linkages. Using the same method as in Section 2.2, the Clarke Transformation can be utilized to rewrite this in the $\alpha \beta$ frame as

$$
\left[\begin{array}{c}
v_{\alpha_{s}} \\
v_{\beta_{s}}
\end{array}\right]=R_{s}\left[\begin{array}{l}
I_{\alpha_{s}} \\
I_{\beta_{s}}
\end{array}\right]+\left[\begin{array}{l}
\dot{\psi}_{\alpha_{s}} \\
\psi_{\beta_{s}}
\end{array}\right]
$$

Similarly, voltage dynamics for the rotor can be written as

$$
\left[\begin{array}{l}
v_{\alpha_{r}} \\
v_{\beta_{r}}
\end{array}\right]=R_{r}\left[\begin{array}{l}
I_{\alpha_{r}} \\
I_{\beta_{r}}
\end{array}\right]+\left[\begin{array}{l}
\dot{\psi}_{\alpha_{r}} \\
\dot{\psi}_{\beta_{r}}
\end{array}\right]+n_{p} \omega\left[\begin{array}{c}
\psi_{\beta_{r}} \\
-\psi_{\alpha_{r}}
\end{array}\right]
$$

where $v_{\alpha_{r}}, v_{\beta_{r}}$ are the rotor voltages, $R_{r}$ is the rotor resistance, $n_{p}=\frac{P}{2}$ is the number of pole pairs, $\psi_{\alpha_{r}}, \psi_{\beta_{r}}$ are the rotor fluxes and $I_{\alpha_{r}}, I_{\beta_{r}}$ are the rotor currents.

Here, it is notable that while IM have both stator and rotor dynamics, SCIG specifically are only accessible through the stator, i.e. the rotor dynamics are not measurable. Additionally, flux is not a measurable quantity regardless of its location in the machine. However, the rotor fluxes have significant influence on the system behavior, as 
outlined in Section 1.3. Therefore, there is a motivation to rewrite the model such that the voltages and currents are in the stator and the fluxes are in the rotor.

To begin translating between the stator and rotor fluxes, it is assumed that each flux can be modeled as a fixed inductance

$$
\begin{aligned}
& L_{s}=L_{l s}+L_{m} \\
& L_{r}=L_{l r}+L_{m}
\end{aligned}
$$

where $L_{l s}, L_{l r}$ are the leakage inductances unique to each location and $L_{m}$ is the mutual inductance that is shared between both. By taking into account the current crossing between the stator and rotor through these inductances, the translation between their fluxes can be defined as

$$
\begin{aligned}
& {\left[\begin{array}{l}
\psi_{\alpha_{s}} \\
\psi_{\beta_{s}}
\end{array}\right]=L_{s}\left[\begin{array}{c}
I_{\alpha_{s}} \\
I_{\beta_{s}}
\end{array}\right]+L_{m}\left[\begin{array}{c}
I_{\alpha_{r}} \\
I_{\beta_{r}}
\end{array}\right]} \\
& {\left[\begin{array}{l}
\psi_{\alpha_{r}} \\
\psi_{\beta_{r}}
\end{array}\right]=L_{r}\left[\begin{array}{l}
I_{\alpha_{r}} \\
I_{\beta_{r}}
\end{array}\right]+L_{m}\left[\begin{array}{c}
I_{\alpha_{s}} \\
I_{\beta_{s}}
\end{array}\right] .}
\end{aligned}
$$

By solving (17) for the rotor flux derivatives and substituting in rearranged (21), it can be found that

$$
\left[\begin{array}{l}
\dot{\psi}_{\alpha_{r}} \\
\dot{\psi}_{\beta_{r}}
\end{array}\right]=\frac{R_{r} L_{m}}{L_{r}}\left[\begin{array}{l}
I_{\alpha_{s}} \\
I_{\beta_{s}}
\end{array}\right]-\left[\begin{array}{cc}
\frac{R_{r}}{L_{r}} & n_{p} \omega \\
-n_{p} \omega & \frac{R_{r}}{L_{r}}
\end{array}\right]\left[\begin{array}{l}
\psi_{\alpha_{r}} \\
\psi_{\beta_{r}}
\end{array}\right]
$$

To obtain the stator current dynamics, (20) is substituted into (16) to obtain

$$
\left[\begin{array}{c}
v_{\alpha_{s}} \\
v_{\beta_{s}}
\end{array}\right]=R_{s}\left[\begin{array}{c}
I_{\alpha_{s}} \\
I_{\beta_{s}}
\end{array}\right]+L_{s}\left[\begin{array}{c}
\dot{I}_{\alpha_{s}} \\
\dot{I}_{\beta_{s}}
\end{array}\right]+L_{m}\left[\begin{array}{c}
\dot{I}_{\alpha_{r}} \\
\dot{I}_{\beta_{r}}
\end{array}\right]
$$

Rearranging (21) once again and substituting into (23) yields

$$
\left(L_{s}-\frac{L_{m}^{2}}{L_{r}}\right)\left[\begin{array}{l}
\dot{I}_{\alpha_{s}} \\
\dot{I}_{\beta_{s}}
\end{array}\right]=\left[\begin{array}{c}
v_{\alpha_{s}} \\
v_{\beta_{s}}
\end{array}\right]-R_{s}\left[\begin{array}{c}
I_{\alpha_{s}} \\
I_{\beta_{s}}
\end{array}\right]-\frac{L_{m}}{L_{r}}\left[\begin{array}{c}
\dot{\psi}_{\alpha_{r}} \\
\dot{\psi}_{\beta_{r}}
\end{array}\right]
$$

which after substituting (22) finally produces 


$$
\left(1-\frac{L_{m}^{2}}{L_{s} L_{r}}\right) L_{s}\left[\begin{array}{l}
\dot{I}_{\alpha_{s}} \\
\dot{I}_{\beta_{s}}
\end{array}\right]=\left[\begin{array}{l}
v_{\alpha_{s}} \\
v_{\beta_{s}}
\end{array}\right]-\left(R_{s}+R_{r} \frac{L_{m}^{2}}{L_{r}^{2}}\right)\left[\begin{array}{l}
I_{\alpha_{s}} \\
I_{\beta_{s}}
\end{array}\right]+\frac{L_{m}}{L_{r}}\left[\begin{array}{cc}
\frac{R_{r}}{L_{r}} & n_{p} \omega \\
-n_{p} \omega & \frac{R_{r}}{L_{r}}
\end{array}\right]\left[\begin{array}{l}
\psi_{\alpha_{r}} \\
\psi_{\beta_{r}}
\end{array}\right]
$$

The electromagnetic torque is defined as [BK BOSE]

$$
T_{E}=\frac{3}{2} n_{p} L_{m}\left(I_{\beta_{s}} I_{\alpha_{r}}-I_{\alpha_{s}} I_{\beta_{r}}\right) .
$$

By rearranging (21) and substituting into (26), followed by a change into matrix form, it can be seen that (26) is equivalent to

$$
T_{E}=\frac{3}{2} n_{p} \frac{L_{m}}{L_{r}}\left[\begin{array}{l}
I_{\alpha_{s}} \\
I_{\beta_{s}}
\end{array}\right]^{T}\left[\begin{array}{cc}
0 & 1 \\
-1 & 0
\end{array}\right]\left[\begin{array}{l}
\psi_{\alpha_{r}} \\
\psi_{\beta_{r}}
\end{array}\right] .
$$

To simplify the completed SCIG electrical model, (22), (25), and (27) can be vectorized as

$$
\begin{gathered}
\dot{\psi}=C_{3} I-C_{2} \psi+n_{p} \omega Q \psi \\
C_{4} \dot{I}=v-C_{6} I+C_{5} \psi+C_{1} \omega Q^{T} \psi \\
T_{E}=\frac{3}{2} C_{1} I^{T} Q \psi
\end{gathered}
$$

where $\psi=\left[\begin{array}{ll}\psi_{\alpha} & \psi_{\beta}\end{array}\right]^{T}, I=\left[\begin{array}{ll}I_{\alpha} & I_{\beta}\end{array}\right]^{T}, v=\left[\begin{array}{ll}v_{\alpha} & v_{\beta}\end{array}\right]^{T}, Q=\left[\begin{array}{cc}0 & -1 \\ 1 & 0\end{array}\right], C_{1}=\frac{n_{p} L_{m}}{L_{r}}, C_{2}=$ $\frac{R_{r}}{L_{r}}, C_{3}=\frac{R_{r} L_{m}}{L_{r}}, C_{4}=L_{S}\left(1-\frac{L_{m}^{2}}{L_{s} L_{r}}\right), C_{5}=\frac{L_{m} R_{r}}{L_{r}^{2}}, C_{6}=R_{S}+\frac{R_{r} L_{m}^{2}}{L_{r}^{2}}$.

\subsection{MODEL UNCERTAINTIES}

Both the mechanical and electrical subsystems include uncertain quantities that are difficult to determine. Among the most difficult of these is the power coefficient of the wind power. This quantity is widely considered to be a function of the tip speed ratio (TSR), defined as

$$
\lambda=\frac{R \omega}{v}
$$


where $R$ is the turbine swept area radius, and the turbine blade angle $\beta$ [14] [24] [25] [31] [70] [71]. However, while this state-dependent function has been estimated linearly by various sources, the exact configuration of this function is not agreed upon, and typically is estimated differently depending on the specific system.

Additionally, there are parametric uncertainties within the mechanical dynamics. The quantities associated with the total rotational inertia $J$ and damping coefficient $B$ are difficult to accurately measure in a system such as a WECS. This means that the given value on the nameplate of a turbine can often be incorrect, which can make control of these turbines more difficult.

There are not many uncertainties within the PMSG electrical dynamics, as measurement of their parameters involves a relatively well-known process and all signals within the model are easily measurable. However, SCIG dynamics include a major uncertainty in that the rotor flux is not measurable. As rotor flux can become too large if left unmanaged, it is important to determine this uncertainty in some way to control the stability of a SCIG-based wind turbine. 


\section{SIMULATION PLATFORM}

The PLECS simulation software is used to simulate the system modeled detailed in Section 2. This simulation platform has the advantage of modelling circuits visually using components from a built-in library, while also managing complex differential equations in mathematical form. In combination, this creates an excellent environment in which to model the wind turbine system alongside the controllers and observers developed later in this work. 


\subsection{PMSG SIMULATION PARAMETERS}

The parameters used in the simulated model of a PMSG are presented in Table 2 below.

Table 2

$\underline{\text { PMSG Simulated Model Parameters }}$

\begin{tabular}{|c|c|c|}
\hline Parameter & Value & Units \\
\hline $\mathrm{J}$ & 0.0078 & $\mathrm{~kg} \cdot \mathrm{m}^{2}$ \\
\hline $\mathrm{B}$ & 0 & $\mathrm{~kg} \cdot \mathrm{m}^{2} / \mathrm{s}$ \\
\hline$p$ & 8 & $\mathrm{poles}$ \\
\hline$L_{s}$ & 6.9 & $\mathrm{mH}$ \\
\hline$R_{s}$ & 0.42 & $\mathrm{~V} \cdot \mathrm{s}$ \\
\hline$\lambda_{m}$ & 0.36 & $\mathrm{~kg} / \mathrm{m}^{3}$ \\
\hline$\rho$ & 1.225 & $\mathrm{~m}$ \\
\hline $\mathrm{R}$ & 3 & $\mathrm{~m} / \mathrm{s}$ \\
\hline$v_{u p}$ & 15 & \\
\hline
\end{tabular}




\subsection{SCIG SIMULATION PARAMETERS}

The parameters used in the simulated model of a SCIG are presented in Table 3 below.

Table 3

$\underline{\text { SCIG Simulated Model Parameters. }}$

\begin{tabular}{|c|c|c|}
\hline Parameter & Value & Units \\
\hline $\mathrm{J}$ & 0.15 & $\mathrm{~kg} \cdot \mathrm{m}^{2}$ \\
\hline B & 0.008 & $\mathrm{~kg} \cdot \mathrm{m}^{2} / \mathrm{s}$ \\
\hline$n_{p}$ & 2 & \# poles pairs \\
\hline$R_{r}$ & 2.553 & $\Omega$ \\
\hline$R_{S}$ & 2.015 & $\Omega$ \\
\hline$L_{r}$ & 245.5 & $\mathrm{mH}$ \\
\hline$L_{S}$ & 241.6 & $\mathrm{mH}$ \\
\hline$L_{m}$ & 230 & $\mathrm{mH}$ \\
\hline$\rho$ & 1.225 & $\mathrm{~kg} / \mathrm{m}^{3}$ \\
\hline $\mathrm{R}$ & 1 & $\mathrm{~m}$ \\
\hline$v_{u p}$ & 15 & $\mathrm{~m} / \mathrm{s}$ \\
\hline$B_{u p}$ & 0.018 & $\mathrm{~kg} \cdot \mathrm{m}^{2} / \mathrm{s}$ \\
\hline
\end{tabular}




\section{CONTROLLERS}

\subsection{PMSG SPEED TRACKING CONTROL}

One of the more difficult quantities to attain in a PMSG system is the torque generated by the wind. Therefore, a nonlinear backstepping controller has been developed that manages the rotational speed of a PMSG to maximize power extraction without knowledge of the WECS torque dynamics. Backstepping methods work similarly to cascaded linear methods in that they manage a time-varying quantity in one dynamic system, which then manages another quantity in the coupled dynamic system. This system requires the input of an optimal tip speed ratio, which can be discovered using well-known MPPT methods. This controller aims to be robust to system operating point changes and torque uncertainties.

\subsubsection{CONTROL DEVELOPMENT}

The objective of this controller is to manage the rotational velocity, $\omega(t)$, of the wind turbine shaft such that it maintains the optimal tip speed ratio, $\lambda_{d}$. This speed regulation is accomplished by managing the $d q$ frame voltages, $v_{d}(t), v_{q}(t)$, at the output of the PMSG. Ultimately, the goal of this system is to achieve maximum power output by tracking the optimal tip speed ratio. This should be accomplished alongside the following assumptions. 
Assumption 4.1.1: The turbine torque $T_{L}(\omega, v)$ is an unknown time-varying quantity that is bounded by a known function $\Omega(\omega) \geq\left|T_{L}(\omega, v)\right|$, where $\Omega(\omega)$ is continuously differentiable. It is assumed that $T_{L}(\omega, v) \in \mathcal{L}_{\infty}$.

Assumption 4.1.2: The rotational velocity, $\omega(t)$, of the turbine shaft is measurable.

Assumption 4.1.3: The generator voltages (control signals) and currents are all measurable, and the dq-frame quantities assume appropriate synchronization.

Assumption 4.1.4: The parameters $A, J, B, P, \lambda_{m}, L_{s}$, and $R_{s}$ are known a priori and are assumed to be constant with respect to time.

Assumption 4.1.5: The wind speed $v$ is assumed to be unknown. However, an upper bound for the wind speed, $v_{u p}$, is assumed to be known a priori and constant with respect to time.

To begin, an error signal $e(t)$ is defined such that the goal of the controller is that $e(t)$ is bounded as $t \rightarrow \infty$. That is,

$$
e \triangleq \omega_{d}-\omega
$$

where $\omega_{d}(t)$ is the desired speed for maximum power extraction found through

$$
\omega_{d} \triangleq \frac{\lambda_{d} v}{R}
$$

where $\lambda_{d}$ is the desired tip speed ratio.

Remark 4.1.1: From the form of (33), it is apparent that such a method requires real-time measurement of the wind speed and knowledge of the optimal tip speed ratio. The need for this knowledge can be eliminated by utilizing commonly used maximum power point tracking (MPPT) methods [13] [72], though this work aims to demonstrate controller tracking ability alone. Therefore, this work assumes for the purposes of speed trajectory 
planning that the wind speed is measurable. However, the subsequent controller itself does not assume a known wind speed, as seen in Remark 4.1.2.

By taking the derivative and multiplying through by $J$, (32) can be altered into

$$
J \dot{e}=J \dot{\omega}_{d}-J \dot{\omega} .
$$

Solving the mechanical dynamics in (3) for the first term and substituting into (34) yields

$$
J \dot{e}=J \dot{\omega}_{d}-\left(\frac{3 P}{4}\right) \lambda_{m} I_{q}+B \omega+T_{L}
$$

In order to use the voltages, $v_{d}(t)$ and $v_{q}(t)$, as the control inputs, a backstepping control objective is utilized through two additional error terms, defined as

$$
\begin{aligned}
& \eta_{q} \triangleq I_{q}-I_{q d} \\
& \eta_{d} \triangleq I_{d}-I_{d d}
\end{aligned}
$$

where $I_{q d}(t), I_{d d}(t)$ are the desired q-axis and d-axis currents respectively. These additional error terms are defined such that the goal of the controller also includes $\eta_{q}(t), \eta_{d}(t)$ are bounded as $t \rightarrow \infty$

By rearranging (36) and substituting into (35) it can be seen that

$$
J \dot{e}=J \dot{\omega}_{d}-\left(\frac{3 P}{4}\right) \lambda_{m} \eta_{q}+\left(\frac{3 P}{4}\right) \lambda_{m} I_{q d}+B \omega+T_{L} .
$$

Motivated by the subsequent stability analysis, the desired q-axis current can be defined as

$$
I_{q d} \triangleq \frac{4}{3 P \lambda_{m}}\left(k e+T_{s u b}+J \dot{\omega}_{d}+B \omega\right)
$$

where $k \in \mathbb{R}$ is a positive control gain,

$$
T_{s u b} \triangleq \frac{\Omega^{2} e}{\varepsilon}
$$

where $\varepsilon \in \mathbb{R}$ is a small constant and $\Omega(\omega)$ is defined as 


$$
\Omega(\omega) \triangleq \frac{\rho A v_{u p}^{3}}{2 \omega}
$$

Remark 4.1.2: The function $T_{\text {sub }}$ is a robust high-gain term designed to compensate for the unknown dynamics of $T_{L}$. The function $\Omega(\omega)$ is chosen as an upper bound for the torque $T_{L}$, which is inferred from (4). Since $C_{p}$ is an efficiency of the wind captured by the turbine blades, removing it from $P_{\text {aero }}$ provides the power of the wind itself, which, alongside an upper bound for the wind speed, can be used as an upper bound on $T_{L}$.

After substituting the q-axis current, the closed loop mechanical dynamics become

$$
J \dot{e}=-k e-\frac{\Omega^{2} e}{\varepsilon}-\left(\frac{3 P}{4}\right) \lambda_{m} \eta_{q}+T_{L}
$$

To obtain this desired q-axis current, $I_{q}(t)$, the electrical dynamics of the system are used. Taking the derivative of (36) and multiplying by $L_{s}$ it can be seen that

$$
L_{s} \dot{\eta}_{q}=L_{s} \dot{I}_{q}-L_{s} \dot{I}_{q d}
$$

By rearranging the bottom half of (13) and substituting into (43), the open-loop error dynamics for the q-axis can be obtained as

$$
L_{s} \dot{\eta}_{q}=v_{q}-\frac{\omega P}{2} L_{s} I_{d}-R_{s} I_{q}-\lambda_{m} \frac{\omega P}{2}-L_{s} \dot{I}_{q d}
$$

Motivated by the subsequent stability analysis, the q-axis voltage can be defined as

$$
v_{q} \triangleq=\left(\frac{3 P}{4}\right) \lambda_{m} e-k_{q} \eta_{q}+\frac{\omega P}{2} L_{s} I_{d}+R_{s} I_{q}+\lambda_{m} \frac{\omega P}{2}+L_{s} \dot{I}_{q d}
$$

where $k_{q} \in \mathbb{R}$ is a positive control gain and

$$
\dot{I}_{q d} \triangleq \frac{4}{3 P \lambda_{m}}\left(k \dot{e}+\dot{T}_{s u b}+J \ddot{\omega}_{d}+B \Gamma\right) .
$$

To implement (46), 


$$
\begin{gathered}
\dot{T}_{\text {sub }} \triangleq-\frac{T_{\text {sub }}}{\omega} \\
\Gamma \triangleq-\frac{1}{J}\left(B \omega+T_{\text {sub }}+\left(\frac{3 P}{4}\right) \lambda_{m} I_{q}\right)
\end{gathered}
$$

are used. Upon substituting the q-axis voltage, the closed loop dynamics become

$$
L_{s} \dot{\eta}_{q}=\left(\frac{3 P}{4}\right) \lambda_{m} e-k_{q} \eta_{q} .
$$

The d-axis equations form similarly to the q-axis. First

$$
L_{s} \dot{\eta}_{d}=L_{s} \dot{I}_{d}-L_{s} \dot{I}_{d d}
$$

is found by taking the derivative of (37) and multiplying by $L_{S}$.

Remark 4.1.3: In typical PMSG applications, the desired d-axis current is set such that $I_{d d}(t)=0$, and therefore $\dot{I}_{d d}(t)=0$.

By rearranging the top half of (13) and substituting into (50), as well as taking into account Remark 4.1.3, the open-loop error dynamics for the d-axis can be obtained as

$$
L_{s} \dot{\eta}_{d}=v_{d}-R_{s} I_{d}+\frac{\omega P}{2} L_{s} I_{q} .
$$

Then the d-axis voltage can be designed as

$$
v_{d} \triangleq R_{S} I_{d}-\frac{\omega P}{2} L_{s} I_{q}-k_{d} \eta_{d}
$$

where $k_{d} \in \mathbb{R}$ is a positive control gain. Substituting this into the d-axis voltage dynamics yields the closed loop system

$$
L_{s} \dot{\eta}_{d}=-k_{d} \eta_{d}
$$

\subsubsection{STABILITY ANALYSIS}

Theorem 4.1: The controlled voltages in (45) and (52) ensure that $e(t), \eta_{q}(t), \eta_{d}(t)$ are Globally Uniformly Ultimately Bounded (GUUB). 
Proof 4.1: The stability of the closed-loop system presented by the combination of (42), (49), and (53) can be shown through a non-negative Lyapunov function $V(t) \in \mathbb{R}$, defined as

$$
V \triangleq \frac{1}{2} J e^{2}+\frac{1}{2} L_{s} \eta_{q}^{2}+\frac{1}{2} L_{s} \eta_{d}^{2}
$$

for which the derivative is

$$
\dot{V}=J e \dot{e}+L_{s} \eta_{q} \dot{\eta}_{q}+L_{s} \eta_{d} \dot{\eta}_{d}
$$

Substituting (42), (49), and (53) into (55) and simplifying yields

$$
\dot{V}=-k e^{2}-\frac{\Omega^{2} e^{2}}{\varepsilon}+T_{L} e-k_{q} \eta_{q}^{2}-k_{d} \eta_{d}^{2}
$$

which from Assumption 4.1.1 can be upper bounded as

$$
\dot{V} \leq-k e^{2}-k_{q} \eta_{q}^{2}-k_{d} \eta_{d}^{2}+|e| \Omega\left(1-\frac{1}{\varepsilon}|e| \Omega\right)
$$

Upon inspection of the $\left(1-\frac{1}{\varepsilon}|e| \Omega\right)$ term, there become two possible cases. If $|e| \Omega>\varepsilon$, then (57) simplifies to

$$
\dot{V} \leq-k e^{2}-k_{s} \eta_{q}^{2}-k_{d} \eta_{d}^{2}
$$

which is negative for all time. However, if $|e| \Omega<\varepsilon$, then (57) simplifies to

$$
\dot{V} \leq-k e^{2}-k_{s} \eta_{q}^{2}-k_{d} \eta_{d}^{2}+\varepsilon
$$

which requires further analysis.

Should (57) simplify to (59), the errors must be vectorized as

$$
Z \triangleq\left[\begin{array}{lll}
e & \eta_{q} & \eta_{d}
\end{array}\right]
$$

From this definition, $V$ can be redefined as

$$
V=\frac{1}{2} Z\left[\begin{array}{ccc}
J & 0 & 0 \\
0 & L_{S} & 0 \\
0 & 0 & L_{S}
\end{array}\right] Z^{T}
$$


which, by using the Raleigh inequality, can be bounded as

$$
\lambda_{\min }\|Z\|^{2} \leq V \leq \lambda_{\max }\|Z\|^{2}
$$

where

$$
\begin{aligned}
& \lambda_{\text {min }} \triangleq \frac{1}{2} \min \left(J, L_{s}, L_{s}\right), \\
& \lambda_{\text {max }} \triangleq \frac{1}{2} \max \left(J, L_{s}, L_{s}\right) .
\end{aligned}
$$

From this, (59) can be rewritten as

$$
\dot{V} \leq-\frac{\gamma V}{\lambda_{\max }}+\varepsilon
$$

where

$$
\gamma \triangleq \min \left(k, k_{q}, k_{d}\right)
$$

Rearranging (65) yields the first order differential equation

$$
\dot{V}+\frac{\gamma V}{\lambda_{\max }}=\varepsilon-s(t)
$$

where $s(t) \geq 0$. Solving this differential equation yields

$$
V(t) \leq V(0) e^{-\frac{\gamma t}{\lambda_{\max }}}+\frac{\varepsilon \lambda_{\max }}{\gamma}\left(1-e^{-\frac{\gamma t}{\lambda_{\max }}}\right)
$$

which from (62) can be rewritten as

$$
\lambda_{\min }\|Z\|^{2} \leq V(0) e^{-\frac{\gamma t}{\lambda_{\max }}}+\frac{\varepsilon \lambda_{\max }}{\gamma}\left(1-e^{-\frac{\gamma t}{\lambda_{\max }}}\right)
$$

Solving (69) for $\|Z\|$ then yields

$$
\|Z\| \leq \sqrt{\frac{V(0)}{\lambda_{\min }} e^{-\frac{\gamma t}{\lambda_{\max }}}+\frac{\varepsilon \lambda_{\max }}{\gamma \lambda_{\min }}\left(1-e^{-\frac{\gamma t}{\lambda_{\max }}}\right)}
$$

which will reduce to $\sqrt{\frac{\varepsilon \lambda_{\max }}{\gamma \lambda_{\min }}}$ as $t \rightarrow \infty$. 
From (70), it can be shown that $e(t), \eta_{q}(t), \eta_{d}(t) \in \mathcal{L}_{\infty}$. Looking at (33) and Assumption 4.1.5 it is apparent that $\omega_{d}(t), \dot{\omega}_{d}(t), \ddot{\omega}_{d}(t) \in \mathcal{L}_{\infty}$. Then, from the form of (32), it is apparent that $\omega(t) \in \mathcal{L}_{\infty}$. From (41) it can be seen that $\Omega(\omega) \in \mathcal{L}_{\infty}$, which can then be used to show that $T_{\text {sub }}(\omega) \in \mathcal{L}_{\infty}$ in (40). Then, from the form of (39) it can be seen that $I_{q d}(t) \in \mathcal{L}_{\infty}$. From (38) and Assumption 4.1.1 it can be concluded that $\dot{e} \in \mathcal{L}_{\infty}$, and furthermore, it can be shown that $\dot{\omega} \in \mathcal{L}_{\infty}$ through (34). By considering Assumption 6.1.1, the form of (3) shows that $I_{q}(t) \in \mathcal{L}_{\infty}$. Looking again at (41), it can now be seen that $\dot{\Omega}(\omega) \in \mathcal{L}_{\infty}$, and therefore through $(40) \dot{T}_{\text {sub }}(\omega) \in \mathcal{L}_{\infty}$. Then, it can be concluded from (46) that $\dot{I}_{q d} \in \mathcal{L}_{\infty}$. Looking at (45) and (52) it can be shown that $v_{q}(t), v_{d}(t) \in$ $\mathcal{L}_{\infty}$. This utilization of standard signal chasing arguments shows that all signals in the closed-loop system remain bounded. Therefore, the system is GUUB.

\subsubsection{SIMULATION RESULTS}

While the turbine torque is considered unknown for the controller, a model is needed for simulation. For the purposes of this wind turbine system, a linearized system is chosen [31] to model the torque effects present in a wind turbine, the profile for which is shown in Figure 12. 


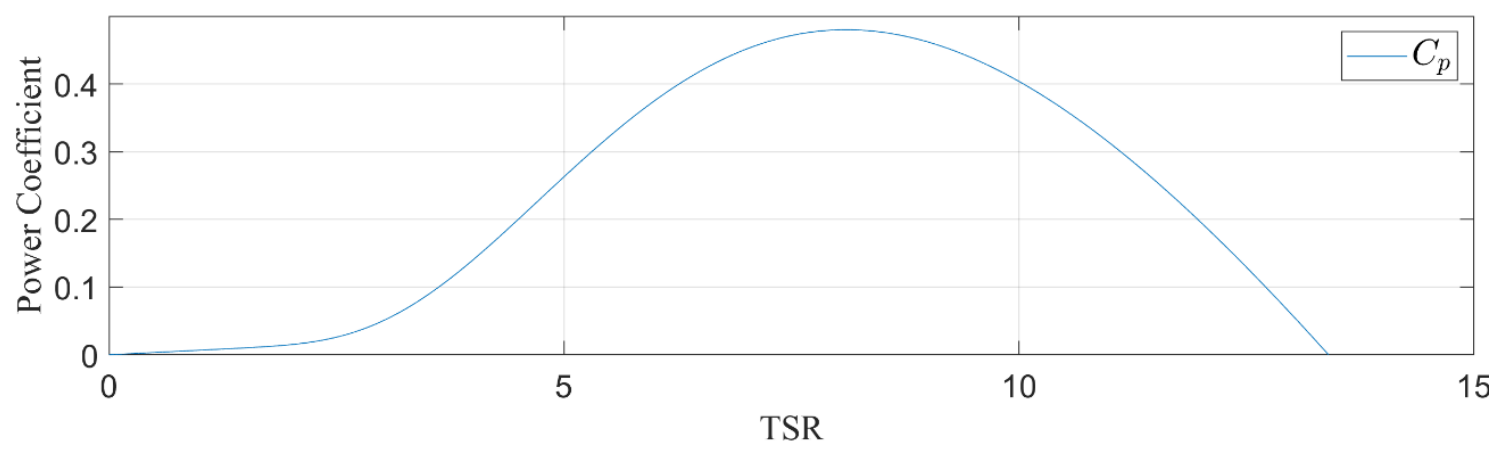

Figure 12. Power coefficient used for simulated WECS for speed controller.

In both systems, a turbulent wind speed is used to simulate the controller and observer under more realistic, changing conditions. The profile for this wind speed is shown in Figure 13.

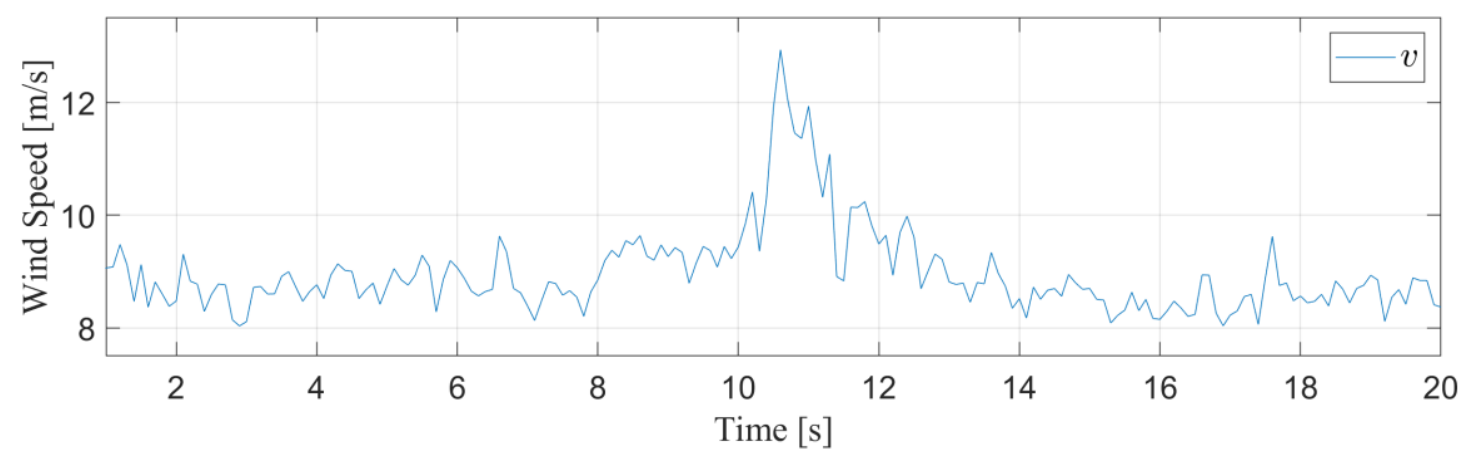

Figure 13. Varied wind speed profile used as input to turbine system in speed controller. 


\section{Table 4}

\section{$\underline{\text { PMSG Speed Controller Parameters }}$}

\begin{tabular}{|c|c|}
\hline Parameter & Value \\
\hline$k$ & 0.01 \\
\hline$k_{q}$ & 100,000 \\
\hline$k_{d}$ & 10 \\
\hline$\varepsilon$ & 1 \\
\hline$\lambda_{d}$ & 8.0 \\
\hline
\end{tabular}

The parameters for the nonlinear controller are presented in Table 4. The below figures show the simulation results for the controller. Figure 14a shows that as the wind profile changes, the speed controller changes to keep the tip speed ratio at the desired value, which is evident in Figure 14b.

Through the backstepping controller objective, the dq frame currents are controlled as seen in Figure 15. Figure 16 shows the errors for both the current and speed objectives, all of which are substantially small. 

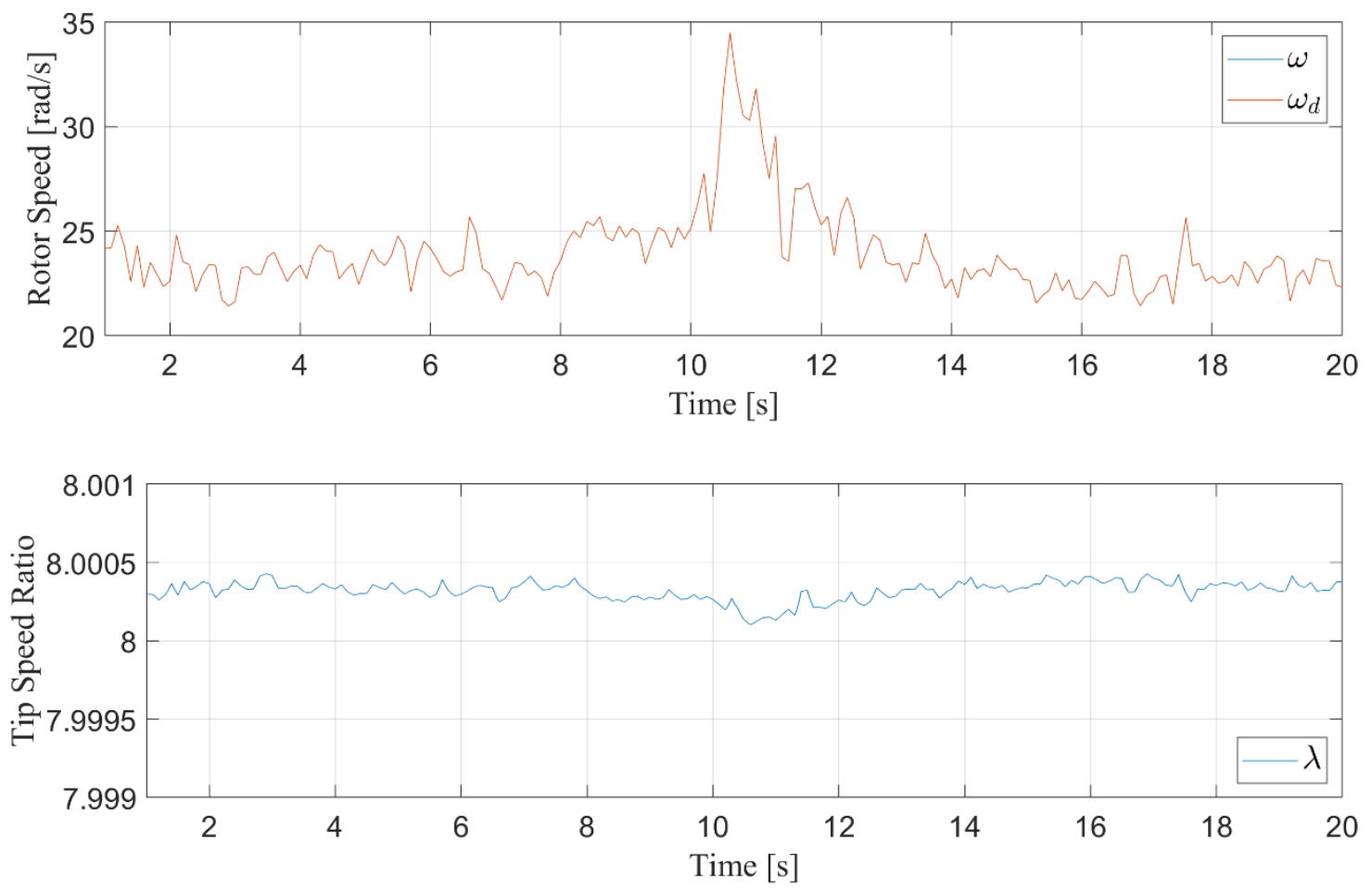

Figure 14. a) rotational speed of PMSG (top), b) TSR of PMSG (bottom).

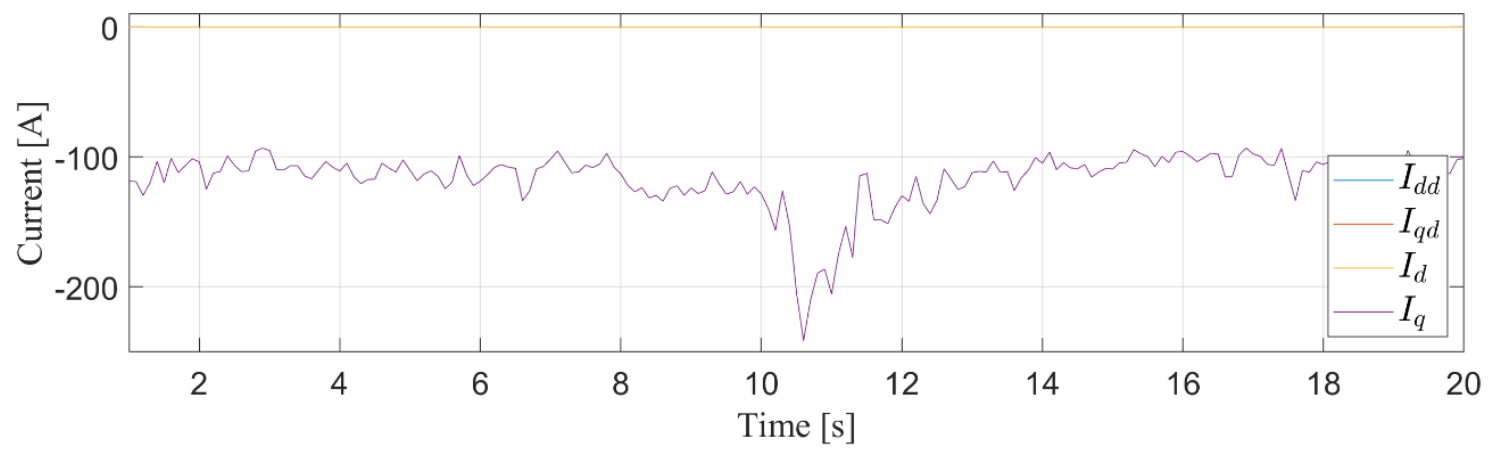

Figure 15. PMSG DQ currents versus their reference values. 


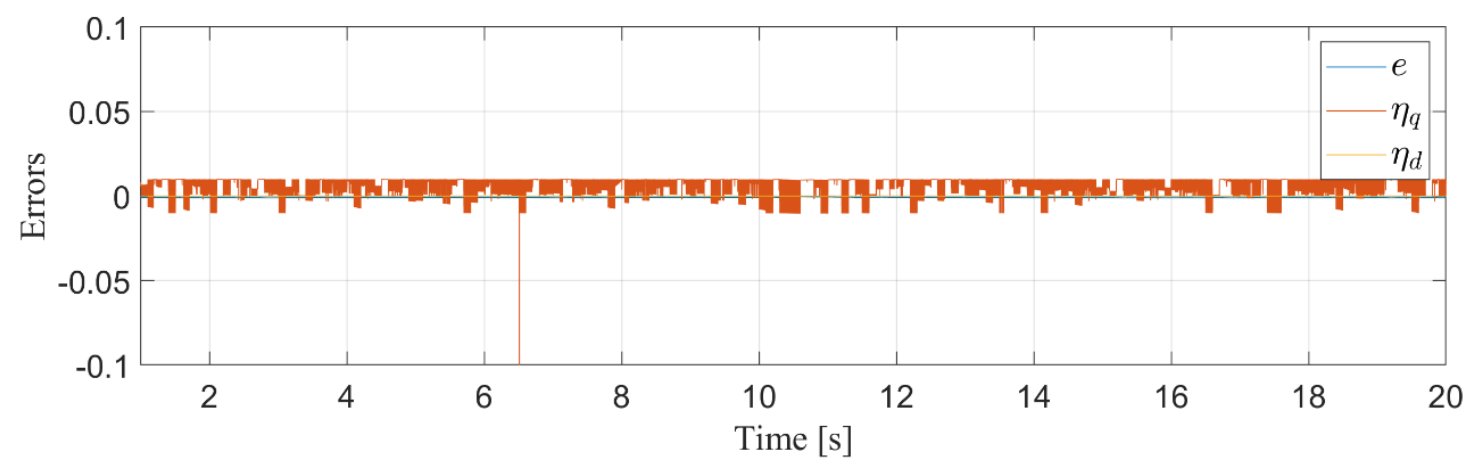

Figure 16. Nonlinear controller error signals.

\subsubsection{LINEAR CONTROLLER STEUP}

The linear controller used for comparison in this experiment is a cascaded PI controller, as shown in Figure 7 [13] [14] [15] [16] [18] [26]. This linear controller has been appropriately tuned for optimal performance with respect to rotational speed control. The control gains used are shown in Table 5.

\section{Table 5}

Control gains for PMSG linear controller.

\begin{tabular}{|c|c|}
\hline Parameter & Value \\
\hline$k_{d P}$ & 10,000 \\
\hline$k_{d I}$ & 0.01 \\
\hline$k_{\omega P}$ & 1,000 \\
\hline$k_{\omega I}$ & 100 \\
\hline$k_{q P}$ & 1 \\
\hline$k_{q I}$ & 500 \\
\hline
\end{tabular}




\subsubsection{COMPARATIVE SIMULATION RESULTS}

To compare the linear and nonlinear controllers, two tests have been done. The first experimental trial performed to compare these two controllers is a wind speed step. While an instantaneous rise in wind speed is not possible in these applications, sharp changes in wind happen regularly, and this experiment simulates a worst-case scenario. For the purposes of this test, a wind speed step occurs at $t=0.75$ from $8 \mathrm{~m} / \mathrm{s}$ to $12 \mathrm{~m} / \mathrm{s}$. As discussed in Remark 4.1.1, this will influence the desired speed trajectory $\omega_{d}$ based on (33).

The response of both controllers is shown in Figure 17. It is clear from the difference in time scales that the nonlinear controller responds much faster to changes in wind speeds as compared to the linear controller. For a numerical comparison, the settling time for each controller is presented in Table 6 .

\section{Table 6}

Settling time of PMSG linear and nonlinear controllers after wind step change.

\begin{tabular}{|c|c|}
\hline Controller & Settling Time (s) \\
\hline Linear & 0.0060000 \\
\hline Nonlinear & 0.0000006 \\
\hline
\end{tabular}



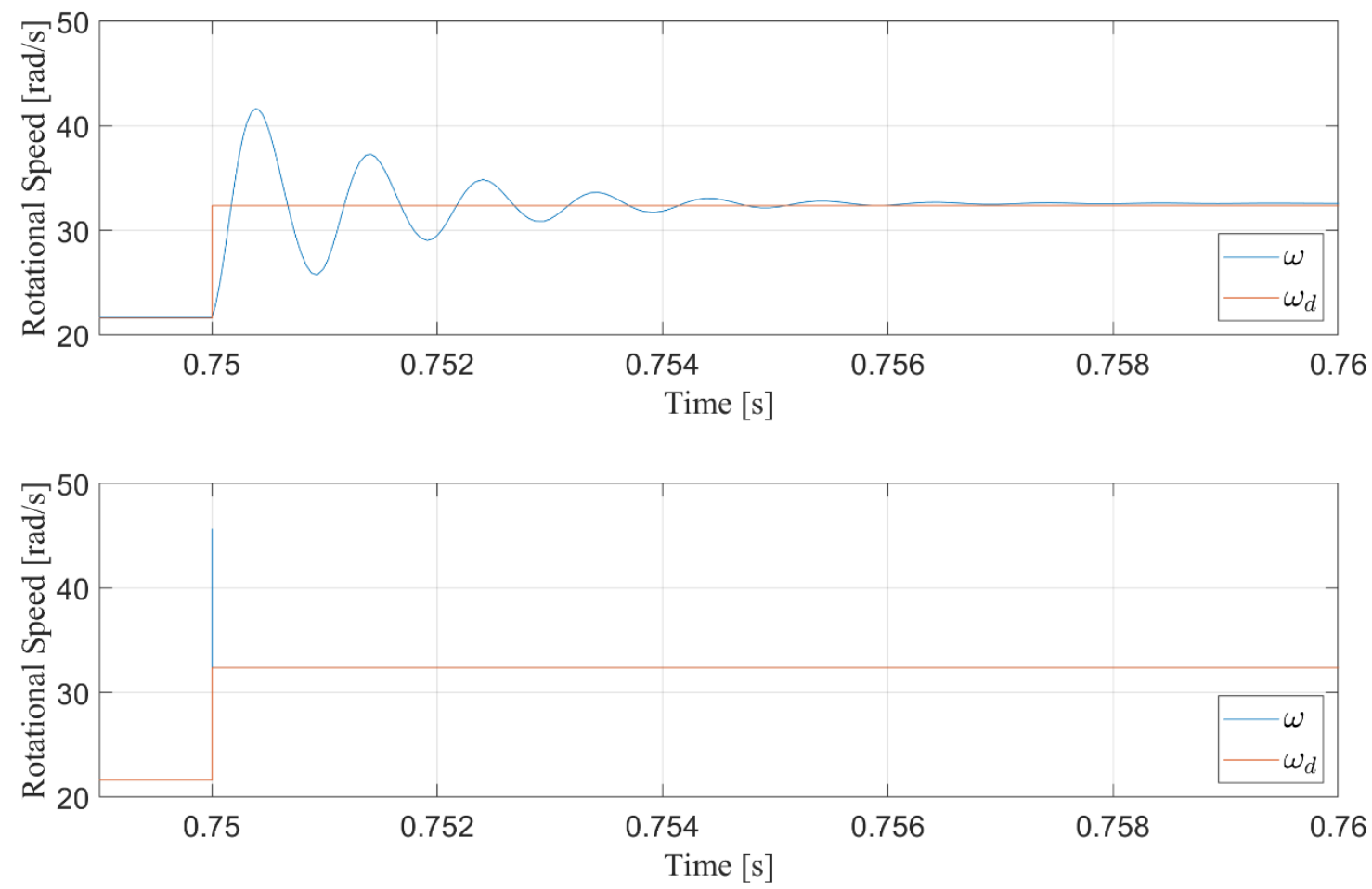

Figure 17. Step response of PMSG linear controller (top) and nonlinear controller (bottom) from a change in wind step.

These results show that the nonlinear controller is roughly 10,000 times faster than the linear controller. This increased responsiveness allows for higher precision control in the face of rapidly changing wind speeds, as illustrated by the next experiment.

The second experiment used to compare these controllers is the input of a more realistic turbulent wind speed. The turbulent wind speed used during this experiment is presented in Figure 18. This corresponds to a torque $T_{L}$ found similarly as in Section 4.1.3. 


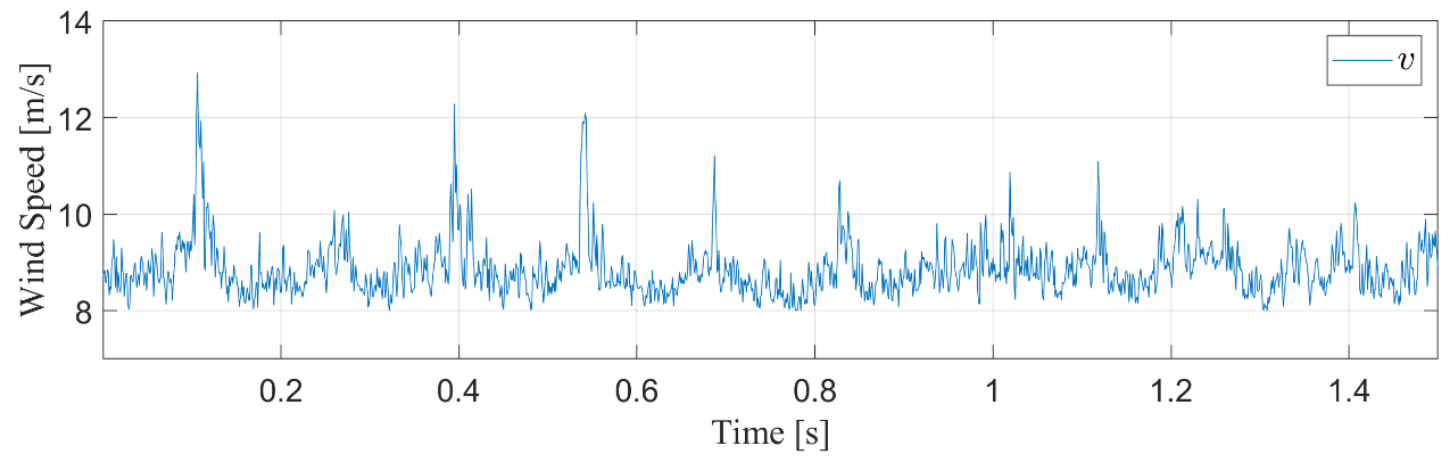

Figure 18. Turbulent wind speed for PMSG controller comparison.

As discussed in Remark 4.1.1, the desired speed trajectory $\omega_{d}$ is designed based on (33), as seen in Figure 19.

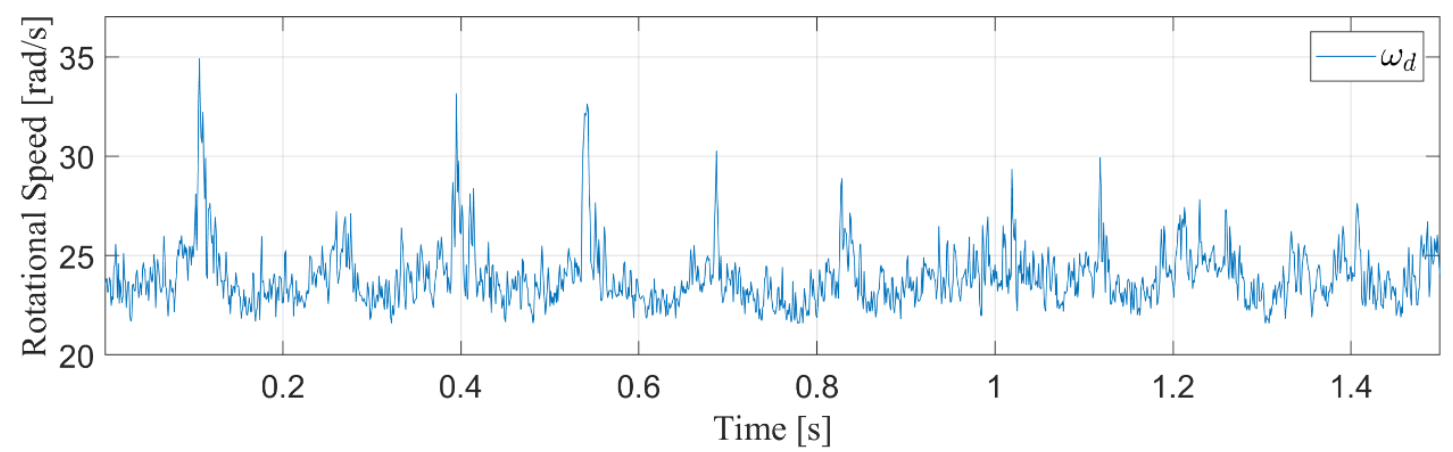

Figure 19. Desired speed trajectory for PMSG controller comparison.

The results for both controllers, in terms of the speed error $e$, are shown in Figure 20. These results can be numerically compared by looking at the RMS errors throughout operation of the wind turbine, as shown in Table 7. It can be seen from the data presented below that the proposed controller manages the rapidly changing wind speeds much better than a traditional controller. Based on Table 7, the nonlinear controller achieves more accurate speed management by four orders of magnitude. 

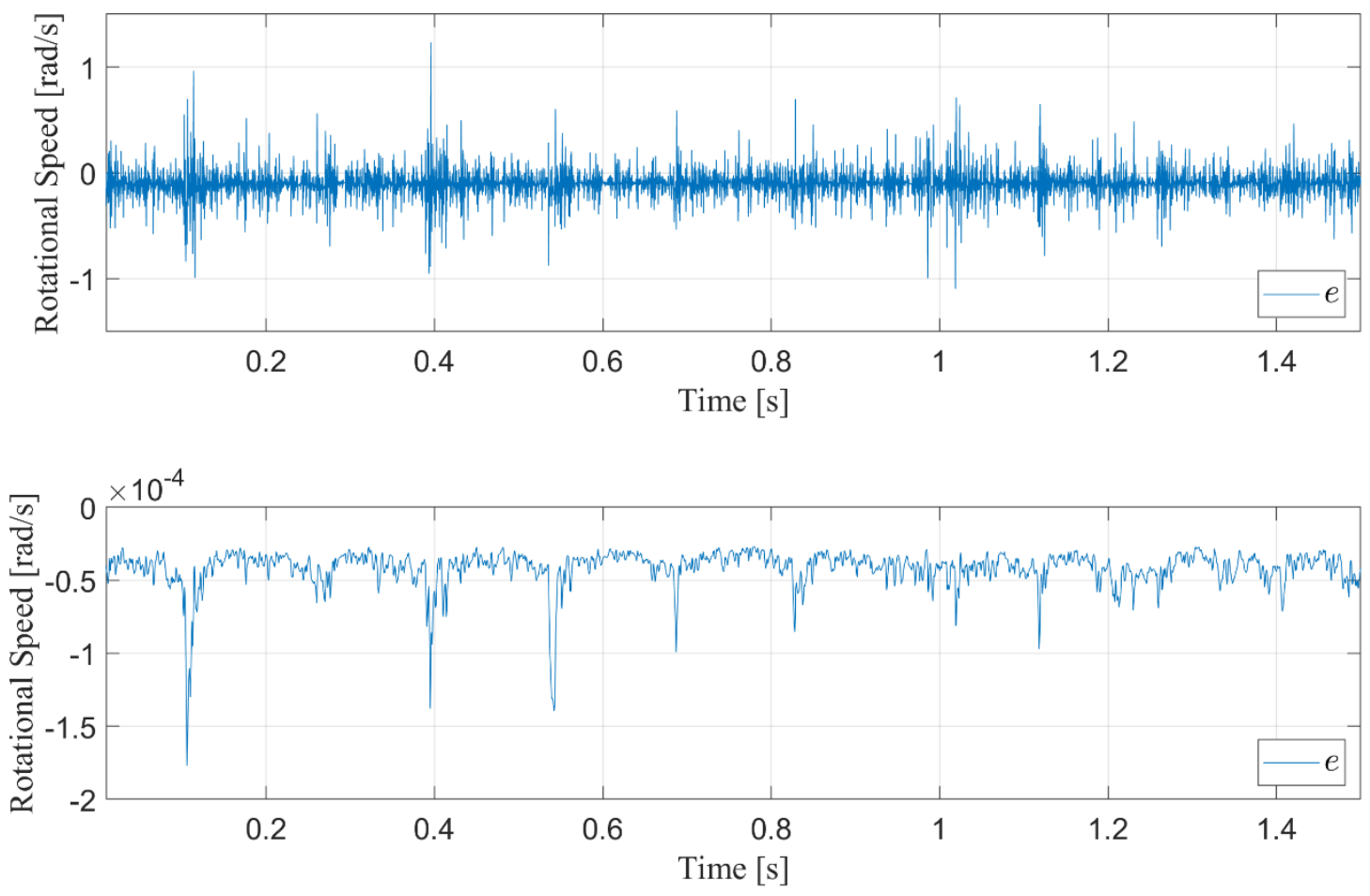

Figure 20. Speed tracking error of PMSG linear controller (top) and nonlinear controller (bottom).

\section{Table 7}

$\underline{\text { RMS speed control errors for PMSG linear and nonlinear controllers. }}$

\begin{tabular}{|c|c|}
\hline Controller & RMS Error (rad/s) \\
\hline Linear & 0.163569 \\
\hline Nonlinear & 0.000044 \\
\hline
\end{tabular}




\subsection{SCIG SPEED TRACKING CONTROL}

In this control scheme, a model-based nonlinear controller is proposed to manage the rotational speed of a SCIG using a Current-Source Converter (CSC). This controller is able to maintain high fidelity control through unknown wind torque characteristics. Turbulent

wind speeds add high nonlinearity to speed control endeavours. The proposed controller also manages the potential for inaccurate mechanical parameters by utilizing adaptive measures to compensate for that uncertainty. It is commonplace in IM applications for mechanical inertia and friction to vary from the environment and wear. Additionally, the proposed scheme is able to manage the generator flux without the need for an observer, which presents a large advantage over vector control schemes.

Typically, SCIG control methods utilize voltage dynamics as the control input to the SCIG. However, there are numerous studies that exploit current dynamics instead using CSC. While the power electronic interface is relatively the same, working in a currentmode operation has some advantages, such as higher horsepower operation and reduced stator terminal stress [73] [74].

\subsubsection{CONTROL DEVELOPMENT}

The objective of this controller is to manage the rotational velocity, $\omega(t)$, of the wind turbine shaft such that it follows the desired speed trajectory, $\omega_{d}(t)$. This speed regulation is accomplished by managing the $\alpha \beta$ frame currents $I(t)$ at the output of the SCIG. Ultimately, the goal of this system is to achieve maximum power output, which can be accomplished through the choice of speed trajectory. 
Hence, the purpose of the proposed control scheme is to manage $I(t)$ such that $\omega(t) \rightarrow$ $\omega_{d}(t)$, which, based on the selection of $\omega_{d}(t)$, implies that $P(t) \rightarrow P_{\max }(t)$, where $P_{\max }(t)$ is the maximum power able to be mechanically extracted from the wind.

This should be accomplished alongside the following assumptions.

Assumption 4.2.1: The turbine torque $T_{L}(\omega, v)$ is an unknown time-varying quantity that is bounded by a known function $\Omega(\omega) \geq\left|T_{L}(\omega, v)\right|$, where $\Omega(\omega)$ is continuously differentiable. It is assumed that $T_{L}(\omega, v) \in \mathcal{L}_{\infty}$.

Assumption 4.2.2: The generator flux $\psi(t)$ is assumed to be an unknown time-varying quantity.

Assumption 4.2.3: The electrical parameters $R_{r}, R_{s}, L_{r}, L_{s}$, and $L_{m}$ are known a priori and are assumed to be constant with respect to time.

Assumption 4.2.4: The mechanical turbine inertia $J$ is assumed to be unknown and slowly time-varying such that $\dot{J}(t) \approx 0$.

Assumption 4.2.5: The wind speed $v$ is assumed to be unknown. However, an upper bound for the wind speed, $v_{u p}$, is assumed to be known a priori and constant with respect to time. Assumption 4.2.6: The desired speed trajectory and flux magnitude and their derivatives, $\omega_{d}(t), f_{d}(t), \dot{\omega}_{d}(t), \dot{f}_{d}(t)$, are assumed to be known and bounded (i.e. $\left.\in \mathcal{L}_{\infty}\right)$.

Assumption 4.2.7: The rotational velocity, $\omega(t)$, of the turbine shaft is measurable.

To begin, an error signal $e(t)$ is defined as

$$
e \triangleq \omega_{d}-\omega
$$

where $\omega_{d}(t)$ is the desired speed trajectory. From this, a filtered error signal $r(t)$ can be defined as

$$
r \triangleq e+\int k_{1} e
$$


where $k_{1} \in \mathbb{R}$ is a positive constant. From the form of (72) it is clear that as $e(t) \rightarrow 0$, $r(t) \rightarrow 0$. Therefore, the goal of this controller is that $r(t)$ remains bounded as $t \rightarrow \infty$.

As aforementioned, a crucial piece to SCIG control is management of the generator flux $\psi(t)$. Therefore, a flux tracking error is also defined as

$$
\eta_{\psi} \triangleq \psi_{d}-\psi
$$

where the goal of the controller is for $\eta_{\psi}=\left[\begin{array}{ll}\eta_{\alpha} & \eta_{\beta}\end{array}\right]^{T}$ is bounded as $t \rightarrow \infty$. Additionally, the desired flux is defined as

$$
\psi_{d} \triangleq f_{d}\left[\begin{array}{c}
\cos \rho_{d} \\
\sin \rho_{d}
\end{array}\right]
$$

where $f_{d}$ is a known desired flux magnitude and $\rho_{d}$ is the subsequently designed function for the synchronous angle of the SCIG.

The current command is implemented as

$$
I \triangleq\left[\begin{array}{cc}
\cos \rho_{d} & -\sin \rho_{d} \\
\sin \rho_{d} & \cos \rho_{d}
\end{array}\right]\left[\begin{array}{l}
I_{d} \\
I_{q}
\end{array}\right]
$$

where $I_{d}(t), I_{q}(t)$ are the subsequently designed equivalent currents in the rotating reference frame, as transformed about $\rho_{d}$. By rearranging (75) and substituting dynamics from (74), the current can be rewritten as

$$
I=I_{d} \frac{\psi_{d}}{f_{d}}+I_{q} Q \frac{\psi_{d}}{f_{d}}
$$

The control development begins by taking the time derivative of (72) and multiplying through by $J$ to obtain

$$
J \dot{r}=J \dot{e}+k_{1} J e
$$

which, after substituting the derivative of (71), can be rewritten as

$$
J \dot{r}=J \dot{\omega}_{d}-J \dot{\omega}+k_{1} J e
$$

Substituting (3) and (30) into (78) yields 


$$
J \dot{r}=J\left(\dot{\omega}_{d}+k_{1} e\right)+B \omega+T_{L}-\frac{3}{2} C_{1} I^{T} Q \psi
$$

Rearranging (73) and then substituting into (79) yields

$$
J \dot{r}=J\left(\dot{\omega}_{d}+k_{1} e\right)+B \omega+T_{L}-\tau_{d}+\frac{3}{2} C_{1} Q^{T} J \eta_{\psi}
$$

where

$$
\tau_{d}=\frac{3}{2} C_{1} I^{T} Q \psi_{d}
$$

is the desired torque of the SCIG. Based on the form of (81), the q-axis current can be defined as

$$
I_{q} \triangleq \frac{\tau_{d}}{\frac{3}{2} C_{1} f_{d}}
$$

To implement the above, the desired torque is defined as

$$
\tau_{d} \triangleq \hat{J}\left(\dot{\omega}_{d}+k_{1} e\right)+B \omega+\frac{\Omega^{2} r}{\varepsilon}+k_{s} r
$$

where $k_{s} \in \mathbb{R}$ is a positive control gain, $\varepsilon \in \mathbb{R}$ is a small constant, $\hat{J}$ is a subsequently designed observer for the turbine inertia, and $\Omega(\omega)$ is defined as

$$
\Omega(\omega) \triangleq \frac{\rho A v_{u p}^{3}}{2 \omega}+B_{u p} \omega
$$

where $v_{\text {up }} \in \mathbb{R}$ is the known upper bound of the wind speed and $B_{\text {up }} \in \mathbb{R}$ is the known upper bound of the mechanical friction.

Remark 1: The term $\frac{\Omega^{2} r}{\varepsilon}$ is a robust high-gain term designed to compensate for the unknown dynamics of $T_{L}$. The function $\Omega(\omega)$ is chosen as an upper bound for the torque $T_{L}$, which is inferred from (4). Since $C_{p}$ is an efficiency of the wind captured by the turbine blades, removing it from $P_{\text {aero }}$ provides the power of the wind itself, which, alongside an upper 
bound for the wind speed, can be used as an upper bound on $T_{L}$. The second term is added to compensate for potential friction dynamics in the generator.

After substituting the desired torque, the closed-loop mechanical dynamics become

$$
J \dot{r}=-k_{s} r+\tilde{J}\left(\dot{\omega}_{d}+k_{1} e\right)+\frac{3}{2} C_{1} I^{T} Q \eta_{\psi}+T_{L}-\frac{\Omega^{2} r}{\varepsilon} .
$$

To obtain the d-axis current $I_{d}(t)$, the flux dynamics of the system are used. Taking the derivative of (73) yields

$$
\dot{\eta}_{\psi}=\dot{\psi}_{d}-\dot{\psi}
$$

which can be further rewritten by substituting in (5) as

$$
\dot{\eta}_{\psi}=\dot{\psi}_{d}-C_{3} I+C_{2} \psi-n_{p} \omega Q \psi
$$

where

$$
\dot{\psi}_{d}=\dot{f}_{d}\left[\begin{array}{c}
\cos \rho_{d} \\
\sin \rho_{d}
\end{array}\right]+f_{d} \dot{\rho}_{d}\left[\begin{array}{c}
-\sin \rho_{d} \\
\cos \rho_{d}
\end{array}\right] .
$$

After substituting in dynamics from (73) and (74), (87) can be rewritten as

$$
\dot{\eta}_{\psi}=\eta_{1}+\eta_{2}-C_{3} I
$$

where

$$
\begin{gathered}
\eta_{1}=\dot{f}_{d} \frac{\psi_{d}}{f_{d}}+\dot{\rho}_{d} Q \psi_{d}, \\
\eta_{2}=C_{2} \psi_{d}-C_{2} \eta_{\psi}-n_{p} \omega Q \psi_{d}+n_{p} \omega Q \eta_{\psi} .
\end{gathered}
$$

Substituting (75) and (77) into (89) yields

$$
\dot{\eta}_{\psi}=\eta_{1}+\eta_{2}-C_{3}\left(I_{d} \frac{\psi_{d}}{f_{d}}+\frac{\tau_{d}}{\frac{3}{2} C_{1} f_{d}^{2}} Q \psi_{d}\right) .
$$

Here, the d-axis current and synchronous speed can be defined as 


$$
\begin{gathered}
I_{d} \triangleq \frac{f_{d}}{C_{3}}\left(\frac{\dot{f}_{d}}{f_{d}}+C_{2}+\frac{r \tau_{d}}{f_{d}^{2}}\right) \\
\dot{\rho}_{d} \triangleq C_{3} \frac{\tau_{d}}{\frac{3}{2} C_{1} f_{d}^{2}}+n_{p} \omega+\frac{3}{2} \frac{C_{1}}{C_{3}} r\left[\left(\frac{\dot{f}_{d}}{f_{d}}\right)+C_{2}+\frac{r \tau_{d}}{f_{d}^{2}}\right] .
\end{gathered}
$$

Substituting these back into (92) and thoroughly rearranging, the closed-loop flux dynamics become

$$
\dot{\eta}_{\psi}=-C_{2} \eta_{\psi}+\frac{3}{2} C_{1} r Q I+n_{p} \omega Q \eta_{\psi}
$$

\subsubsection{STABILITY ANALYSIS}

Theorem 4.2.1: The controlled currents implemented by (82), (93), and (94) ensure that $e(t), r(t), n_{\psi}(t)$ are GUUB.

Proof 4.2.1: The stability of the closed-loop system presented by the combination of (85) and (95) can be shown through a non-negative Lyapunov function $V(t) \in$, defined as

$$
V=\frac{1}{2} J r^{2}+\frac{1}{2} \eta_{\psi}^{T} \eta_{\psi}+\frac{1}{2 k_{J}} \tilde{J}^{2}
$$

where $k_{J} \in \mathbb{R}$ is a positive control gain and

$$
\tilde{J}=J-\hat{J}
$$

is the inertia observer error. Taking the derivative of (96) yields

$$
\dot{V}=J r \dot{r}+\eta_{\psi}^{T} \dot{\eta}_{\psi}+\frac{1}{k_{J}} \tilde{J} \dot{\tilde{J}}
$$

Substituting (85) and (95) into (98) and simplifying yields

$$
\dot{V}=-k_{s} r^{2}-C_{2} \eta_{\psi}^{T} \eta_{\psi}+V_{J}+T_{L} r-\frac{\Omega^{2} r^{2}}{\varepsilon}
$$

where 


$$
V_{J}=r \tilde{J}\left(\dot{\omega}_{d}+k_{1} e\right)-\frac{1}{k_{J}} \tilde{J} \dot{\hat{J}}
$$

From this, the adaptive update law for the unknown turbine inertia can be defined as

$$
\dot{\hat{J}} \triangleq k_{J} r\left(\dot{\omega}_{d}+k_{1} e\right)
$$

Substituting this update law back into (99) yields

$$
\dot{V}=-k_{s} r^{2}-C_{2} \eta_{\psi}^{T} \eta_{\psi}+T_{L} r-\frac{\Omega^{2} r^{2}}{\varepsilon}
$$

which from Assumption 4.2.1 can be upper bounded as

$$
\dot{V} \leq-k_{s} r^{2}-C_{2} \eta_{\psi}^{T} \eta_{\psi \lambda}+|r| \Omega\left(1-\frac{1}{\varepsilon}|r| \Omega\right)
$$

Upon inspection of the $\left(1-\frac{1}{\varepsilon}|r| \Omega\right)$ term, there become two possible cases. If $|r| \Omega>\varepsilon$, then (103) simplifies to

$$
\dot{V} \leq-k_{s} r^{2}-C_{2} \eta_{\psi}^{T} \eta_{\psi \lambda}
$$

which is negative for all time. However, if $|r| \Omega<\varepsilon$, then (103) simplifies to

$$
\dot{V} \leq-k_{s} r^{2}-C_{2} \eta_{\psi}^{T} \eta_{\psi \lambda}+\varepsilon
$$

which requires further analysis.

Should (103) simplify to (105), the errors must be vectorized as

$$
Z \triangleq\left[\begin{array}{lll}
r & \eta_{\alpha} & \eta_{\beta}
\end{array}\right]
$$

From this definition, $V$ can be redefined as

$$
V=\frac{1}{2} Z\left[\begin{array}{lll}
J & 0 & 0 \\
0 & 1 & 0 \\
0 & 0 & 1
\end{array}\right] Z^{T}
$$

which, by using the Raleigh inequality, can be bounded as

$$
\lambda_{\min }|| Z\left\|^{2} \leq V \leq \lambda_{\max }|| Z\right\|^{2}
$$

where 


$$
\begin{aligned}
& \lambda_{\text {min }}|| Z||^{2} \triangleq \frac{1}{2} \min (J, 1,1), \\
& \lambda_{\text {max }}|| Z||^{2} \triangleq \frac{1}{2} \max (J, 1,1) .
\end{aligned}
$$

From this, (105) can be rewritten as

$$
\dot{V} \leq-\frac{\gamma V}{\lambda_{\max }}+\varepsilon
$$

where

$$
\gamma \triangleq \min \left(k_{1}, k_{s}\right)
$$

Rearranging (106) yields the first order differential equation

$$
\dot{V}+\frac{\gamma V}{\lambda_{\max }}=\varepsilon-s(t)
$$

where $s(t) \geq 0$. Solving this differential equation yields

$$
V(t) \leq V(0) r^{-\frac{\gamma t}{\lambda_{\max }}}+\frac{\varepsilon \lambda_{\max }}{\gamma}\left(1-r^{-\frac{\gamma t}{\lambda_{\max }}}\right)
$$

which from (108) can be rewritten as

$$
\lambda_{\min }\|Z\|^{2} \leq V(0) r^{-\frac{\gamma t}{\lambda_{\max }}}+\frac{\varepsilon \lambda_{\max }}{\gamma}\left(1-r^{-\frac{\gamma t}{\lambda_{\max }}}\right)
$$

Solving (115) for ||$Z||$ then yields

$$
\|Z\| \leq \sqrt{\frac{V(0)}{\lambda_{\min }} r^{-\frac{\gamma t}{\lambda_{\max }}}+\frac{\varepsilon \lambda_{\max }}{\gamma \lambda_{\min }}\left(1-r^{-\frac{\gamma t}{\lambda_{\max }}}\right)}
$$

which will reduce to $\sqrt{\frac{\varepsilon \lambda_{\max }}{\gamma \lambda_{\min }}}$ as $t \rightarrow \infty$.

From (116), it can be shown that $r(t), \eta_{\psi}(t) \in \mathcal{L}_{\infty}$. As stated in Assumption 4.2.6, $\omega_{d}(t), \dot{\omega}_{d}(t) \in \mathcal{L}_{\infty}$ and $f_{d}(t), \dot{f}_{d}(t) \in \mathcal{L}_{\infty}$. Based on the definition of (72), it can be seen that $e(t) \in \mathcal{L}_{\infty}$. Then, from the form of (73), it is apparent that $\omega(t) \in \mathcal{L}_{\infty}$. From (84) it 
can be determined that $\Omega(\omega) \in \mathcal{L}_{\infty}$. Then, it is apparent from (84) that $\tau_{d}(t) \in \mathcal{L}_{\infty}$. Then, the form of (82) indicated that $I_{q}(t) \in \mathcal{L}_{\infty}$. From (93) and (94), it can be shown that $I_{d}(t), \dot{\rho}_{d} \in \mathcal{L}_{\infty}$ respectively, and by extension $\rho_{d} \in \mathcal{L}_{\infty}$. From the form of (74) and (75), it is apparent that $\psi_{d}(t), I(t) \in \mathcal{L}_{\infty}$ respectively. This utilization of standard signal chasing arguments shows that all signals in the closed-loop system remain bounded. Therefore, the system is GUUB.

\subsubsection{LINEAR CONTROLLER SETUP}

The linear controller used for comparison in this experiment is a cascaded PI controller [58], as shown in Figure 8. This is a voltage-mode vector control scheme, as is popularly used in IM and SCIG applications. In the control scheme above, two separate control loops are used to manage the flux magnitude, $f$, and the speed, $\omega$, which output the desired dq current values respectively. Note that all variables in Figure 8 with an asterisk are desired values. The vectorized current trajectory is then sent to a third control loop, which outputs a dq voltage.

This linear controller has been appropriately tuned for optimal performance with respect to rotational speed control. The control gains used are shown in Table 8. 


\section{Table 8}

Control gains for SCIG vector controller.

\begin{tabular}{|c|c|}
\hline Parameter & Value \\
\hline$k_{f P}$ & 100 \\
\hline$k_{f I}$ & 60 \\
\hline$k_{\omega P}$ & 200 \\
\hline$k_{\omega I}$ & 1 \\
\hline$k_{i P}$ & 20 \\
\hline$k_{i I}$ & 100 \\
\hline
\end{tabular}

\subsubsection{COMPARATIVE SIMULATION RESULTS}

The nonlinear controller and the above vector controller have been tested for two experimental conditions. For the purposes of these experiments, the desired speed trajectory $\omega_{d}(t)$ is calculated using (33). Note that the use of (52) does not override Assumption 4.2.5, as the controller itself doesn't require knowledge of $v$. The control objective values and nonlinear control gains can be found in Table 9 and Table 10 respectively. 


\section{Table 9}

Desired values for SCIG control.

\begin{tabular}{|c|c|c|}
\hline Parameter & Value & Units \\
\hline$f_{d}$ & 0.4 & $\mathrm{~V} \cdot \mathrm{s}$ \\
\hline$\lambda_{d}$ & 8.0977 & - \\
\hline
\end{tabular}

\section{Table 10}

Control gains for nonlinear SCIG controller.

\begin{tabular}{|c|c|}
\hline Parameter & Value \\
\hline$k_{1}$ & 0.1 \\
\hline$k_{S}$ & 1,000 \\
\hline$k_{J}$ & 1 \\
\hline$\varepsilon$ & 1 \\
\hline
\end{tabular}

The linear and nonlinear controllers are compares using two experiments. The first test utilizes a step in wind speed from 3 to $6 \mathrm{~m} / \mathrm{s}$. While an instantaneous step in wind speed does not occur realistically, this presents a worst-case scenario for the purposes of comparing each controller's ability to respond to changes in operating point. This experiment illustrates the response time of each controller.

The second experiment involves a more realistic turbulent wind speed profile applied to each controller. As the wind speed changes, the controllers need to constantly 
adapt, which is a common occurrence in some locations. The goal of this test is to expose the average error of each controller over extended period of time.

The results of the wind step test can be seen in Figure 21. It is evident from this that as the operating point shifts abruptly, the nonlinear controller is about 75 times faster than the vector controller.
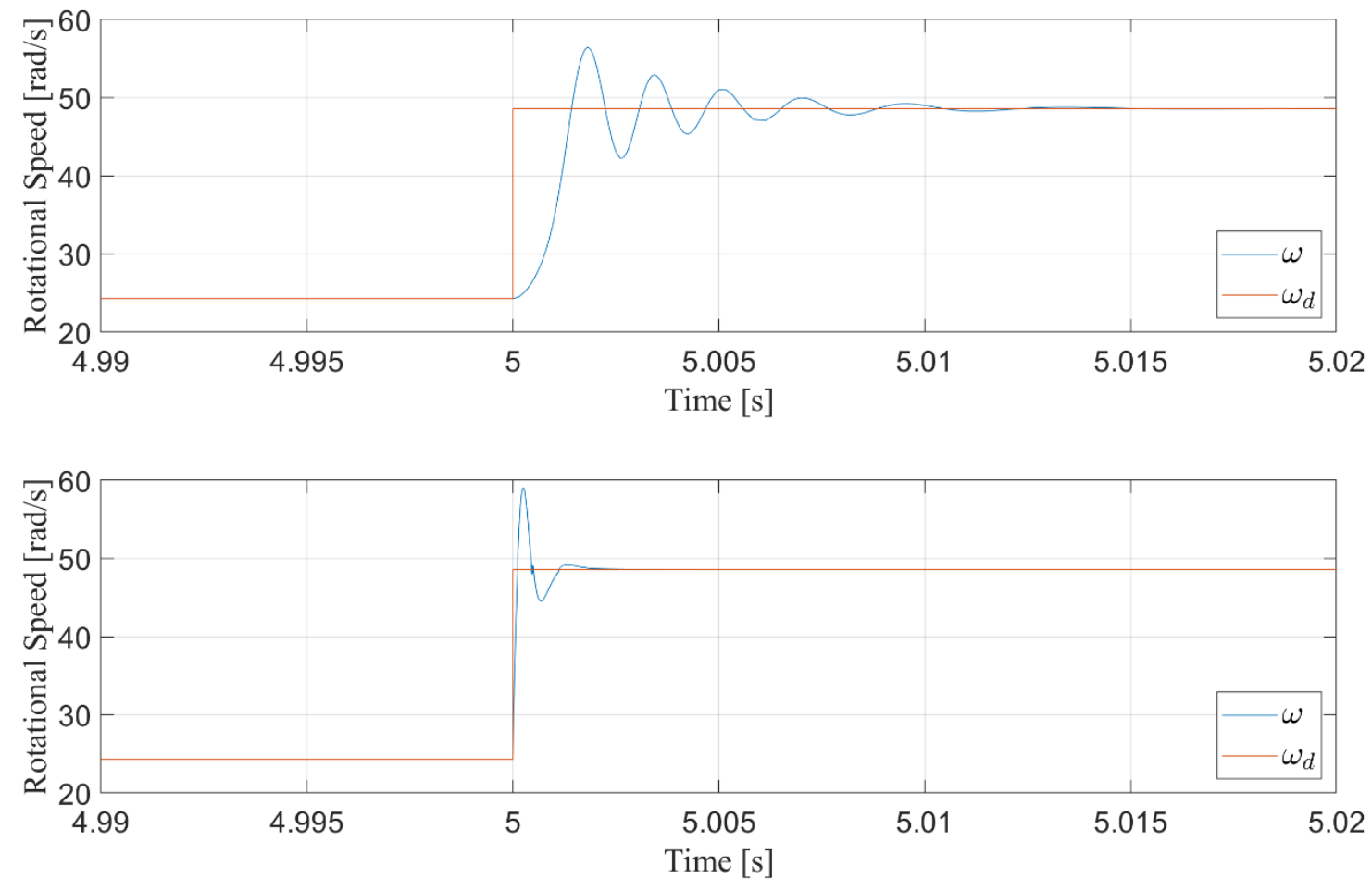

Figure 21. Response of SCIG vector controller (top) and nonlinear controller (bottom) to a step in wind speed.

Additionally, the illustrate the convergence of all error signals from Section 4.2.2, the error signals $e(t), r(t), \eta_{\psi}(t)$ from the nonlinear controller are displayed in Figure 22 - Figure $\underline{24}$ during the same wind step experiment. Note that the flux error $\eta_{\psi}(t)$ is not a realizable signal due to Assumption 4.2.2 but is available for viewing in a simulation environment 
here. It is evident from these figures that all errors in the closed-loop system for the nonlinear controller quickly converge to a near-zero value.

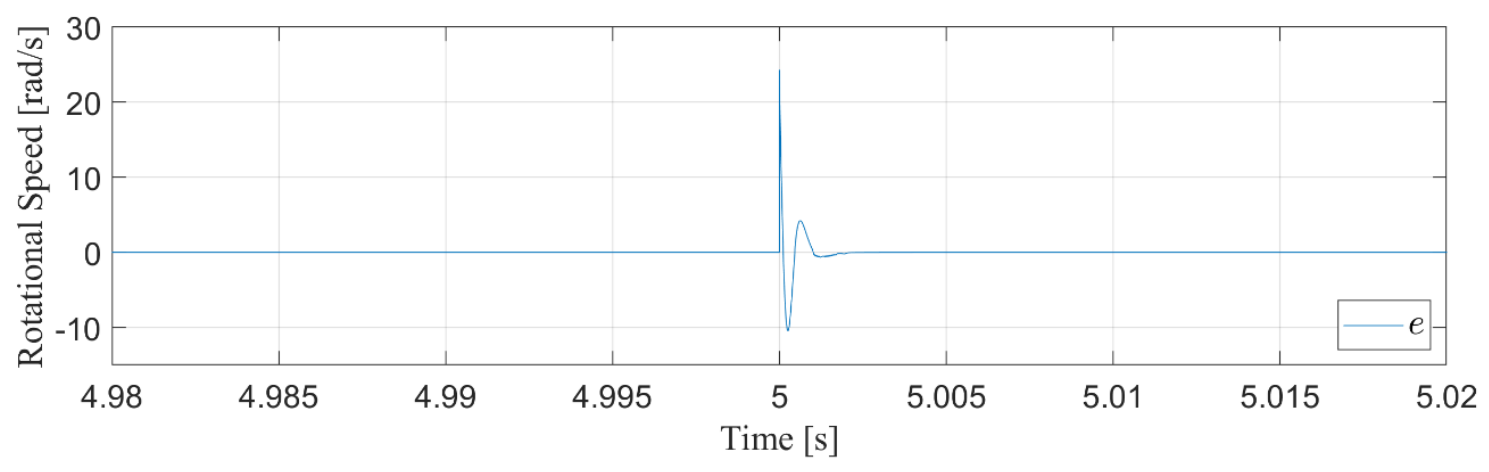

Figure 22. Nonlinear SCIG controller speed error during wind step.

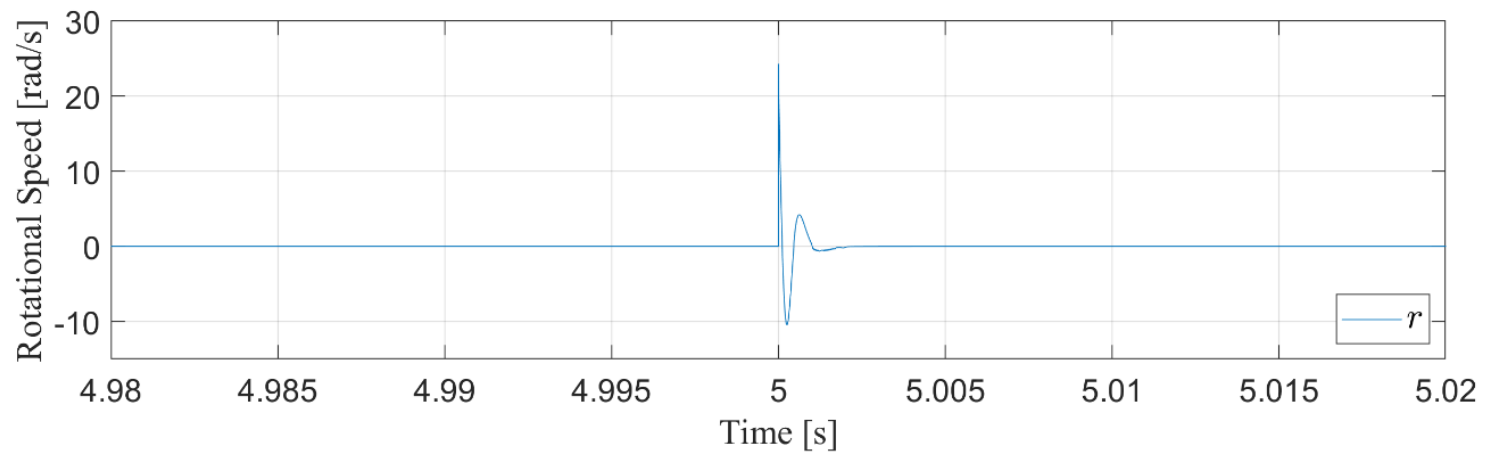

Figure 23. Nonlinear SCIG controller filtered speed error during wind step.

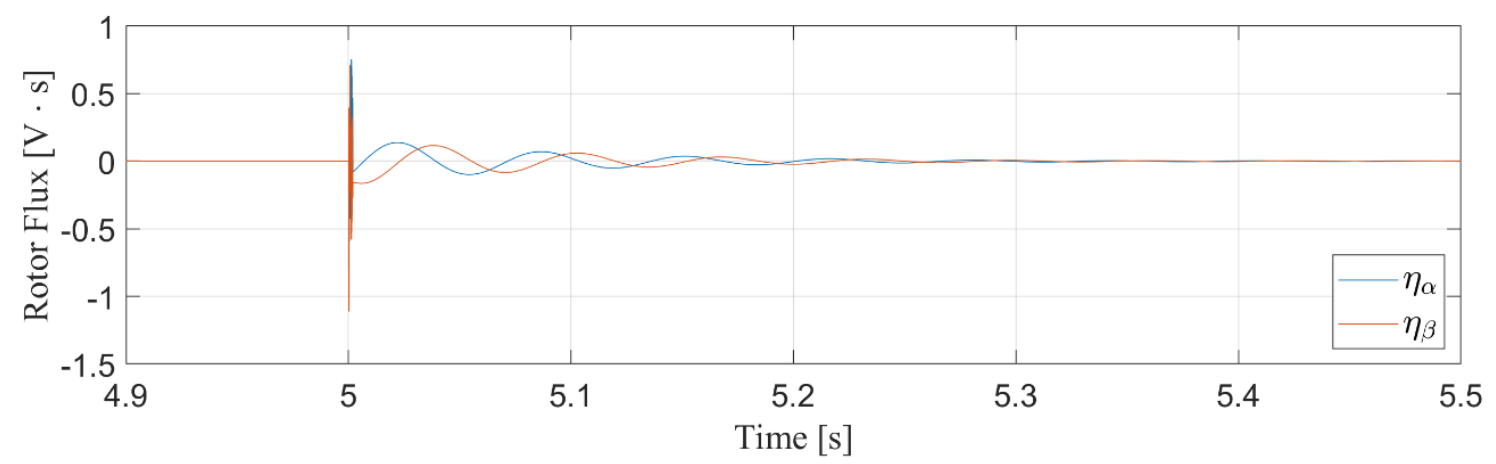

Figure 24. Nonlinear SCIG controller flux error during wind step. 
It is also pertinent to show that the adaptive inertia term $\hat{J}(t)$ converges to a steady-state value. This can be shown for the wind step experiment in Figure 25.

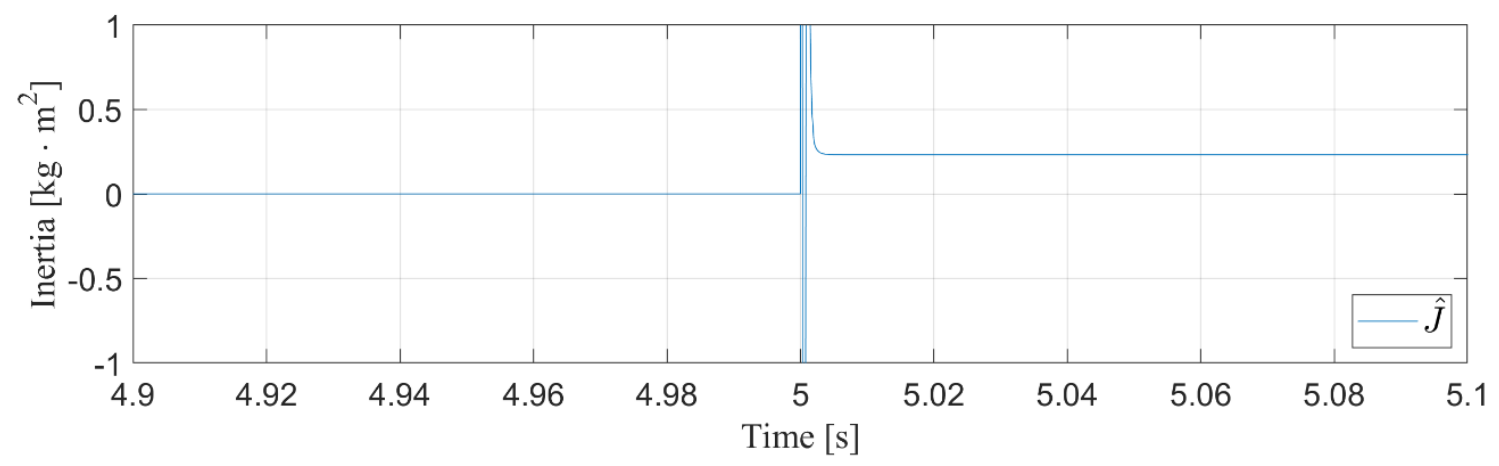

Figure 25. Nonlinear SCIG controller adaptive inertia observer during wind step.

The turbulent wind speed profile used for the second test is shown in Figure 26, which corresponds to a desired speed trajectory shown in Figure 27.

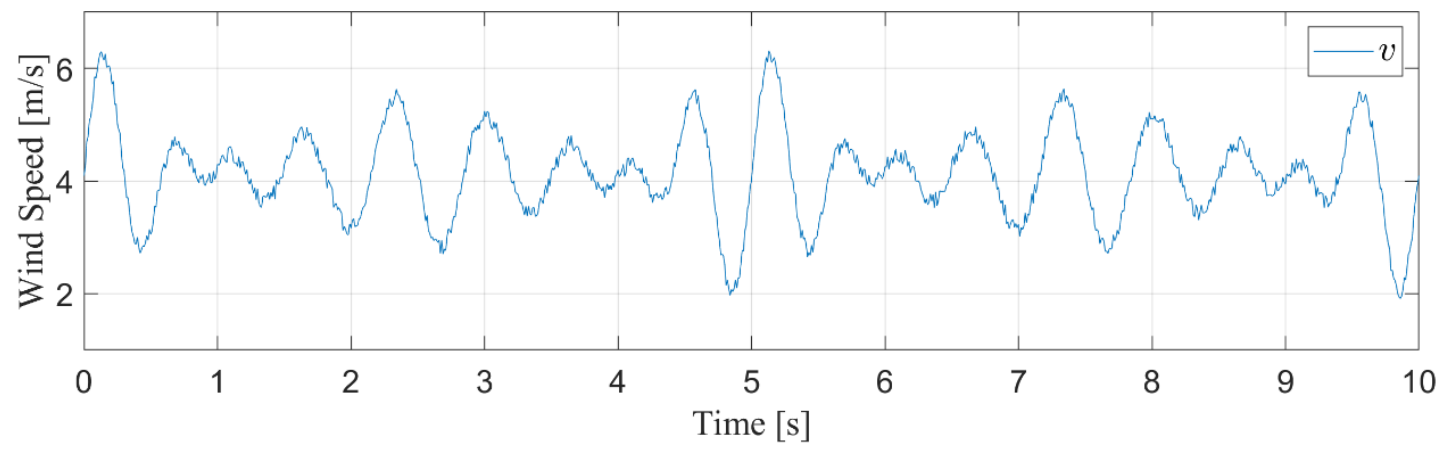

Figure 26. Turbulent wind speed profile used for SCIG controller comparison. 


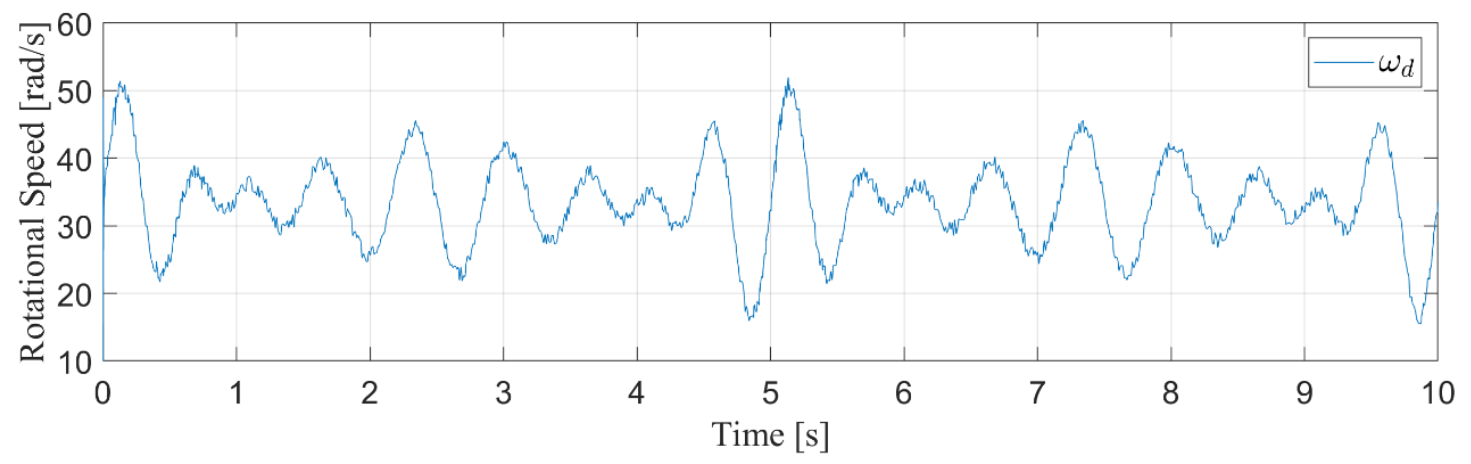

Figure 27. Desired speed trajectory used for SCIG controller comparison.

The results of applying this turbulence to each controller is displayed in Figure 28 in the form of the controller error $e(t)$. The RMS error of each controller indicates that the proposed scheme is about 250 times faster than the vector control scheme.
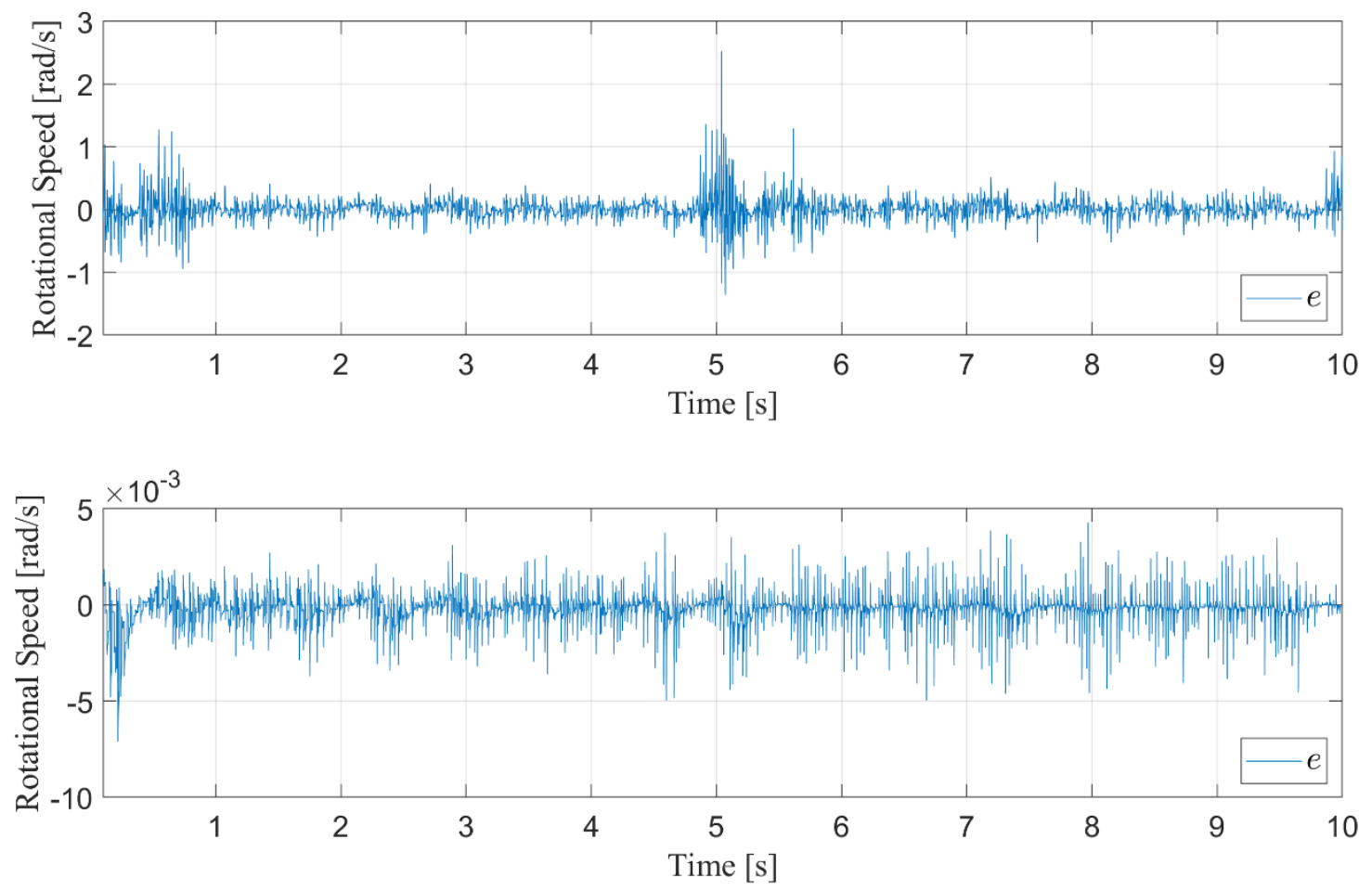

Figure 28. SCIG speed controller errors for a vector controller (top) and nonlinear controller (bottom) in response to wind turbulence. 


\section{OBSERVERS}

\subsection{PMSG WIND TORQUE OBSERVER}

Understanding the efficiency of a wind turbine cannot be achieved without first measuring or calculating the wind torque. While some attempts have been made to create generic equations that model this quantity, they typically vary between systems and are difficult to determine through mechanical testing. Therefore, a nonlinear observer is presented that can discover these dynamics in real time. This observer can learn the trajectory of the wind torque through minimal knowledge, most notably a lack of wind speed measurement.

There have been other attempts to observer this state through both linear and nonlinear methods. Linear methods struggle with having to choose an operating point to linearize about, making the observer inaccurate when deviating from that point [75] [76]. Nonlinear methods, such as sliding mode controllers, have been developed for DFIG systems, and use a similar Lyapunov approach as the one used below [77]. However, as

PMSG systems are increasing in popularity, these nonlinear observers must be updated to function for newer generators.

Note that this observer could be performed for a SCIG system so long as the electromagnetic torque term $T_{E}$ is measurable or observable. 


\subsubsection{OBSERVER DEVELOPMENT}

The goal of this observer is to track the turbine torque such that $\widehat{T}_{L}(t) \rightarrow T_{L}(t)$ as $t \rightarrow \infty$, where $\widehat{T}_{L}(t)$ is the observed torque. Before achieving this objective though, an observer must first be developed for the rotational acceleration. The following observer necessitates the following assumptions.

Assumption 5.1.1: The rotational velocity, $\omega(t)$, of the turbine shaft and the q-axis current of the generator, $I_{q}(t)$, are measurable.

Assumption 5.1.2: The parameters $J, B, P, \lambda_{m}$ are known a priori and are assumed to be constant with respect to time.

Assumption 5.1.3: The signals $T_{L},\left|\dot{T}_{L}\right|,\left|\ddot{T}_{L}\right|$, and $\dot{\omega}(t)$ are assumed to be piecewise continuous and bounded.

Through rearrangement, (3) can be expressed as

$$
\dot{\omega}=-\bar{B} \omega+\tau_{L}+\tau_{\text {em }}
$$

where

$$
\begin{gathered}
\bar{B} \triangleq \frac{B}{J} \\
\tau_{L} \triangleq-\frac{T_{L}}{J}, \\
\tau_{e m} \triangleq \frac{T_{E}}{J}=\left(\frac{3 P}{4 J}\right) \lambda_{m} I_{q} .
\end{gathered}
$$

From (119) the augmented observer for the torque can be defined as

$$
\hat{\tau}_{L} \triangleq-\frac{\widehat{T}_{L}}{J}
$$

which then allows for the acceleration observer to be defined as

$$
\dot{\widehat{\omega}} \triangleq-\bar{B} \omega+\hat{\tau}_{L}+\tau_{e m}
$$


From here, a speed observer error term,

$$
e_{o} \triangleq \omega-\widehat{\omega}
$$

is defined such that the first purpose of the observer is $e_{o}(t) \rightarrow 0$ as $t \rightarrow \infty$. By taking the derivative of (123) and substituting (117) and (122) in, it can be determined that

$$
\dot{e}_{o}=\tau_{L}-\hat{\tau}_{L}
$$

Here, an auxiliary error signal is defined to facilitate a closed-loop system as

$$
\begin{aligned}
& s \triangleq \dot{e}_{\mathrm{o}}+e_{o} \\
& \dot{s}=\ddot{e}_{\mathrm{o}}+\dot{e}_{\mathrm{o}}
\end{aligned}
$$

such that the observer objective is for $s(t) \rightarrow 0$ as $t \rightarrow \infty$. By taking the derivative of (124) and substituting it into (126) it can be seen that

$$
\dot{s}=\dot{\tau}_{L}-\dot{\hat{\tau}}_{L}+\dot{e}_{o}
$$

The auxiliary torque observer can then be defined as

$$
\dot{\hat{\tau}}_{L} \triangleq\left(k_{1}+1\right) s+k_{2} \operatorname{sgn}\left(e_{o}\right)
$$

where $k_{1}, k_{2} \in \mathbb{R}$ are positive control gains and $\operatorname{sgn}(\cdot)$ is the signum function. By integrating, the implementable form of this observer is

$$
\hat{\tau}_{L}=\left(k_{1}+1\right)\left(e_{o}(t)-e_{o}\left(t_{o}\right)+\int_{t_{o}}^{t} e_{o}\right)+k_{2} \int_{t_{o}}^{t} \operatorname{sgn}\left(e_{o}\right)
$$

\subsubsection{STABILITY ANALYSIS}

Theorem 5.1: The torque observer in (128) ensures that $e_{o}(t), \mathrm{s}(t) \rightarrow 0$ as $t \rightarrow \infty$.

Proof 5.1: The stability of the closed-loop system presented by (128) can be shown through a non-negative Lyapunov function $V_{o}(t) \in \mathbb{R}$ defined as 


$$
V_{o}=\frac{1}{2} e_{o}^{2}+\frac{1}{2} s^{2}
$$

for which the derivative is

$$
\dot{V}_{\mathrm{o}}=e_{o} \dot{e}_{\mathrm{o}}+s \dot{S} .
$$

Solving (125) for $\dot{e}_{o}$ and substituting it alongside (127) into (131) and simplifying yields

$$
\dot{\mathrm{V}}_{o}=s^{2}-e_{o}^{2}+s\left(\dot{\tau}_{L}-\dot{\hat{\tau}}_{L}\right)
$$

Substituting in (128) and rearranging will eventually yield

$$
\begin{gathered}
\dot{V}_{\mathrm{o}}=-e_{o}^{2}-k_{1} s^{2}+\dot{e}_{o} \dot{\tau}_{L}-\dot{e}_{o} k_{2} \operatorname{sgn}\left(e_{o}\right) \\
+e_{o}\left(\dot{\tau}_{L}-k_{2} \operatorname{sgn}\left(e_{o}\right)\right) .
\end{gathered}
$$

Integrating both sides of (133) yields

$$
V_{o} \leq V_{o}\left(t_{f}\right)+I_{1}-I_{2}+I_{3}-I_{4}
$$

where

$$
\begin{gathered}
I_{1}=\int_{t_{o}}^{t} \dot{e}_{o}(\sigma) \dot{\tau}_{L}(\sigma) d \sigma, \\
I_{2}=k_{2} \operatorname{sgn}\left(e_{o}\right) \int_{t_{o}}^{t} e_{o}(\sigma) d \sigma, \\
I_{3}=\int_{t_{o}}^{t} e_{o}(\sigma)\left(\dot{\tau}_{L}(\sigma)-k_{2} \operatorname{sgn}\left(e_{o}(\sigma)\right)\right) d \sigma, \\
I_{4}=\int_{t_{o}}^{t} e_{o}^{2}(\sigma) d \sigma+k_{1} \int_{t_{o}}^{t} s^{2}(\sigma) d \sigma,
\end{gathered}
$$

and $V_{o}\left(t_{f}\right)$ is the final value of $V_{o}$. Using integration by parts on (135) yields

$$
I_{1}=e_{o}(t) \dot{\tau}_{L}(t)-e_{o}\left(t_{o}\right) \dot{\tau}_{L}\left(t_{o}\right)-\int_{t_{o}}^{t} e_{o}(\sigma) \ddot{\tau}_{L}(\sigma) d \sigma
$$


and evaluating (136) yields

$$
I_{2}=k_{2} \operatorname{sgn}\left(e_{o}(t)\right) e_{o}(t)-k_{2} \operatorname{sgn}\left(e_{o}\left(t_{o}\right)\right) e_{o}\left(t_{o}\right) .
$$

Substituting (139) and (140) into (134) and simplifying yields

$$
V_{o} \leq-\int_{t_{o}}^{t} e_{o}^{2}(\sigma) d \sigma-k_{1} \int_{t_{o}}^{t} s^{2}(\sigma) d \sigma+C
$$

where

$$
C=V_{o}\left(t_{f}\right)-e_{o}\left(t_{o}\right)\left(\dot{\tau}_{L}\left(t_{o}\right)-k_{2} \operatorname{sgn}\left(e_{o}\left(t_{o}\right)\right)\right) .
$$

From the structure of (141) and the definition of (142), it can be shown that $V_{o}(t) \in \mathcal{L}_{\infty}$; hence, $e_{o}(t), s(t) \in \mathcal{L}_{\infty} \cap \mathcal{L}_{2}$. From this, it can then be said from the form of (125) that $\dot{e}_{o} \in \mathcal{L}_{\infty}$. From the form of (128) it is then true that $\dot{\hat{\tau}}_{L} \in \mathcal{L}_{\infty}$. Looking at (127), using Assumption 5.1.3 it can be said that $\dot{s} \in \mathcal{L}_{\infty}$ Since $e_{o}, \dot{e}_{o}, s, \dot{s} \in \mathcal{L}_{\infty}$, then Barbalat's Lemma can be used to prove that $\left|e_{o}(t)\right|,|s(t)| \rightarrow 0$ as $t \rightarrow \infty$.

\subsubsection{SIMULATION RESULTS}

The parameters for the nonlinear observer are presented in Table 11. For the purposes of testing this observer, the PMSG system is observed while running the same test found in Section 4.1.3. 


\section{Table 11}

Wind torque observer parameters.

\begin{tabular}{|c|c|c|}
\hline Parameter & Value & Units \\
\hline$k_{1}$ & 10,000 & - \\
\hline$k_{2}$ & 1,000 & - \\
\hline
\end{tabular}

The below figures show the simulation results for the observer. In Figure 29 it is evident that the observed value for the rotational velocity closely follows that of the actual value. While there are small deviations when the speed has a high slew rate, the error is relatively minimal.

The torque dynamics are shown in Figure 30, which presents the observed torque following the actual torque value so closely that it is visually difficult to distinguish the two lines.

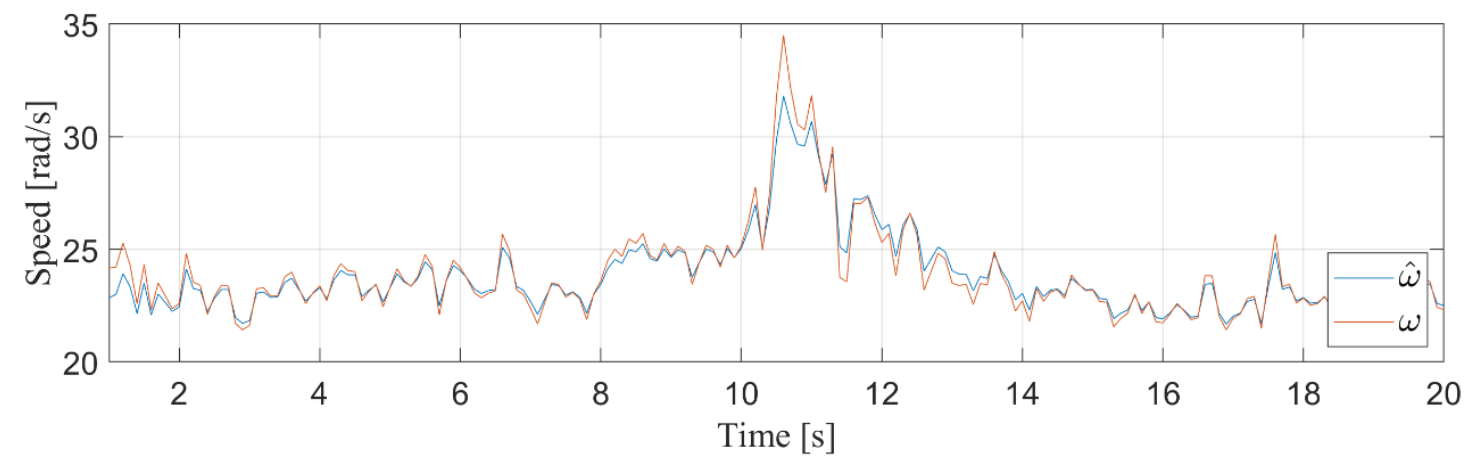

Figure 29. Observed versus actual rotational speed of PMSG. 


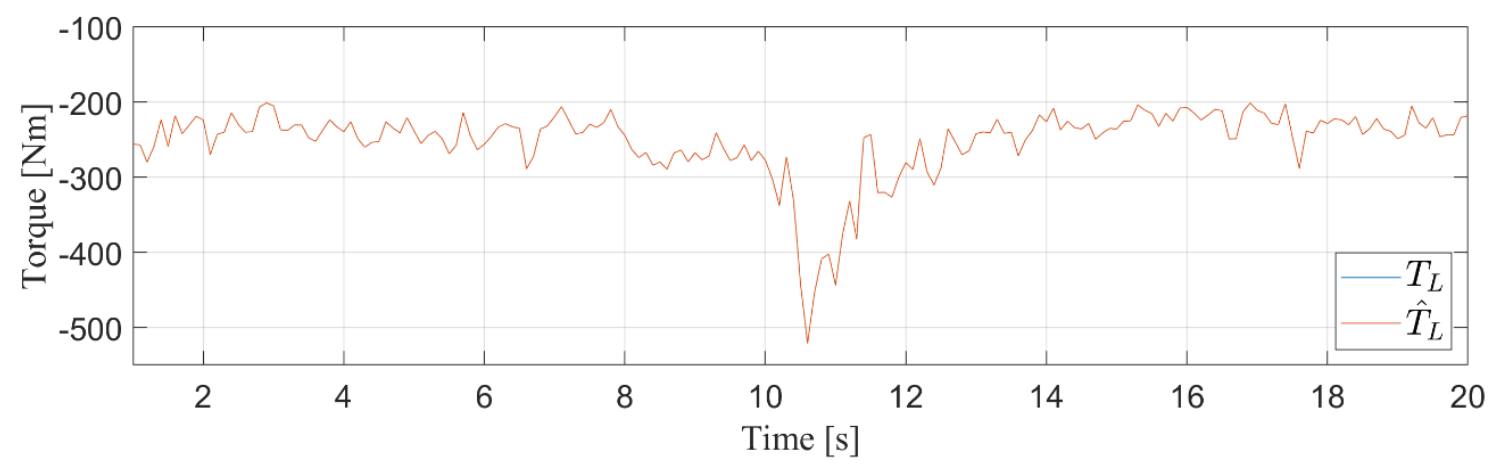

Figure 30. Observed versus actual wind torque of PMSG.

\subsection{SCIG FLUX OBSERVER}

As previously mentioned, the flux of an induction machine is impractical to measure, which motivates the ability to observe its magnitude over time. Since traditional vector controllers for these machines (see Figure 8) seek to control the flux magnitude using the $\mathrm{d}$ axis current of the machine, a flux observer is often required. The magnitude of the flux is important for the performance of induction machines to ensure that the machine doesn't become over or under excited. Operating an induction machine with an unbounded flux magnitude can cause serious damage to the motor.

The other purpose of these observers, typically, is to determine the machine's synchronous speed, as such a quantity is also unmeasurable. Knowledge of this is necessary for conversion between the dq and abc frames, which is done in vector control.

\subsubsection{OBSERVER DEVELOPMENT}

The goal of this observer is to determine the SCIG rotor flux and synchronous speed such that $\hat{\psi}_{d}^{\prime}(t), \hat{\psi}_{q}^{\prime}(t) \rightarrow \psi_{d}^{\prime}(t), \psi_{q}^{\prime}(t)$ and $\widehat{\omega}_{e}(t) \rightarrow \omega_{e}(t)$ as $t \rightarrow \infty$. To accomplish this, 
the stator current must first be observed such that $\hat{I}_{d}^{\prime}(t), \hat{I}_{q}^{\prime}(t) \rightarrow I_{d}^{\prime}(t), I_{q}^{\prime}(t)$ as $t \rightarrow \infty$. This is done alongside the following assumptions.

Assumption 5.2.1: The stator voltages $v_{\alpha}, v_{\beta}$ and stator currents $I_{\alpha}, I_{\beta}$ are measurable and bounded.

Assumption 5.2.2: The parameters $C_{1}, C_{2}, C_{3}, C_{4}, C_{5}, C_{6}$ are known a priori and are constant with respect to time.

Assumption 5.2.3: The synchronous speed $\omega_{e}$, its integral $\theta_{e}$, and the rotor flux $\psi$ are unmeasurable quantities.

Assumption 5.2.4: The SCIG is operated such that the rotor speed $\omega$ and the rotor flux magnitude $\psi_{\text {mag }}$ are both bounded.

To begin, the model as presented in (22) and (25) must be transformed into the dq frame. This transformation is done about the integral to the observed synchronous speed. Therefore, a speed error term can be designed as

$$
\widetilde{\omega}_{e} \triangleq \omega_{e}-\widehat{\omega}_{e}
$$

where the goal of the observer is for $\widetilde{\omega}_{e}(t) \rightarrow 0$ as $t \rightarrow \infty$. Transforming (22) and (25) about the observed speed's integral yields

$$
\begin{gathered}
C_{4}\left[\begin{array}{l}
\dot{I}_{d}^{\prime} \\
\dot{I}_{q}^{\prime}
\end{array}\right]= \\
{\left[\begin{array}{l}
v_{d}^{\prime} \\
v_{q}^{\prime}
\end{array}\right]-\left[\begin{array}{cc}
C_{6} & -C_{4} \widehat{\omega}_{e} \\
C_{4} \widehat{\omega}_{e} & C_{6}
\end{array}\right]\left[\begin{array}{l}
I_{d}^{\prime} \\
I_{q}^{\prime}
\end{array}\right]+\frac{L_{m}}{L_{r}}\left[\begin{array}{cc}
C_{2} & n_{p} \omega_{r} \\
-n_{p} \omega_{r} & C_{2}
\end{array}\right]\left[\begin{array}{l}
\psi_{d}^{\prime} \\
\psi_{q}^{\prime}
\end{array}\right]} \\
{\left[\begin{array}{c}
\dot{\psi}_{d}^{\prime} \\
\dot{\psi}_{q}^{\prime}
\end{array}\right]=C_{3}\left[\begin{array}{c}
I_{d}^{\prime} \\
I_{q}^{\prime}
\end{array}\right]-\left[\begin{array}{cc}
C_{2} & -\left(\widehat{\omega}_{e}-n_{p} \omega_{r}\right) \\
\widehat{\omega}_{e}-n_{p} \omega_{r} & C_{2}
\end{array}\right]\left[\begin{array}{l}
\psi_{d}^{\prime} \\
\psi_{q}^{\prime}
\end{array}\right]}
\end{gathered}
$$

where variables with ' are auxiliary terms transformed about the observed speed. Here, the observer error terms can be defined as 


$$
\begin{gathered}
{\left[\begin{array}{c}
\tilde{I}_{d}^{\prime} \\
\tilde{I}_{q}^{\prime}
\end{array}\right] \triangleq\left[\begin{array}{l}
I_{d}^{\prime} \\
I_{q}^{\prime}
\end{array}\right]-\left[\begin{array}{l}
\hat{I}_{d}^{\prime} \\
\hat{I}_{q}^{\prime}
\end{array}\right]} \\
{\left[\begin{array}{c}
\tilde{\psi}_{d}^{\prime} \\
\tilde{\psi}_{q}^{\prime}
\end{array}\right] \triangleq\left[\begin{array}{l}
\psi_{d}^{\prime} \\
\psi_{q}^{\prime}
\end{array}\right]-\left[\begin{array}{l}
\hat{\psi}_{d}^{\prime} \\
\hat{\psi}_{q}^{\prime}
\end{array}\right]}
\end{gathered}
$$

where the goal of the observers is for $\tilde{I}_{d}^{\prime}(t), \tilde{I}_{q}^{\prime}(t), \tilde{\psi}_{d}^{\prime}(t), \tilde{\psi}_{q}^{\prime}(t) \rightarrow 0$. Taking the derivative of (146) and multiplying through by $C_{4}$ yields

$$
C_{4}\left[\begin{array}{c}
\dot{I}_{d}^{\prime} \\
\tilde{\tilde{I}}_{q}^{\prime}
\end{array}\right]=C_{4}\left[\begin{array}{c}
\dot{I}_{d}^{\prime} \\
\dot{I}_{q}^{\prime}
\end{array}\right]-C_{4}\left[\begin{array}{c}
\hat{\hat{I}}_{d}^{\prime} \\
\hat{I}_{q}^{\prime}
\end{array}\right]
$$

and substituting (144) into (148) provides

$$
C_{4}\left[\begin{array}{c}
\dot{I}_{d}^{\prime} \\
\dot{I}_{q}^{\prime}
\end{array}\right]=\left[\begin{array}{c}
v_{d}^{\prime} \\
v_{q}^{\prime}
\end{array}\right]-\left[\begin{array}{cc}
C_{6} & -C_{4} \widehat{\omega}_{e} \\
C_{4} \widehat{\omega}_{e} & C_{6}
\end{array}\right]\left[\begin{array}{c}
I_{d}^{\prime} \\
I_{q}^{\prime}
\end{array}\right]+\frac{L_{m}}{L_{r}}\left[\begin{array}{cc}
C_{2} & n_{p} \omega_{r} \\
-n_{p} \omega_{r} & C_{2}
\end{array}\right]\left[\begin{array}{c}
\psi_{d}^{\prime} \\
\psi_{q}^{\prime}
\end{array}\right]-C_{4}\left[\begin{array}{c}
\dot{I}_{d}^{\prime} \\
\dot{I}_{q}^{\prime}
\end{array}\right] .
$$

This form and the subsequent stability analysis motivate the definition of the current observer as

$C_{4}\left[\begin{array}{c}\hat{I}_{d}^{\prime} \\ \hat{I}_{q}^{\prime}\end{array}\right] \triangleq\left[\begin{array}{c}v_{d}^{\prime} \\ v_{q}^{\prime}\end{array}\right]-\left[\begin{array}{cc}C_{6} & -C_{4} \widehat{\omega}_{e} \\ C_{4} \widehat{\omega}_{e} & C_{6}\end{array}\right]\left[\begin{array}{l}I_{d}^{\prime} \\ I_{q}^{\prime}\end{array}\right]+\frac{L_{m}}{L_{r}}\left[\begin{array}{cc}C_{2} & n_{p} \omega_{r} \\ -n_{p} \omega_{r} & C_{2}\end{array}\right]\left[\begin{array}{c}\hat{\psi}_{d}^{\prime} \\ \widehat{\psi}_{q}^{\prime}\end{array}\right]+\left[\begin{array}{cc}k_{1} & 0 \\ 0 & k_{1}\end{array}\right]\left[\begin{array}{l}\tilde{I}_{d}^{\prime} \\ \tilde{I}_{q}^{\prime}\end{array}\right]$

where $k_{1} \in \mathbb{R}$ is a positive control gain. Substituting (150) back into (149) yields the closed loop error system for the current dynamics as

$$
C_{4}\left[\begin{array}{c}
\dot{\tilde{I}}_{d}^{\prime} \\
\tilde{I}_{q}^{\prime}
\end{array}\right]=\frac{L_{m}}{L_{r}}\left[\begin{array}{cc}
C_{2} & n_{p} \omega_{r} \\
-n_{p} \omega_{r} & C_{2}
\end{array}\right]\left[\begin{array}{c}
\tilde{\psi}_{d}^{\prime} \\
\tilde{\psi}_{q}^{\prime}
\end{array}\right]-\left[\begin{array}{cc}
k_{1} & 0 \\
0 & k_{1}
\end{array}\right]\left[\begin{array}{l}
\tilde{I}_{d}^{\prime} \\
\tilde{I}_{q}^{\prime}
\end{array}\right]
$$

Next, the flux observer is considered. Taking the derivative of (147), it can be seen that

$$
\left[\begin{array}{c}
\dot{\tilde{\psi}}_{d}^{\prime} \\
\dot{\bar{\psi}}_{q}^{\prime}
\end{array}\right]=\left[\begin{array}{c}
\dot{\psi}_{d}^{\prime} \\
\dot{\psi}_{q}^{\prime}
\end{array}\right]-\left[\begin{array}{c}
\dot{\hat{\psi}}_{d}^{\prime} \\
\dot{\hat{\psi}}_{q}^{\prime}
\end{array}\right] .
$$

Substituting (145) into (152) yields

$$
\left[\begin{array}{c}
\dot{\tilde{\psi}}_{d}^{\prime} \\
\dot{\bar{\psi}}_{q}^{\prime}
\end{array}\right]=C_{3}\left[\begin{array}{l}
I_{d}^{\prime} \\
I_{q}^{\prime}
\end{array}\right]-\left[\begin{array}{cc}
C_{2} & -\left(\widehat{\omega}_{e}-n_{p} \omega_{r}\right) \\
\widehat{\omega}_{e}-n_{p} \omega_{r} & C_{2}
\end{array}\right]\left[\begin{array}{c}
\psi_{d}^{\prime} \\
\psi_{q}^{\prime}
\end{array}\right]-\left[\begin{array}{c}
\dot{\hat{\psi}}_{d}^{\prime} \\
\dot{\hat{\psi}}_{q}^{\prime}
\end{array}\right],
$$

which motivates the flux observer definition 


$$
\left[\begin{array}{c}
\dot{\hat{\psi}}_{d}^{\prime} \\
\dot{\psi}_{q}^{\prime}
\end{array}\right] \triangleq C_{3}\left[\begin{array}{c}
I_{d}^{\prime} \\
I_{q}^{\prime}
\end{array}\right]-\left[\begin{array}{cc}
C_{2} & -\left(\widehat{\omega}_{e}-n_{p} \omega_{r}\right) \\
\widehat{\omega}_{e}-n_{p} \omega_{r} & C_{2}
\end{array}\right]\left[\begin{array}{c}
\hat{\psi}_{d}^{\prime} \\
\widehat{\psi}_{q}^{\prime}
\end{array}\right]+\frac{L_{m}}{L_{r}}\left[\begin{array}{cc}
C_{2} & -n_{p} \omega_{r} \\
n_{p} \omega_{r} & C_{2}
\end{array}\right]\left[\begin{array}{l}
\tilde{I}_{d}^{\prime} \\
\tilde{I}_{q}^{\prime}
\end{array}\right] .
$$

Substituting (154) back into (153) provides the closed loop error system for the flux dynamics as

$$
\left[\begin{array}{c}
\dot{\tilde{\psi}}_{d}^{\prime} \\
\dot{\tilde{\psi}}_{q}^{\prime}
\end{array}\right]=-\left[\begin{array}{cc}
C_{2} & -\left(\widehat{\omega}_{e}-n_{p} \omega_{r}\right) \\
\widehat{\omega}_{e}-n_{p} \omega_{r} & C_{2}
\end{array}\right]\left[\begin{array}{c}
\tilde{\psi}_{d}^{\prime} \\
\tilde{\psi}_{q}^{\prime}
\end{array}\right]-\frac{L_{m}}{L_{r}}\left[\begin{array}{cc}
C_{2} & -n_{p} \omega_{r} \\
n_{p} \omega_{r} & C_{2}
\end{array}\right]\left[\begin{array}{c}
\tilde{I}_{d}^{\prime} \\
\tilde{I}_{q}^{\prime}
\end{array}\right] .
$$

Finally, the synchronous speed must be observed. Typically, the synchronous speed is defined in such as way that the flux magnitude is entirely in the $\mathrm{d}$ axis, i.e. $\psi_{d}=$

$\psi_{m a g}, \psi_{q}=0$. Therefore, the $\mathrm{q}$ axis flux can be treated as an error system similar to $\tilde{I}$ and $\tilde{\psi}$. Based on the form of (154), the speed observer can be defined as

$$
\widehat{\omega}_{e} \triangleq \frac{1}{\hat{\psi}_{d}^{\prime}}\left(C_{3} I_{q}^{\prime}+n_{p} \omega_{r} \hat{\psi}_{d}^{\prime}-C_{2} \hat{\psi}_{q}^{\prime}+\frac{L_{m}}{L_{r}}\left(n_{p} \omega_{r} \tilde{I}_{d}^{\prime}+C_{2} \tilde{I}_{q}^{\prime}\right)+k_{\omega} \hat{\psi}_{q}^{\prime}\right)
$$

where $k_{\omega} \in \mathbb{R}$ is a positive control gain. Substituting (156) back into the lower half of (154) yields

$$
\dot{\hat{\psi}}_{q}^{\prime}=k_{\omega} \hat{\psi}_{q}^{\prime}
$$

\subsubsection{STABILITY ANALYSIS}

Theorem 5.2: The observers in (150), (154), and (156)(128) ensure that $\tilde{I}_{d}^{\prime}(t), \tilde{I}_{q}^{\prime}(t), \tilde{\psi}_{d}^{\prime}(t), \tilde{\psi}_{q}^{\prime}(t), \hat{\psi}_{q}^{\prime}(t) \rightarrow 0$ as $t \rightarrow \infty$.

Proof 5.2: The stability of the closed-loop system presented by the combination of (151), (155), and (157) can be shown through a non-negative Lyapunov function $V(t) \in \mathbb{R}$ defined as

$$
V \triangleq \frac{1}{2} C_{4}{\tilde{I}_{d}^{\prime}}^{2}+\frac{1}{2} C_{4} \tilde{I}_{q}^{\prime 2}+\frac{1}{2} \tilde{\psi}_{d}^{\prime 2}+\frac{1}{2}{\tilde{\psi}_{q}^{\prime}}^{2}+\frac{1}{2}{\hat{\psi}_{q}^{\prime}}^{2},
$$

for which the derivative is 


$$
\dot{V}=C_{4} \tilde{I}_{d}^{\prime} \dot{\tilde{I}}_{d}^{\prime}+C_{4} \tilde{I}_{q}^{\prime} \dot{\tilde{I}}_{q}^{\prime}+\tilde{\psi}_{d}^{\prime} \dot{\widetilde{\psi}}_{d}^{\prime}+\tilde{\psi}_{q}^{\prime} \dot{\widetilde{\psi}}_{q}^{\prime}+\hat{\psi}_{q}^{\prime} \dot{\bar{\psi}}_{q}^{\prime}
$$

Substituting (151), (155), and (157) into (159) and simplifying yields

$$
\dot{V}=-k_{1} \tilde{I}_{d}^{\prime 2}-k_{1} \tilde{I}_{q}^{\prime 2}-C_{2} \tilde{\psi}_{d}^{\prime 2}-C_{2}{\tilde{\psi_{q}}}^{2}-k_{\omega}{\hat{\psi}_{q}^{\prime}}^{2} .
$$

Since $(158) \geq 0$ and $(160) \leq 0$ for all time, it can be concluded that $\tilde{I}_{d}^{\prime}, \tilde{I}_{q}^{\prime}, \tilde{\psi}_{d}^{\prime}, \tilde{\psi}_{q}^{\prime}, \hat{\psi}_{q}^{\prime} \in$ $\mathcal{L}_{\infty}$. From the form of (147) and Assumption 5.2.4, it can be seen that $\hat{\psi}_{d}^{\prime}, \hat{\psi}_{q}^{\prime} \in \mathcal{L}_{\infty}$. Then, based on (156), it is clear that $\widehat{\omega}_{e} \in \mathcal{L}_{\infty}$. Additionally, it can be seen from the form of (157)

that $\dot{\hat{\psi}}_{q}^{\prime} \in \mathcal{L}_{\infty}$. Based on (155), it is evident that $\dot{\tilde{\psi}}_{d}^{\prime}, \dot{\tilde{\psi}}_{q}^{\prime} \in \mathcal{L}_{\infty}$. Finally, from the form of (151), it can be seen that $\dot{\tilde{I}}_{d}^{\prime}, \dot{\tilde{I}}_{q}^{\prime} \in \mathcal{L}_{\infty}$.

Based on the signal chasing above, it can be concluded that $\dot{\tilde{I}}_{d}^{\prime}, \dot{\tilde{I}}_{q}^{\prime}, \dot{\tilde{\psi}}_{d}^{\prime}, \dot{\tilde{\psi}}_{q}^{\prime}, \dot{\hat{\psi}}_{q}^{\prime} \in \mathcal{L}_{\infty}$, which implies that $\ddot{V} \in \mathcal{L}_{\infty}$. Thus, Barbalat's Lemma can be used to state that $\dot{V}(t) \rightarrow 0$ and thus $\tilde{I}_{d}^{\prime}, \tilde{I}_{q}^{\prime}, \tilde{\psi}_{d}^{\prime}, \tilde{\psi}_{q}^{\prime}, \hat{\psi}_{q}^{\prime} \rightarrow 0$ as $t \rightarrow \infty$.

\subsubsection{SIMULATION RESULTS}

The flux observer above is demonstrated while a SCIG system is simulated under scalar control, the architecture for which is shown in Figure 31. The parameters needed for this implementation are shown in Table 12. Additionally, the observer gains are presented in Table 13. 


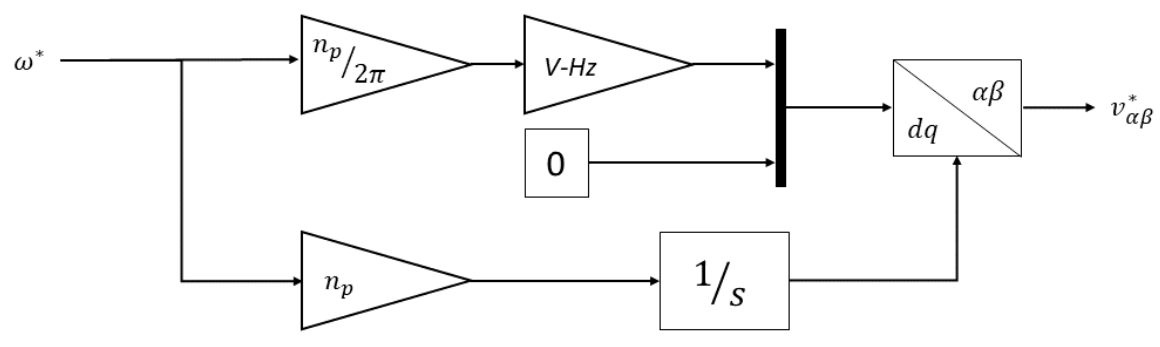

Figure 31. Scalar control architecture for SCIG.

Table 12

Implementation parameters for SCIG flux observer under scalar control.

\begin{tabular}{|c|c|c|}
\hline Parameter & Value & Units \\
\hline $\mathrm{V}-\mathrm{Hz}$ & 8 & - \\
\hline$T_{L}$ & 0.2 & $N \cdot m$ \\
\hline
\end{tabular}

\section{Table 13}

Observer gains for SCIG flux observer.

\begin{tabular}{|c|c|}
\hline Parameter & Value \\
\hline$k_{1}$ & 50 \\
\hline$k_{\omega}$ & 70,000 \\
\hline
\end{tabular}

For the purposes of highlighting convergence, the scalar controller is sent a speed trajectory that steps from 100 to $200 \mathrm{rad} / \mathrm{s}$ at $t=2.5 \mathrm{sec}$. The performance of the current, flux, and synchronous speed observers are demonstrated in Figure 32 through Figure 34. It is evident that the observers quickly converge to the actual values with little steady-state errors. 


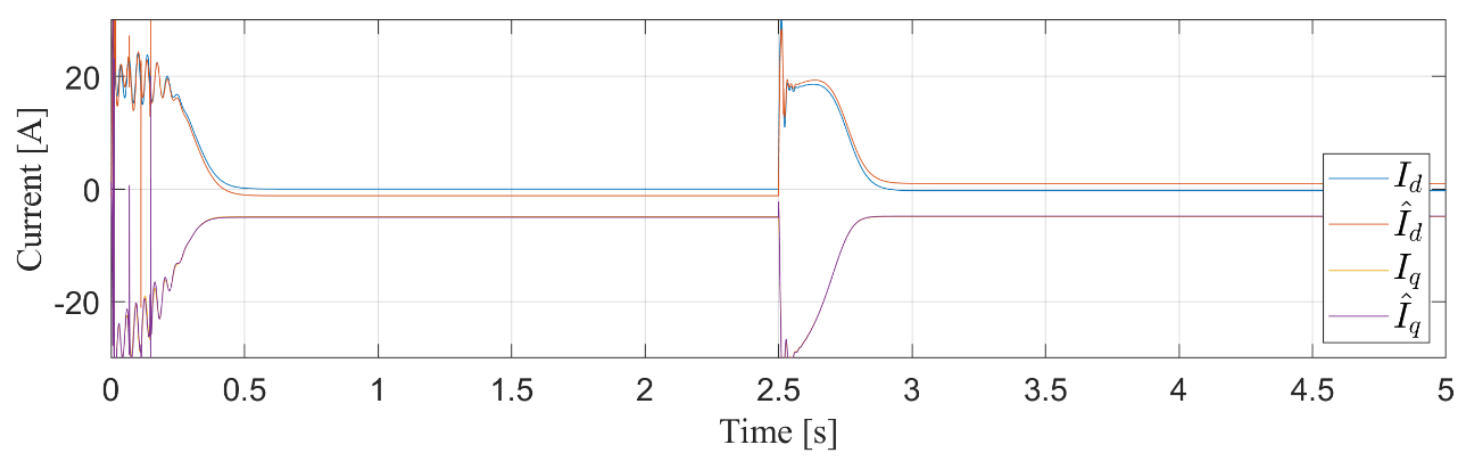

Figure 32. SCIG current versus observed values.

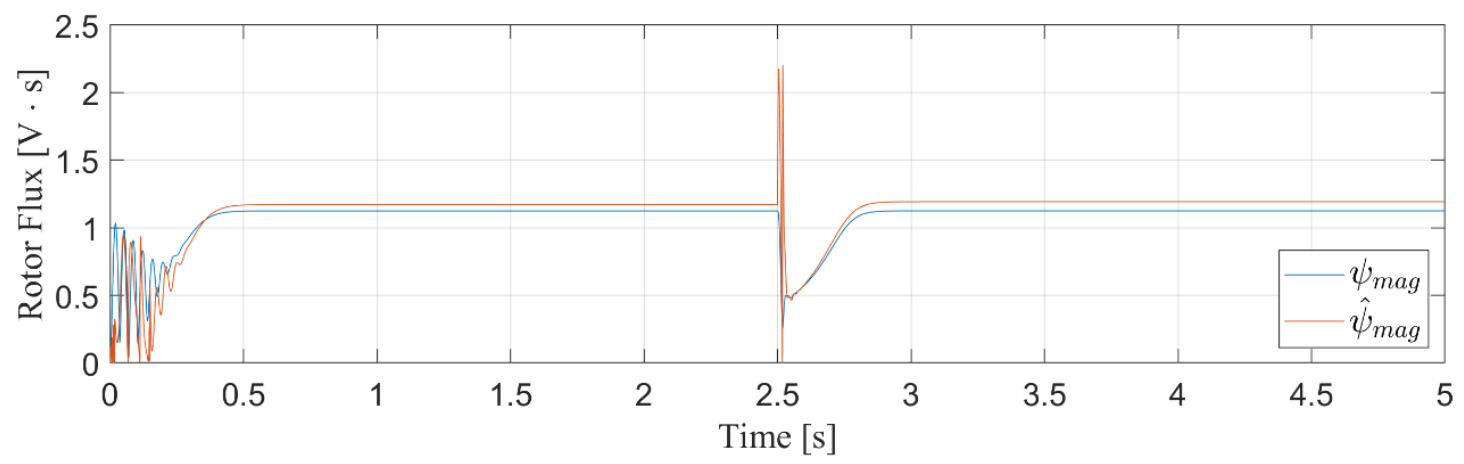

Figure 33. SCIG rotor flux magnitude versus observed value.

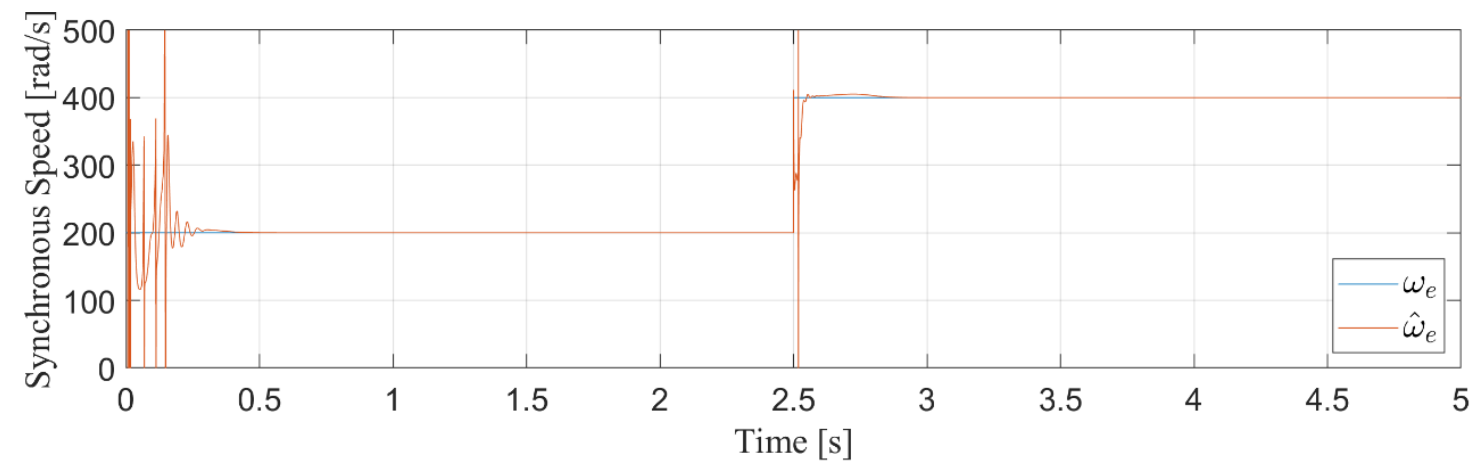

Figure 34. SCIG synchronous speed versus observed value. 


\section{CONCLUSION}

A series of controllers and observers have been presented to improve the overall performance of Type 4 wind turbine systems. The speed controllers for both PMSG and SCIG wind turbines optimize the mechanical efficiency of wind power conversion through turbulent wind speed characteristics, which has been shown to include significant performance improvements from standard industrial control schemes. The presented observers help provide those working on wind turbine systems access to states otherwise unmeasurable, which greatly helps keep these generators in proper working order for longer periods of time. Simulations results illustrate that these controllers and observers achieve high precision during intense wind turbulence. 


\section{REFERENCES}

[1] Z. Chen, J. M. Guerrero and F. Blaabjerg, "A Review of the State of the Art of Power Electronics for Wind Turbines," IEEE Transactions on Power Electronics, vol. 24, no. 8, pp. 1859-1875, Aug. 2009.

[2] V. Yaramasu, B. Wu, P. C. Sen, S. Kouro and M. Narimani, "High-power wind energy conversion systems: State-of-the-art and emerging technologies," Proceedings of the IEEE, vol. 103, no. 5, pp. 740-788, May 2015.

[3] I. R. E. A. (IRENA), "Wind Energy," 2018. [Online]. Available: irena.org/wind. [Accessed 2019].

[4] U. E. I. Administration, "Table 10.1 Renewable Energy Production and Consumption by Source," 2018.

[5] U.S. Department of Energy, "Wind Vision: A New Era for Wind Power in the United States," 2015.

[6] A. S. L. E. B. M. P. W. Carlin, "The History and State of the Art of Variable-Speed wind Turbine Technology," Wind Energy, vol. 6, no. 2, pp. 129 - 159, 2003.

[7] B. Boukhezzar and H. Siguerdidjane, "Nonlinear Control of Variable Speed Wind Turbines without wind speed measurement," in IEEE Conference on Decision and Control, Seville, Spain, 2005.

[8] F. Fateh, W. N. White and D. Gruenbacher, "A Maximum Power Tracking Technique for Grid-Connected DFIG-Based Wind Turbines," IEEE Journal of Emerging and Selected Topics in Power Electronics, vol. 3, no. 4, pp. 957 - 966, 2015.

[9] M. E. Haque, M. Negnevitsky and K. M. Muttaqi, "A Novel Control Strategy for a Variable-Speed Wind Turbine With a Permanent-Magnet Synchronous Generator," IEEE Transactions on Industry Applications, vol. 46, no. 1, pp. 331 - 339, 2010.

[10] W. D. Z. N. Goudarzi, "A review on the development of wind turbine generators across the world," International Journal of Dynamics and Control, vol. 1, no. 2, pp. 192 - 202, 2013.

[11] H. Polinder, J. A. Ferreira, B. B. Jensen, A. B. Abrahamsen, K. Atallah and R. A. McMahon, "Trends in Wind Turbine Generator Systems," IEEE Journal of Emerging and Selected Topics in Power Electronics, vol. 1, no. 3, pp. 174 - 185, Sep. 2013.

[12] K. Tan and S. Islam, "Optimum control strategies in energy conversion of PMSG wind turbine system without mechanical sensors," IEEE Transactions on Energy Conversion, vol. 19, no. 2, pp. 392 - 399, June 2004.

[13] K. Han and G.-z. Chen, "A novel control strategy of wind turbine MPPT implementation for direct-drive PMSG wind generation imitation platform," in IEEE 
6th International Power Electronics and Motion Control Conference, Wuhan, China, 2009.

[14] A. Uehara, A. Pratap, T. Goya, T. Senjyu, A. Yona, N. Urasaki and T. Funabashi, "A Coordinated Control Method to Smooth Wind Power Fluctuations of a PMSG-Based WECS," IEEE Transactions on Energy Conversion, vol. 26, no. 2, pp. 550 - 558, 2011.

[15] W. Torki, F. Grouz and L. Sbita, "Vector control of a PMSG direct-drive wind turbine," in 2017 International Conference on Green Energy Conversion Systems (GECS), Hammamet, Tunisia, 2017.

[16] S. Sahu, G. Panda and S. P. Yadav, "Dynamic Modelling and Control of PMSG based Stand-alone Wind Energy Conversion System," in 2018 Recent Advances on Engineering, Technology and Computational Sciences (RAETCS), Allahabad, India, 2018.

[17] C. Wen, G. Lu, P. Wang, Z. Li, X. Liu and Z. Fan, "Vector control strategy for smallscale grid-connected PMSG wind turbine converter," in 2011 2nd IEEE PES International Conference and Exhibition on Innovative Smart Grid Technologies, Manchester, UK, 2011.

[18] Y. Errami, M. Maaroufi and M. Ouassaid, "Modelling and control strategy of PMSG based variable speed wind energy conversion system," in 2011 International Conference on Multimedia Computing and Systems, Ouarzazate, Morocco, 2011.

[19] R. Davoodnezhad, D. G. Holmes, B. P. McGrath and A. Vahidnia, "Selfsynchronising stator terminal control of permanent magnet synchronous generators for wind energy conversion systems," in IEEE 7th International Symposium on Power Electronics for Distributed Generation Systems (PEDG), Vancouver, BC, Canada, 2016.

[20] M. Boobalan, S. Vijayalakshmi and R. Brindha, "A fuzzy-PI based power control of wind energy conversion system using PMSG," in 2013 International Conference on Energy Efficient Technologies for Sustainability, Nagercoil, India, 2013.

[21] S. Rhaili, A. Abbou, A. Ziouh and R. Elidrissi, "Comparative study between PI and FUZZY logic controller in vector controlled five-phase PMSG based variable-speed wind turbine," in 2018 IEEE 12th International Conference on Compatibility, Power Electronics and Power Engineering (CPE-POWERENG 2018), Doha, Qatar, 2018.

[22] W. E. Dixon, A. Behal, D. M. Dawson and S. P. Nagarkatti, Nonlinear Control of Engineering Systems: A Lyapunov-Based Approach, Springer, 2012.

[23] N. Djagarov, Z. Grozdev, M. Bonev, J. Djagarova, A. Pazderin and S. Kokin, "Adaptive control of wind PMSG," in 2016 17th International Scientific Conference on Electric Power Engineering (EPE), Prague, Czech Republic, 2016.

[24] A. Kchaou, A. Naamane, Y. Koubaa and N. K. M'Sirdi, "Nonlinear control of a permanent magnet synchronous generator in wind energy conversion system with maximum power extraction," in 18th International Conference on Sciences and Techniques of Automatic Control and Computer Engineering (STA), Monastir, Tunisia, 2017. 
[25] W. Torki, F. Grouz and L. Sbita, "A sliding mode model reference adaptive control of PMSG wind turbine," in International Conference on Green Energy Conversion Systems (GECS), Hammamet, Tunisia, 2017.

[26] N. K. Jena, K. B. Mohanty, H. Pradhan and S. K. Sanyal, "A comparison between PI \& SMC used for decoupled control of PMSG in a variable speed wind energy system," in 2015 International Conference on Energy, Power and Environment: Towards Sustainable Growth (ICEPE), Shillong, India, 2015.

[27] P. Gajewski and K. Pieńkowski, "Analysis of Sliding Mode Control of variable speed wind turbine system with PMSG," in 2017 International Symposium on Electrical Machines (SME), Naleczow, Poland, 2017.

[28] K.-H. Kim, Y.-C. Jeung, D.-C. Lee and H.-G. Kim, "Robust control of PMSG wind turbine systems with back-to-back PWM converters," in The 2nd International Symposium on Power Electronics for Distributed Generation Systems, Hefei, China, 2010.

[29] M. Ali, F. Guo and B. Gou, "Nonlinear control design using exact linearization for permanent magnet synchronous generator," in IEEE International Conference on Electro-Information Technology, EIT 2013, Rapid City, SD, USA, 2013.

[30] X.-c. Li, Y.-n. Zhao and X. Zui-Bing, "Nonlinear control of permanent magnet wind turbine generation (PSMG)," in 2013 International Conference on Power, Energy and Control (ICPEC), Sri Rangalatchum Dindigul, India, 2013.

[31] A. Abir, D. Mehdi and S. Lassaad, "Pitch angle control of the variable speed wind turbine," in 2016 17th International Conference on Sciences and Techniques of Automatic Control and Computer Engineering (STA), Sousse, Tunisia, Dec. 2016.

[32] J. Zhou, S. Li, J. Li and J. Zhang, "A combined control strategy of wind energy conversion system with direct-driven PMSG," in 2016 31st Youth Academic Annual Conference of Chinese Association of Automation (YAC), Wuhan, China, 2016.

[33] X. Zhang and K. Wang, "Model predictive current control for the semi-controlled open winding PMSG," in 2017 20th International Conference on Electrical Machines and Systems (ICEMS), Sydney, NSW, Australia, 2017.

[34] S. Srilad, S. Tunyasrirut and T. Suksri, "Implementation of a Scalar Controlled Induction Motor Drives," in 2006 SICE-ICASE International Joint Conference, Busan, South Korea, 2006.

[35] J. M. Peña and E. V. Díaz, "Implementation of V/f scalar control for speed regulation of a three-phase induction motor," in 2016 IEEE ANDESCON, Arequipa, Peru, 2016.

[36] M. Bechar, A. Hazzab and M. Habbab, "Real-Time scalar control of induction motor using rt-lab software," in 2017 5th International Conference on Electrical Engineering - Boumerdes (ICEE-B), Boumerdes, Algeria, 2017.

[37] L. K. Jisha and A. A. P. Thomas, "A comparative study on scalar and vector control of Induction motor drives," in 2013 International conference on Circuits, Controls and Communications (CCUBE), Bengaluru, India, 2013.

[38] S. Pati, M. Patnaik and A. Panda, "Comparative performance analysis of fuzzy PI, PD and PID controllers used in a scalar controlled induction motor drive," in 2014 
International Conference on Circuits, Power and Computing Technologies [ICCPCT-2014], Nagercoil, India, 2014.

[39] P. Verma, R. Saxena, A. Chitra and R. Sultana, "Implementing fuzzy PI scalar control of induction motor," in 2017 IEEE International Conference on Power, Control, Signals and Instrumentation Engineering (ICPCSI), Chennai, India, 2017.

[40] B. Kimiaghalam, M. Rahmani and H. Halleh, "Speed \& torque vector control of induction motors with Fuzzy Logic Controller," in 2008 International Conference on Control, Automation and Systems, Seoul, South Korea, 2008.

[41] S. Masoudi, M. R. Feyzi and M. B. B. Sharifian, "Speed control in vector controlled induction motors," in 2009 44th International Universities Power Engineering Conference (UPEC), Glasgow, UK, 2009.

[42] J. Chiasson, "A new approach to dynamic feedback linearization control of an induction motor," IEEE Transactions on Automatic Control, vol. 43, no. 3, pp. 391 397, 1998.

[43] M. Wlas, Z. Krzeminski, J. Guzinski, H. Abu-Rub and H. Toliyat, "Artificial-neuralnetwork-based sensorless nonlinear control of induction motors," IEEE Transactions on Energy Conversion, vol. 20, no. 3, pp. 520 - 528, 2005.

[44] J. Talla, V. Q. Leu, V. Šmídl and Z. Peroutka, "Adaptive Speed Control of Induction Motor Drive With Inaccurate Model," IEEE Transactions on Industrial Electronics, vol. 65, no. 11, pp. 8532 - 8542, 2018.

[45] D. Karagiannis, A. Astolfi, R. Ortega and M. Hilairet, "A Nonlinear Tracking Controller for Voltage-Fed Induction Motors With Uncertain Load Torque," IEEE Transactions on Control Systems Technology, vol. 17, no. 3, pp. 608 - 619, 2009.

[46] M. Rashed, P. MacConnell and A. Stronach, "Nonlinear adaptive state-feedback speed control of a voltage-fed induction motor with varying parameters," IEEE Transactions on Industry Applications, vol. 42, no. 3, pp. 723 - 732, 2006.

[47] K. Ohyama, G. Asher and M. Sumner, "Comparative Analysis of experimental performance and stability of sensorless induction motor drives," IEEE Transactions on Industrial Electronics, vol. 53, no. 1, pp. 178 - 186, 2006.

[48] J. Vonkomer and M. Žalman, "Induction motor sensorless vector control for very wide speed range of operation," in 2011 12th International Carpathian Control Conference (ICCC), Velke Karlovice, Czech Republic, 2011.

[49] M. Rodic and K. Jezernik, "Speed-sensorless sliding-mode torque control of an induction motor," IEEE Transactions on Industrial Electronics, vol. 49, no. 1, pp. 87 $-95,2002$.

[50] A. Benchaib and C. Edwards, "Induction motor control using nonlinear sliding mode theory," in 1999 European Control Conference (ECC), Karlsruhe, Germany, 1999.

[51] M. Horch, A. Boumédiène and L. Baghli, "Backstepping approach for nonlinear super twisting sliding mode control of an induction motor," in 20153 rd International Conference on Control, Engineering \& Information Technology (CEIT), Tlemcen, Algeria, 2015. 
[52] R. Hedjar, R. Toumi, P. Boucher and D. Dumur, "A finite horizon cascaded nonlinear predictive control of induction motor," in 2001 European Control Conference (ECC), Porto, Portugal, 2001.

[53] A. Z. Diab, V. Vdovin, D. Kotin, V. Anosov and V. Pankratov, "Cascade model predictive vector control of induction motor drive," in 2014 12th International Conference on Actual Problems of Electronics Instrument Engineering (APEIE), Novosibirsk, Russia, 2014.

[54] V. Nayanar, N. Kumaresan and N. A. Gounden, "A Single-Sensor-Based MPPT Controller for Wind-Driven Induction Generators Supplying DC Microgrid," IEEE Transactions on Power Electronics, vol. 31, no. 2, pp. 1161 - 1172, 2016.

[55] M. Sasikumar, R. Madhusudhanan and S. ChenthurPandian, "Modeling and analysis of cascaded H-bridge inverter for wind driven isolated squirrel cage induction generators," in Recent Advances in Space Technology Services and Climate Change 2010 (RSTS \& CC-2010), Chennai, India, 2010.

[56] A. Mesbahi, M. Khafallah, A. Saad and A. Nouaiti, "Emulator design for a small wind turbine driving a self excited induction generator," in 2017 International Conference on Electrical and Information Technologies (ICEIT), Rabat, Morocco, 2017.

[57] O. M. Arafa, M. E. Abdallah and G. A. A. Aziz, "Realisation and HIL testing of wind turbine emulator based on DTC squirrel cage inductor motor drive," International Journal of Industrial Electronics and Drives, vol. 4, no. 3, pp. 155 - 168, 2018.

[58] M. Pucci, "Induction machines sensors-less wind generator with integrated intelligent maximum power point tracking and electric losses minimisation technique," IET Control Theory \& Applications, vol. 9, no. 12, pp. 1831 - 1838, 2015.

[59] A. G. Abo-Khalil, "Model-based optimal efficiency control of induction generators for wind power systems," in 2011 IEEE International Conference on Industrial Technology, Auburn, AL, USA, 2011.

[60] J. C. Ferreira, I. R. Machado, E. H. Watanabe and L. G. B. Rolim, "Wind power system based on Squirrel Cage Induction Generator," in XI Brazilian Power Electronics Conference, Praiamar, Brazil, 2011.

[61] Y. Yan, F. Lin, X. Wen, G. Hu and T. Q. Zheng, "The Experimental System for Variable-speed Constant-frequency Wind-power Generation Using Induction Machines," in 2006 International Conference on Power System Technology, Chongqing, China, 2006.

[62] C. Kumar, A. Sarma and P. Prasad, "Fuzzy Logic Based Control of Wind Turbine Driven Squirrel Cage Induction Generator Connected to Grid," in 2006 International Conference on Power Electronic, Drives and Energy Systems, New Delhi, India, 2006.

[63] A. Mesemanolis, C. Mademlis and I. Kioskeridis, "High-Efficiency Control for a Wind Energy Conversion System With Induction Generator," IEEE Transactions on Energy Conversion, vol. 27, no. 4, pp. 958 - 967, 2012.

[64] T. Brasil, L. Crispino and W. Suemitsu, "Fuzzy MPPT control of grid-connected three-phase induction machine for wind power generation," in 2015 IEEE 24th International Symposium on Industrial Electronics (ISIE), Buzios, Brazil, 2015. 
[65] C.-M. Hong, W.-M. Lin and F.-S. Cheng, "Application of Fuzzy Neural Network Sliding Mode Controller for Wind Driven Induction Generator System," in 2007 International Conference on Intelligent Systems Applications to Power Systems, Toki Messe, Niigata, Japan, 2007.

[66] M. Zribi, M. Alrifai and M. Rayan, "Sliding Mode Control of a Variable-Speed Wind Energy Conversion System Using a Squirrel Cage Induction Generator," Energies, MDPI, vol. 10, no. 5, pp. 1 - 21, 2017.

[67] N. R. E. Laboratory, "Enabling the SMART Wind Power Plant of the Future Through Science-Based Innovation," US Department of Energy, Golden, CO, 2017.

[68] R. Carriveau, Fundamental and Advanced Topics in Wind Power, Rijeka, Croatia: InTech, 2011.

[69] N. Mohan, Electric Machines and Drives, Hoboken, NJ, USA: John Wiley \& Sons, 2012.

[70] M. Li and K. Smedley, "One-cycle control of PMSG for wind power generation," in IEEE Power Electronics and Machines in Wind Applications, Lincoln, NE, USA, 2009.

[71] H. Li, K. Shi and P. McLaren, "Neural-network-based sensorless maximum wind energy capture with compensated power coefficient," IEEE Transactions on Industry Applications, vol. 41, no. 6, pp. 1548 - 1556, Nov.-Dec. 2005.

[72] M. Fdaili, A. Essadki, M. Nadour and T. Nasser, "Comparative Study of MPPT and Pitch Angle Control Strategies for a Wind Energy Conversion System," in 2017 International Renewable and Sustainable Energy Conference (IRSEC), Tangier, Morocco, 2017.

[73] M. Salo and H. Tuusa, "vector-controlled PWM current-source-inverter-fed induction motor drive with a new stator current control method," IEEE Transactions on Industrial Electronics, vol. 52, no. 2, pp. 523 - 531, 2005.

[74] M. Adamowicz and M. Morawiec, "Advances in CSI-fed induction motor drives," in 2011 7th International Conference-Workshop Compatibility and Power Electronics (CPE), Tallinn, Estonia, 2011.

[75] A. Martyanov, N. Martyanov and E. Sirotkin, "State Observer for Variable Speed Wind Turbine," in International Ural Conference on Green Energy (UralCon), Chelyabinsk, Russia, 2018.

[76] T. Puleva and J. Osusky, "Wind turbine power control based on aero dynamical torque estimation," in Cybernetics \& Informatics (K\&I), Levoca, Slovakia, 2016.

[77] O. Barambones and J. M. G. d. Durana, "Adaptive sliding mode control strategy for a wind turbine systems using a HOSM wind torque observer," in IEEE International Energy Conference (ENERGYCON), Leuven, Belgium, 2016. 


\section{CURRICULUM VITAE}

NAME: $\quad$ Nicholas Alexander Hawkins

ADDRESS: $\quad$ Department of Electrical and Computer Engineering

W. S. Speed Hall, Rm 217

University of Louisville

Louisville, KY, 40292

DOB: $\quad$ Louisville, Kentucky - August 16, 1993

EDUCATION

\& TRAINING: $\quad$ B. S. Electrical and Computer Engineering

University of Louisville

$2012-2016$

M. Eng. Electrical and Computer Engineering

University of Louisville

$2016-2017$

$\mathrm{Ph}$. D. Electrical and Computer Engineering

University of Louisville

$2017-2020$

\section{PUBLICATIONS:}

\section{$\underline{\text { Under Review }}$}

Bhagwat, B., Alqatamin, M., Hawkins, N., McIntyre, M. (2020). Filter-Based Control of a Buck Converter for Uncertain Nonlinear Loads, IET Power Electronics.

Hawkins, N., Nimon, S., Bhagwat, B., Alqatamin, M., Latham, J., McIntyre, M. (2020). Nonlinear Control of a CCM Power Factor Correction Circuit, IET Power Electronics.

Hawkins, N., McIntyre, M. (2020). Robust Nonlinear Control for PMSG Wind Turbines, IET Renewable Power Generation.

Hawkins, N., Bhagwat, B., McIntyre, M. (2020). Nonlinear Current-Mode Control of SCIG Wind Turbines, IET Renewable Power Generation. 


\section{Accepted}

Hawkins, N., Robinson, B., Lewis, J. (June 2020). Employment of Active Learning Pedagogy Throughout a Makerspace-Based, First-Year Introduction to Engineering Course, American Society of Engineering Education Conference, Montreal, Quebec, CAN.

Robinson, B., Lewis, J., Hawkins, N. (June 2020). Addressing First-Year Interest in Engineering via a Makerspace-Based Introduction to Engineering Course, American Society of Engineering Education Conference, Montreal, Quebec, CAN.

Lewis, J., Hawkins, N., Robinson, B. (June 2020). First-Year Engineering Student Perceptions in Programming Self-Efficacy and the Effectiveness of Associated Pedagogy Delivered via an Introductory, Two-Course Sequence in Engineering, American Society of Engineering Education Conference, Montreal, Quebec, CAN.

Hawkins, N., Alqatamin, M., Bhagwat, B., McIntyre, M. (2020 July). Nonlinear Control and Observation of a PMSG Wind Turbine Through Unknown Wind Torque Characteristics, American Controls Conference, Denver, CO.

Hawkins, N., Jewell, N., Alqatamin, M., Bhagwat, B., McIntyre, M. (2020 July). A Nonlinear Fault Detection Scheme for PV Applications, American Controls Conference, Denver, CO.

Alqatamin, M., Hawkins, N., McIntyre, M. (2020 July). Filter-Based Controller to Improve the Power Quality of Single-Phase Grid-Connected Inverters, American Controls Conference, Denver, CO.

Alqatamin, M., Bhagwat, B., Hawkins, N., McIntyre, M. (2020 July). SelfSynchronizing Current Control for Single-Stage Three-Phase Grid-Connected Photovoltaic Systems, American Controls Conference, Denver, CO.

Hawkins, N., Lewis, J., Robinson, B., Foreman, C. (2019 June). Computational Instruction through PLCs in a Multi-Disciplinary Introduction to Engineering Course, American Society of Engineering Education Conference, Tampa, FL.

Robinson, B., Hawkins, N., Lewis, J., Foreman, C. (2019 June). Creation, Development, and Delivery of a New Interactive First-Year Introduction to Engineering Course, American Society of Engineering Education Conference, Tampa, FL.

Hawkins, N., McIntyre, M., Latham, J. (2018 October). Nonlinear Control for Power Factor Correction of a Dual-Boost Bridgeless Circuit, IEEE Industrial Electronics Conference IECON, Washington D.C.. 
Alqatamin, M., McIntyre, M., Latham, J., Rivera, P., Hawkins, N., (2018 June). Nonlinear Adaptive Control Design for Power System with STATCOM device, American Controls Conference, Milwaukee WI.

McNeil, J. C., Thompson, A., Hawkins, N. (2018 June). A Comparison of Students Learning Programming with Instruction and Team Activities, American Society of Engineering Education Conference, Salt Lake City, UT. 